\title{
The use of a multi-gate pulsed doppler system in the evaluation of the carotid artery circulation
}

Citation for published version (APA):

van Merode, T. (1986). The use of a multi-gate pulsed doppler system in the evaluation of the carotid artery circulation. [Doctoral Thesis, Maastricht University]. Rijksuniversiteit Limburg. https://doi.org/10.26481/dis.19861121tm

Document status and date:

Published: 01/01/1986

DOI:

10.26481/dis.19861121tm

Document Version:

Publisher's PDF, also known as Version of record

\section{Please check the document version of this publication:}

- A submitted manuscript is the version of the article upon submission and before peer-review. There can be important differences between the submitted version and the official published version of record.

People interested in the research are advised to contact the author for the final version of the publication, or visit the DOI to the publisher's website.

- The final author version and the galley proof are versions of the publication after peer review.

- The final published version features the final layout of the paper including the volume, issue and page numbers.

Link to publication

\footnotetext{
General rights rights.

- You may freely distribute the URL identifying the publication in the public portal. please follow below link for the End User Agreement:

www.umlib.nl/taverne-license

Take down policy

If you believe that this document breaches copyright please contact us at:

repository@maastrichtuniversity.nl

providing details and we will investigate your claim.
}

Copyright and moral rights for the publications made accessible in the public portal are retained by the authors and/or other copyright owners and it is a condition of accessing publications that users recognise and abide by the legal requirements associated with these

- Users may download and print one copy of any publication from the public portal for the purpose of private study or research.

- You may not further distribute the material or use it for any profit-making activity or commercial gain

If the publication is distributed under the terms of Article $25 \mathrm{fa}$ of the Dutch Copyright Act, indicated by the "Taverne" license above, 
THE USE OF A MULTI-GATE

PULSED DOPPLER SYSTEM

in the evaluation of the carotid artery circulation

\section{Proefschrift}

ter verkrijging van de graad van doctor in de geneeskunde aan de Rijksuniversiteit Limburg te Maastricht, op gezag van de Rector Magnificus Prof. Dr. F.I.M. Bonke, volgens het besluit van het College van Dekanen, in het openbaar te verdedigen op vrijdag 21 november 1986 , om 16.00 uur.

door

Tïny van Merode

geboren te Leeuwarden 
Promotar : Prof. Dr. R.S. Reneman

Co-promoter : Dr. A.P.G. Hoeks

Referenten : Prof. Dr. R. Gosling, London, U.K.

Prof. Dr. M. Hennerici, Dusseldorf, BRD

Prof. Dr. J.M.F.A. Moll, Heerlen

Financial support by the Netherlands Heart Foundation for the publication of this thesis is gratefully acknowledged. 


\section{CONTENTS}

Chapter I : INTRODUCTION

Chapter II : MULTI-GATE PULSED DOPPLER SYSTEM WITH SERIAL DATAPROCESSING

2.1 Introduction

2.2 Description of the device

Chapter III : SPECTRAL ANALYSIS OF THE DOPPLER SIGNAL

Chapter IV : LIMITATIONS OF DOPPLER SPECTRAL BROADENING IN THE EARLY DETECTION OF CAROTID ARTERY DISEASE DUE TO THE SIZE OF THE SAMPLE VOLUME

\subsection{Introduction}

4.2 Materials and methods

4.3 Results

4.4 Discussion

Chapter $V$ : THE DIAGNOSTIC ACCURACY OF THE MULTI-GATE PULSED DOPPLER SYSTEM IN DETECTING MODERATE CAROTID ARTERY LESIONS. A COMPARISON WITH BIPLANE ARTERIOGRAPHY

Chapter VI : SERUM HDL/TOTAL CHOLESTEROL RATIO AND BLOOD PRESSURE IN ASYMPTOMATIC ATHEROSCLEROTIC LESIONS OF THE CERVICAL CAROTID ARTERIES IN MEN 
Chapter VII : THE DETECTION OF FLOW DISTURBANCES AND RELATIVE

ARTERIAL DIAMETER CHANGES DURIMG THE CARDIAC CYCLE

7.1 The recording of velocity patterns 71

7.2 Velocity patterns in the carotid artery bifurca- 71 tion

7.3 The use of relative arterial diameter changes

Chapter VIII : FLOW VELOCITY PATTERNS IN AND DISTENSIBILITY OF THE

CAROTID ARTERY BULB IN SUBJECTS OF VARIOUS AGES

WITHOUT DETECTABLE CAROTID ARTERY DISEASE

8.1 Introduction

8.2 Materials and methods

8.3 Results

8.4 Discussion

Chapter IX : AGE RELATED CHANGES IN CAROTID ARTERY WALL PROPERTIES IN NORMOTENSIVE PRESUMED NORMAL MALES

9.1 Introduction

9.2 Materials and methods

9.2.1 Volunteers and methods of investigation

9.2.2 Calculations

9.2.3 Data analys is and statistics

9.3 Results

9.4 Discussion

Chapter $X$ : FLOW VELOCITY PATTERNS IN AND DISTENSIBILITY OF THE CAROTID ARTERY BULB IN THE DIAGNOSIS OF MINOR CAROTID ARTERY STEMOSIS 
Chapter XI : VESSEL WALL PROPERTIES OF THE CAROTID ARTERY IN NORM0123 TENSIVE AND BORDERLINE HYPERTENSIVE MALE SUBJECTS OF VARIOUS AGE

11.1 Introduction

11.2 Materials and methods 124

11.3 Results 126

11.4 Discussion

Chapter XII : GENERAL DISCUSSION

SUMMARY

SAMENVATTING

APPENDIX I

APPENDIX II 


\section{CHAPTER I}

\section{INTRODUCTION}

Extracranial carotid artery occlusive disease is thought to be a major factor in the pathogenes is of cerebrovascular events 1,2,3. Atherosclerotic lesions tend to narrow and eventually to occlude the afferent cerebral arteries in the neck, thereby impairing cerebral blood flow. Serious narrowing or even occlusion of a carotid artery, however, is also known to develop asymptomatically in a number of patients 4 , probably because of adequate collateral circulation. At an earlier stage of the disease, (ulcerative) vessel wall lesions may give rise to platelet adhesion and embolization, causing smaller intracerebral vessels to occlude. This embolic theory has been accepted as a cause of transient ischemic attacks by a variety of investiglators $5,6,7$, but the question whether minor carotid artery stenosis is a latent threat for neurological deficit and therefore needs treatment is still a matter of debate ${ }^{8-11}$.

In the last decade, non-invasive techniques for the detection of extracranial carotid artery stenosis have become reliable diagnostic methods. They are currently used in many vascular laboratories for evaluation of the carotid artery circulation. The extracranial carotid artery systen is rather suitable for non-invasive assessment, because of its superficial position in the neck. Besides, atherosclerotic disease is often localized in and limited to the carotid artery bifurcation and the first centimeters of the internal carotid artery. Moreover, changes in pressure and/or flow direction, as induced by carotid artery narrowing, can be detected in such peripheral vessels as the periorbital arteries.

Ultrasonic techniques are most commonly used to examine the extracranial carotid artery bifurcation. With Continuous Wave (CW) $12,13,14$ as well as pulsed Doppler techniques $15,16,17,18$, with or without B-mode imaging, marked stenosis (>50\% diameter reduction) can be diagnosed accurately. Carotid artery occlusion can be detected more easily with CW Doppler systems than with pulsed Doppler devices, because of the wider soundbeam and the independency of depth in the former devices. By combining a pulsed Doppler system with a B-mode imager, however, carotid artery occlusion can 
be accurately diagnosed. Accurate detection of atheroscleratic lesions, associlated with minor or moderate degrees of artery narrowing, however, is stil1 problematic $19,20,21$.

Since the diagnosis of low grade atherosclerotic lesions is generally based upon the detection of flow disturbances, as induced by these lesions, more detailed information about the blood flow patterns in normal carotid arteries may contribute to more accurate diagnosis of minor carotid artery disease. Especially, a better understanding of the rather complicated flow patterns, as observed in in vitro models of the carotid artery bulb 22-25, where most atherosclerotic lesions develop 23,26 , will serve this purpose.

In man rather detalled information about the flow patterns in arteries can be obtained with multi-gate pulsed Doppler systems 27,28,29. These systems allow the on-line recording of the instantaneous velocities, simultaneousily at various sites in the artery, and, hence, the welocity profile, that is the velocity distribution over the cross-sectional area of the vessel at discrete time intervals during the cardiac cycle. Besides, multigate pulsed Doppler devices allow the an-line recording of changes in arterial dianeter during the cardiac cycle ${ }^{30}$, while with these systems the internal arterial diameter can be estimated from the width of the vellacity profile. In this way non-invasive assessment of the properties of the vessel wall, such as distensibility and cross-sectional compliance, becomes feasible. These features make it possible to detect atherosclerotic lesions in the carotid artery bifurcation at an early stage of the disease. This, and the possibility to abtain information about wessel wall properties make the multi-gate pulsed Doppler system rather suitable for population studies on, for instance, the prevalence of carotid artery disease or the changes in arterial wall properties with age. Another interesting aspect is that detailed information about the flow patterns at arterial bifurcations, in relation to the site where atherosclerotic lesions are located, may provide more insight into the pathogenesis of this disease.

In the present thesis a short description of the characteristics of the multi-gate pulsed Doppler system employed is followed by a study on the 1 initations of broadening of the Doppler spectrum as a diagnostic tool in the detection of moderate carotid artery disease ( $<50 \%$ diameter reduction). A combination of spectral analysis of the Doppler signal and the detection of disturbances in the flow patterns is proposed as a method to diagnose 
these lesions. This approach is used as a gold-standard in distinguishing between (early) disease and nomalcy in a population study on the prevalence of asymptomatic carotid artery lesions in male volunteers in relation to their arterial blood pressure and serum cholesterol levels.

A study on the non-invasive assessment of the complicated flow patterns in and the vessel wall properties of the carotid artery bifurcation in presumed healthy men of varying age offers the basis of a new approach to the diagnosis of minor carotid artery disease ( $<30 \%$ diameter reduction) in this bifurcation, based upon the detection of changes in the flow pattern and vessel wall properties.

In separate studies the multi-gate pulsed Doppler system is used to assess the carotid artery wall properties, as a function of age, in presumed heal thy male volunteers and in borderline hypertensive patients.

For those less familiar with the anatomy of the carotid artery bifurcation and the structure of the arterial wall, some information concerning these aspects is presented in Appendix I. 


\section{REFERENCES}

1. JF Toole, CP Yuson, $R$ Janeway, $F$ Johnston, C Davis, AR Cordell, G Howard: Transient ischemic attacks. A prospective study on 225 patients.

Neuralogy 28: 746-753 (1975).

2. MS Pesson, RC Hinton, KR Davis, GW Roberson, RH Ackerman, JP Mohr: Mechanisms of acute carotid stroke.

Ann Neurol 6: 245-252 (1979).

3. CP Warlow: Transient ischemic attacks. In: Recent advances in clinical neurology 3. Ed. WB Matthews, GH Glaser.

Churchill-Livingstone, Edinburgh (1982).

4. R Cote, HJM Barnett, DW Taylor: Internal carotid occlusion: a prospective study.

Stroke 14: 898-902 (1983).

5. DJ McBrien, RD Bradley, W Ashton: The nature of retinal enboli in stenosis of the internal carotid artery.

Lancet i: 697-699 (1963).

6. RWR Russel1: Transient cerebral ischemia. In: Cerebral arterial disease. Ed. RWR Russell.

Churchill-Livingstone, Edinburgh (1976).

7. Carotid Stenosis.

Lancet i: $535-536$ (1981).

8. WS Moore, C Boren, JM Malone, AJ Roon, R Eisenberg, J Goldstone, R Mani: Natural history of nonstenotic, asymptomatic ulcerative lesions of the carotid artery.

Arch Surg 113: 1352-1358 (1978). 
9. RJ Lusby, LD Ferrel1, WK Ehrenfeld, RJ Stoney, EJ Wylle: Carotid plaque hemorhage.

Arch Surg 117: 1479-1487 (1982).

10. RS Lees: The natural history of carotid artery disease.

Stroke 15: 603-604 (1984).

11. G0 Roederer, YE Langlois, KA Jager, JF Primozich, KW Beach, DJ Phillips, DE Strandness: The natural history of carotid arterial disease in asymptomatic patients with cervical bruits.

Stroke 15: 605-613 (1984).

12. JM van Baalen, JJ Jakimowicz, RS Reneman: Noninvasive evaluation of carotid artery stenosis - comparison of direct and indirect techniques. Vasc Surg 18: 88-95 (1984).

13. MP Spencer: Doppler evaluation of the aortocranial circulation using carotid imaging and hand-held probing. In: Doppler Ultrasound in the diagnosis of cerebrovascular disease. Ed. RS Reneman, APG Hoeks. Research Studies Press, Chichester (1982).

14. RR Lewis, TS Padayachee, RG Gosling: Ultrasound screening for internal carotid disease-II. Sensitivity and specificity of a single site periorbital artery test.

U1trasound Med Biol 10: 17-25 (1984).

15. WM Blackshear, DJ Phillips, BL Thiele et al: Detection of carotid occlusive disease by ultrasonic imaging and pulsed Doppler spectrum amalys is.

Surg 86: 698-706 (1979).

16. G Fell, DJ Phillips, PM Chikos, JD Harley, BL Thiele, DE Strandness: Ultrasonic Duplex scanning for disease of the carotid artery. Circulation 64: 1191-1195 (1981). 
17. PJ Breslau: Ultrasonic Duplex scanning in the evaluation of carotid artery dussease.

Thesis, University of Limburg, Mastricht, The Netherlands (1982).

18. Y Laniglois, Go Roederer, A Chan, DJ Phillips, KW Beach, D Martin, PM Chikos, DE Strandness: Evaluating caratid artery disease.

Ultrasound Hed B101 9: 51-63 (1983).

19. MG Hennerici, U Rautenberg, U Trochel, RG Kladetzky: Spontaneous progresstion and regression of smal1 carotid atheroma.

Lancet i : $1415-1419(1985)$.

20. RA Knox, FM Greene, $K$ Beach, DJ Phillips, PM Chikos, DE Strandness: Computer based classification of carotid arterial disease: A prospective assessment.

Stroke 13: $589-594(1982)$.

21. V Zbornikova, C Lassvik, I Johansson: Duplex scanning and periorbital pulsed Doppler in the diagnosis of external carotid artery disease: analysis of causes of error.

Clin Physiology 5: 271-279 (1985).

22. BK Bharadvaj, RF Mabon, DP Giddens: Steady flow in a model of the human carotid bifurcation.

J Biomech 15: 349-378 (1982).

23. CK Zarins, DP Giddens, BK Bharadvaj, VS Sottiurai, RF Mabon, S Glagov: Carotid bifurcation atherosclerosis: quantitative correlation of plaque locallization with flow velocity profiles and wall shear stress.

Circ Res 53: $502-514(1983)$.

24. M Motomiya, T Karino: Flow patterns in the human carotid artery bifurcation.

Stroke 15: $50-56$ (1985). 
25. DN Ku, DP Giddens: Pulsatile flow in a model carotid bifurcation. Arteriosclerosis 3: $31-39$ (1983).

26. M Kjaernes, A Svindland, L Walløe, Sø Wille: Localization of early atherosclerotic lesions in an arterial bifurcation in humans. Acta Pathol Microbiol Scand [A] 89: 35-40 (1981).

27. APG Hoeks, RS Reneman, PA Peronneau: A multi-gate pulsed Doppler system with serial data processing.

IEEE Trans Sonics Ultrasonics, SU-28: 242-247 (1981).

28. APG Hoeks: On the development of a multi-gate pulsed Doppler system with serial data-processing.

Thesis, University of Limburg, Maastricht, The Netherlands (1982).

29. APG Hoeks, HPM Peeters, CJ Ruissen, RS Reneman: A novel frequency estimator for sampled Doppler signals. IEEE Trans Biomed Eng BME-31: 212-220 (1984).

30. APG Hoeks, CJ Ruissen, P Hick, RS Reneman: Transcutaneous detection of relative changes in artery diameter. Ultrasound Med Biol 11: 51-59 (1985). 

CHAPTER II

MULTI-GATE PULSED DOPPLER SYSTEM WITH SERIAL DATA-PROCESSING

\subsection{Introduction}

Multi-gate pulsed Doppler systems have the ability to detect simultaneously and instantaneously velocities over the full range of interest. A single gate pulsed Doppler system can be converted into a multi-gate pulsed Doppler system by duplicating the circuitry needed for the intermediate storage of the phase signals, the filtering of the Doppler signals and the detection of the average velocity for each of the additional gates. Assessment of the velocity distribution in large arteries with relatively small sample volumes requires a large number of processing gates which should be identical to ensure that the outputs of the different gates can be compared with each other 1,2. The approach of processing the phase signals by parallel gates becomes more and more problematic with an increasing number of gates. Hence, processing of data in serial form by a single circuit should be preferred. The mean velocity as an instantaneous function of time in the different gates can thus be recorded on-line, and hence the velocity profiles at discrete time intervals during the cardiac cycle. For reliable velocity profiles, the sample resolution has to be high and the sample distance along the ultrasonic beam must be small. An insufficient number of independent sample points along the cross-section of the vessel will smooth the recorded velacity profiles and result in a significant overestimation of vessel diameters ${ }^{3}$.

\subsection{Description of the device}

In pulsed Doppler systems usually one crystal, operating alternately as emitter and receiver, is used. The pulses are emitted with a certain frequency, the pulse repetition frequency (PRF), depending on the depth of the vessel of interest and the velocity to be measured. The crystal receives the backscattered signals from the red blood cells and the vessel wall 


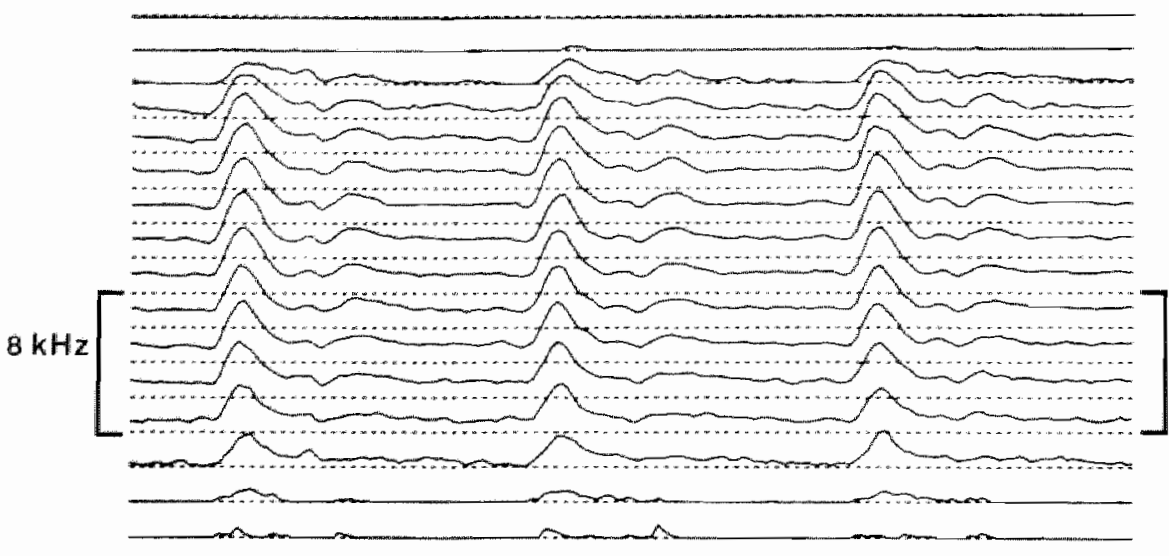

ant.

wall

$2 \mathrm{~mm}$

post.

wall

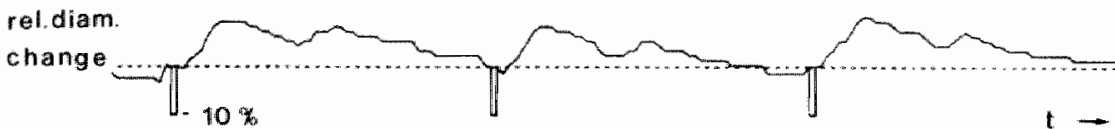

Fig. 2.1 A: The instantaneous mean velocity wavefoms as recorded simultaneously at vamious sites along the uItrasound beam in the common carotid artery of a young, healthy subject.

B: The axial velocity profiles at discrete tume intervals during the cardiac cycte as synthesized from the velocity waveforms in Fig. $2.1 \mathrm{~A}$. Note the symmetric and relatively flat velocity profiles. In both Pig. $A$ and $B$ the relative diameter changes of the comon carotid artery during the cardiac cycte are presented as weti. The negative deflection represents the troigger derived from the R-wave of the $B C G$.

B
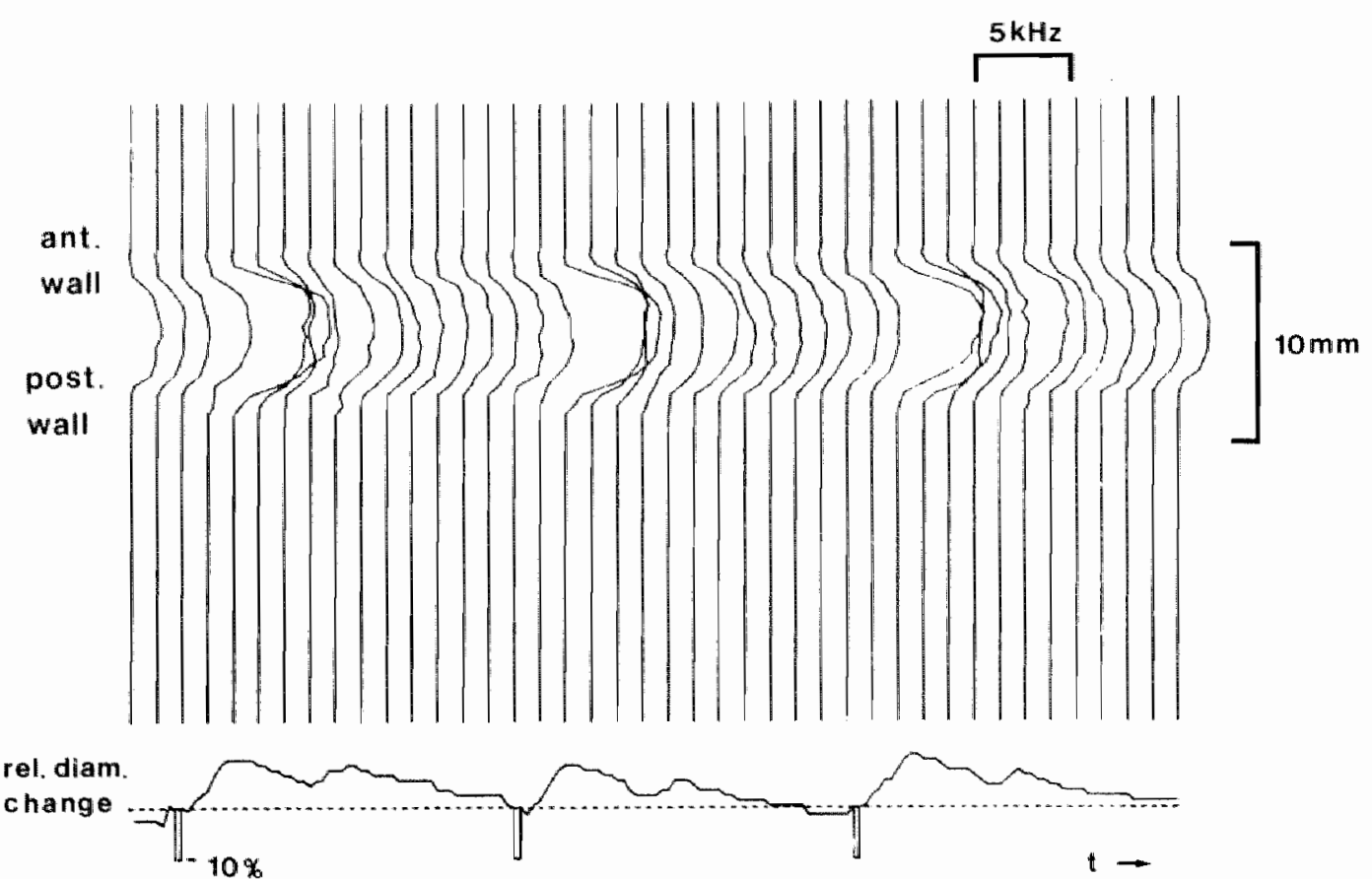
during the interval between pulses. In puised Doppler systems single gate and multi-gate instruments can be distinguished.

In single gate pulsed Doppler systems an electronic gate allows the selection of scattering either from the vessel wall or the red blood cells at a given distance from the transducer. This makes it possible to determine the mean velocity as an instantaneous function of time in a small sample volume at various sites in an artery, thus avoiding contamination of the desired signal by unwanted signals, like those from vessel wall and veins. In principle velocity profiles can be detemined with single gate pulsed Doppler systems. In these systems, however, during one cardiac cycle the velocity as an instantaneous function of time can only be determined at. one site in the vessel. Therefore, synthesis of velocity profiles requires that the instantaneous velocities at various sites in an artery are assessed during consecutive heart beats. This limits the applicability of these systems because the velocity profile has been found to change during the cardiac cycle, both under normal circumstances 4 and around stenotic lesions 5 . Besides, positioning and maintenance of the sample volume at the site of interest requires some skill. The use of $B$-mode imaging systems in combination with single gate pulsed Doppler systems 6,7 will facillitate this task.

More recently multi-gate pulsed Doppler systems have been developed that have the ability to detect simultaneously and instantaneously velocities over the full range of interest $8,9,1,2$. With these systems the mean velocity as an instantaneaus function of time can be recorded on-line, simultaneously at various sites along the ultrasound beam $(\mathrm{Fig}, 2.1 \mathrm{~A})$, and, hence, the velocity profiles at discrete time intervals during the cardiac cycle (Fig. 2.1B). Processing of the velocity information occurs in a serial rather than a parallel way, which means that all the signals are processed after each other in between the emission of pulses. The principle of serial signal processing is schematically depicted in Fig. 2.2. Serial signal processing has the advantage that tuning of the various gates, a tideous procedure in parallel silgnal processing, can be avoided. In multigate pulsed Doppier devices zero-crossing meters can be used to determine the mean frequency of the Doppler spectrum and to convert the signal into an analog signal. Since in these devices narrow frequency spectra are fed into the zero-crossing meter, the error made in assessing the mean fre- 


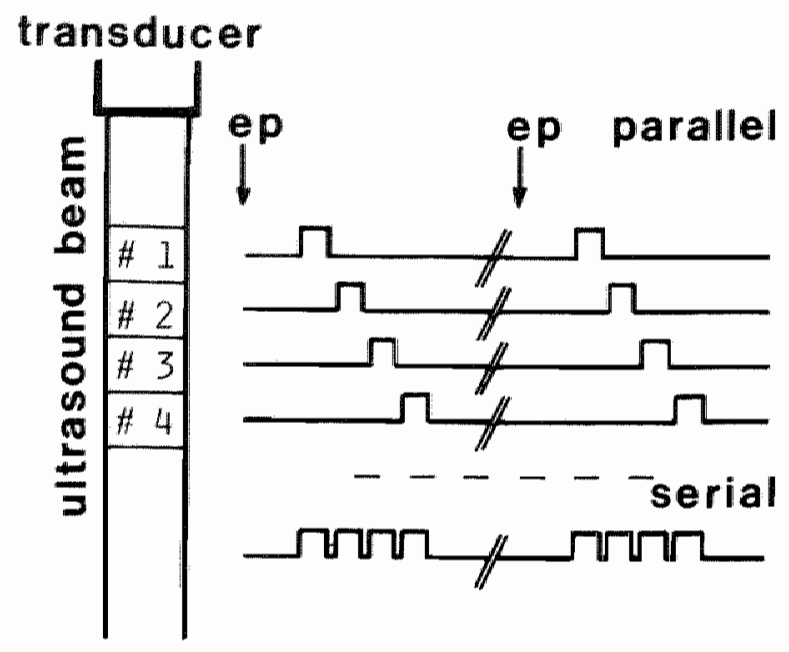

Fig. 2.2: Schematic representation of paraltel and serial data processing in multigate putaed Doppter devices. The numberg refer to the channets processed. $e p=$ emiseion pulse.

quency is relatively smal1 10. For high performance, at frequencies near the Nyquist frequency $(=P R F / 2)$, however, more accurate frequency estimators are required 11,2 . Although serial data processing can be performed with signals in analog form, data processing on a digital base is preferred because of the high dynanic range of the signals. In multi-gate pulsed Doppler systems appropriate evaluation of the time-dependent behavior of the velocity profiles can be achieved by using a multi-channel storagedisplay. With an 8-kbyte memory, 256 instantaneous velocity profiles, composed of 64 sample points, can be preserved simultaneously during a cardiac cycle. As mentioned before (section 2.1) the sample resolution has to be high, and the sample distance along the ultrasound beam has to be small to obtain detailed and reliable velocity information. Small sample volumes can only be abtained if the beamwidth, which mainly determines the lateral resolution, is narrow (Fig. 2.3A) and the effective duration of the measurement, the principal determinant of the axial resolution (Fig. 2.3B), is sma11. The effective duration of the measurement is set by the emission duration, the bandwidth of the receiver and the gate-width 10 . Increasing 
the bandwidth, shortening the duration of emission (high amission frequency) and diminishing the gate-width will reduce the sample wolume but will decrease the signal to noise ratio. To be adequately informed of the features of a pulsed Doppler system it is important to measure the size of the sample volume rather than following the specification provided by the mamufacturer. A conventional way to give the dimensions of the sample volume is to mention the width of the lateral and axial sampling function at a given reference level with respect to its peak value (for instance $10 \%$ of this peak value). However, this may be misleading because these dimensions do not reflect the actual shape of the sampling function. The size of the sample volume was therefore defined as the volume from which $90 \%$ of the backscattered Doppler intensity is received ${ }^{12}$. The characteristics of the multi-gate system, as used in our laboratories for peripheral applications,

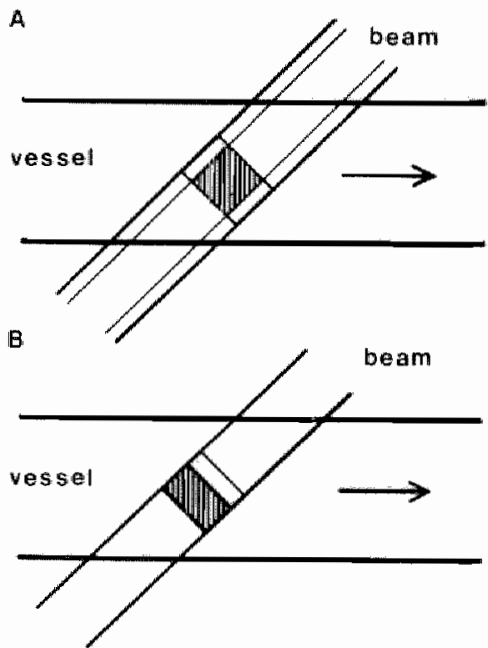

Fig. 2.3: Schematic representation of a sample volume. The cample aiae in the tateral direction is matnzy determined by the beamwidth (A) and in the axial direction mainly by the duration of the meacurement (B). Note that extension of the Bample volume in either direction influences in both directions the area in the vesel from which the velocities are campled. 
are: emission frequency: $6.1 \mathrm{MHz}$, PRF: $18 \mathrm{kHz}$, duration of emission: $2 / 3$ us, gate-width: $2 / 3$ us, sample distance: $0.5 \mathrm{~mm}$, sample volume: $1.2-1.7 \mathrm{~mm}^{3}$ and number of gates 64 . This system covers a range up to $3.2 \mathrm{~cm}$. A block diagram of the system is schenatically depicted in Fig. 2.4.

With multi-gate pulsed Doppler systems one can also detemine on-line the relative changes in arterial diameter $(\Delta d / d \times 100 \%)$ during the cardiac cycle (Fig. 2.1) 13,4. This assessment is based upon the detection of low frequency Doppler signals, ariginating from the sample volumes coinciding with the anterior and posterior walls 14 . Integration of these velocity signals delivers displacement. To ensure that the initial relative change in arterial diameter at the beginning of the cardiac cycle is constant, it is reset to zero by a trigger derived from the R-wave of the ECG. This trigger can also be used to mark the start of the cardiac cycle when blood flow velacities are recorded. The relative arterial diameter changes are independent of the angle of interragation and can be determined with a variable error depending on the size of vessel diameter and relative diameter changes ${ }^{14}$. The absolute error in measurement does not exceed $0.5 \%$, which means that for a relative excursion of, for instance, $7 \%$ a relative change in arterial diameter between $6.5 \%$ and $7.5 \%$ can be measured. The

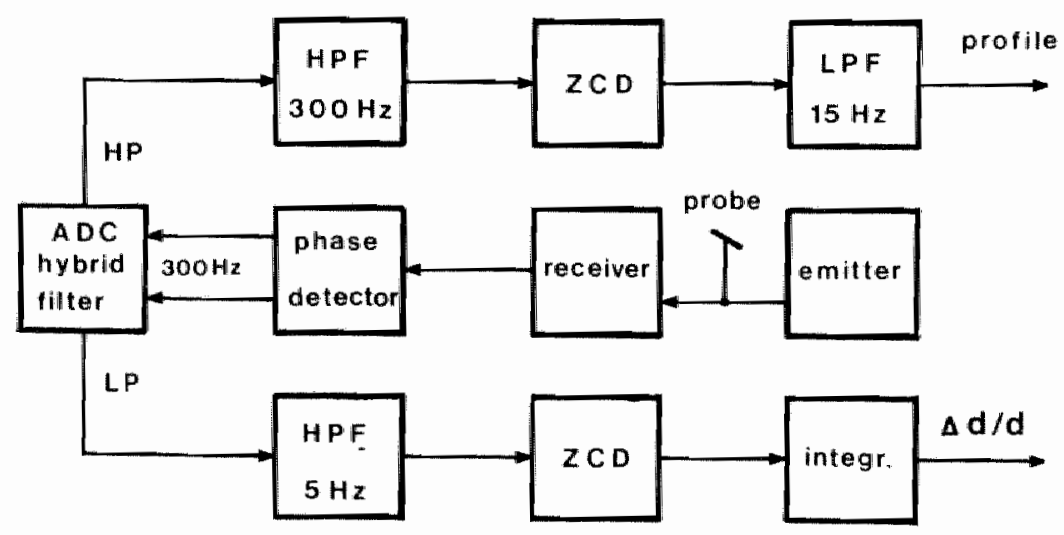

Fig. 2.4: Block diagram of the multi-gate pulsed Doppler system used in most of oum studies described in this thesis. HPF and $L P F=h i g h-p a s s$ and low pass filter, respectively. $A P$ and $L P=$ high- and low-pass, respectivety. $A D C=$ analog to digital converter. $Z C D=$ zero-crossing detector. 
reader should not be misleaded by the use of the unit percentage for the absolute error in the relative arterial diameter changes. This absolute error is given as a percentage because the unit of the relative change in vessel diameter itself is a percentage. See also Hoeks 1982, p. 68-70 1 . The multi-gate system also allows the assessment of the absolute internal arterial diameter from the width of the velocity profile (fig. 2.5). The internal diameter as obtained in this way is dependent on the angle of interrogation."

In multi-gate pulsed Doppler systems the vessel of interest can be localized easily without the use of a B-mode imager; the velocity profile being continuously displayed in A-mode on a Cathode Ray Tube (CRT). The sound-gate of interest can be selected with a cursor. The A-mode of vessel wall displacement is also displayed on the CRT. Although not strictly necessary, the combination of a multi-gate system and a B-mode or 2-D echo imager is preferred for proper localization of the site of sampling in relation to the carotid artery bifurcation ${ }^{4}$ or the diseased area, and to be informed of the angle of interrogation. The multi-gate pulsed Doppler systems presently in use in our laboratories can be connected to most of the commercially available mechanical sector scanners.
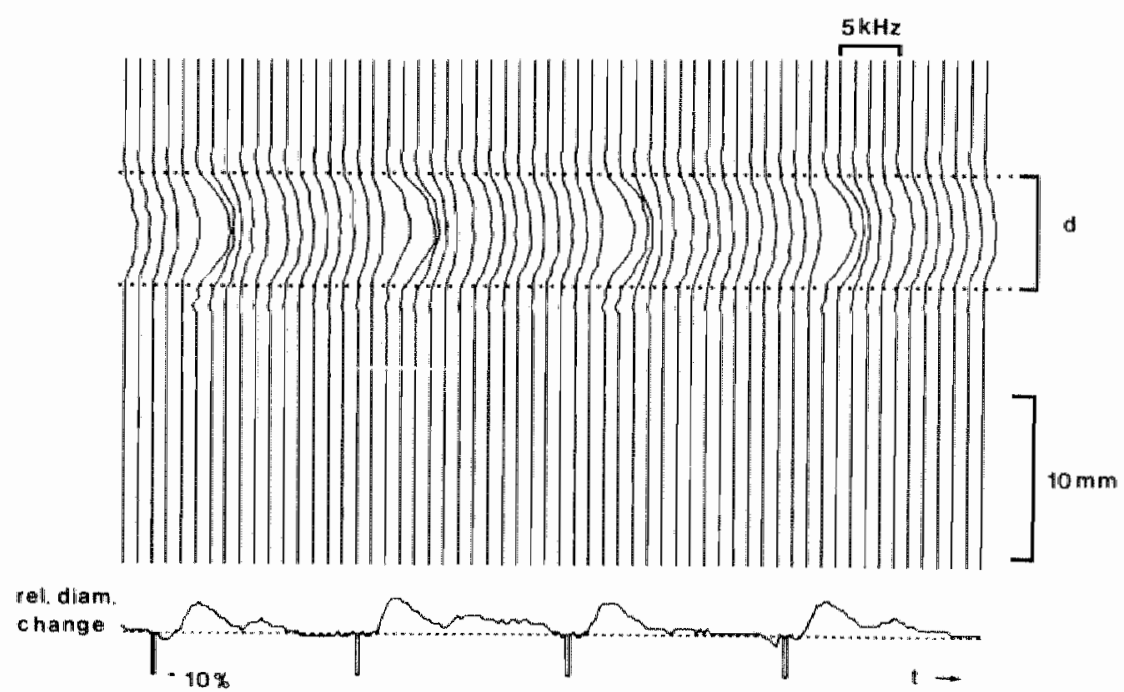

Fig. 2.5: Estimation of the intermat arterial diameter during systole from the width of the velocity profiles ar recorded in the common carotid artery of a volunteer. 
A major Jimitation of pulsed Doppler over CW Doppler devices is that the Doppler bandwidth of the system is limited. The maximum Doppler velocity that can be detected unambiguously depends on the distance between probe and vessel, and the transmitter frequency 15 . This distance sets an upper bound to the PRF, which theoretically should exceed the maximum Doppler frequency at least twice. However, recently a frequency estimator for sampled Doppler signals has been developed that tracks frequencies beyond the Nyquist frequency (half the PRF), significantly increasing the maximum Doppler frequency that can be detected unambiguously ${ }^{2}$.

The mean velocity as an instantaneous function of time at various sites in the common carotid artery as recorded in a young, healthy adult, is presented in Fig. 2.1A. The relative diameter change of this artery during the cardiac cycle is presented as well. The velocity profile in the common carotid artery at discrete time intervals during the cardiac cycle as synthesized from the analog velocity trace in Fig. 2.1A is shown in Fig. 2.1B. The velocity profile in this artery is flat, representing plug flow. In young adults the relative diameter changes of the common carotid artery during systole are in the order of 10 per cent. In older healthy volunteers relative diameter changes of about 6 per cent are recorded in this artery during systole. Under normal circumstances the anterior and the posterior wall are contributing approximately equally to the increase in vessel diameter as indicated by the symmetric widening of the velocity profile during systole (Fig. 2.1B).

Preliminary findings indicate that information about the presence and localization of vascular lesions can be derived from both the velocity profile at discrete time intervals during the cardiac cycle and the mean velocity as an instantaneous function of time as recorded at various sites in an artery, as will be discussed in Chapter IV. An example is given in Fig. 2.6, showing that in the case of a slight stenosis proximally in the left internal carotid artery ( $<30 \%$ diameter reduction, confirmed by biplane arteriography), the velocity profile as recorded in the common carotid artery was found to be asymmetric. The contralateral (normal) side showed a symmetric velocity profile in the common carotid artery. Quantification of disturbances in a velocity profile, however, is difficult. The positioning and maintenance of the sample volume within a tight stenosis requires some skill, especially when narrow sound beams are used. Multi-gate pulsed 
Doppler system can be easily combined with spectral analysis of the Doppler signal, a method widely used in the diagnosis of arterial lesions.

\section{Common Carotid A}

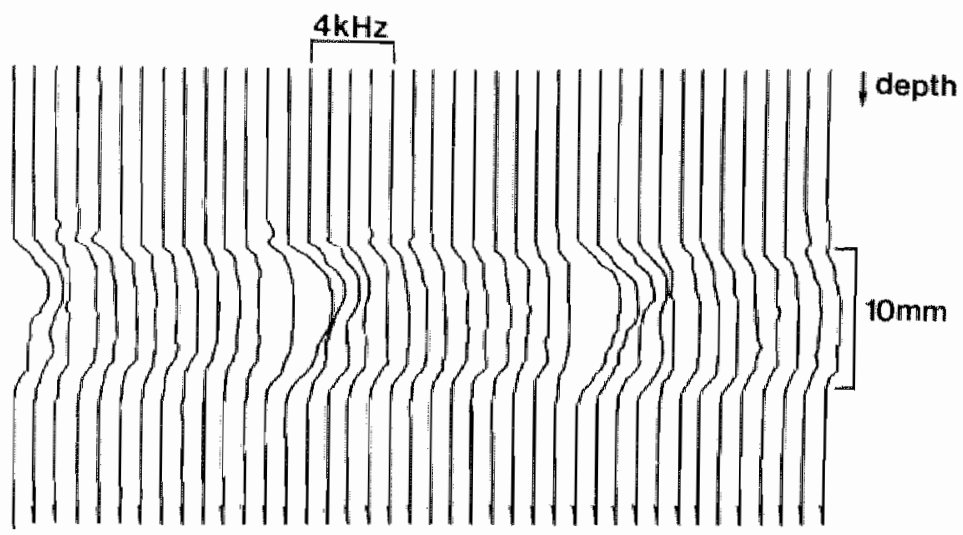

rel. diam.

change

$4 \%$

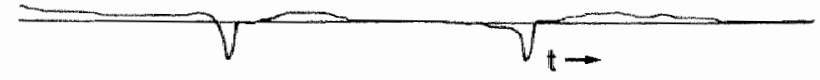

Stenosis < 30\% L. Int. Carotid A

Fig. 2.6: The axiat velocity profites at discrete time intervals during the cardiac cycle, as recorded in the left and right common carotid arteries of a patient with a minon stenosis lless than $30 \%$ ) of the left intemal carotid artery at the bifureation. On the diseased side the velocity profile during systole $i s$ asymmetric and the relative increase in diameter of the artery during systote is diminished. An inerease of $6 \%$ is normat for this age (66 yeara). The negative deflection coincides with the trigger derived from the R-wave of the ECG. 


\section{REFERENCES}

1. APG Hoeks: On the development of a multi-gate pulsed Doppler system with serial data-processing.

Thesis. University of Limburg, Mastricht, The Netherlands (1982).

2. APG Hoeks, HPM Peeters, CJ Ruissen, RS Reneman: A novel frequency est mator for sampled Doppler signals.

IEEE Trans Biomed Eng BME-31: 212-220 (1984).

3. M Anliker: Diagnostic analysis of arterial flow pulses in man. In: Cardiovascular system dynamics, Ed. J Baan.

113-123, MIT Press, Cambridge (1978).

4. RS Reneman, T van Merode, P Hick, APG Hoeks: Flow velocity patterns in and distensibility of the carotid artery bulb in volunteers of varying age.

Circulation 71: 500-509 (1985).

5. SQ Wille: Numerical models of arterial blood flow.

Thesis, Institute of Informatics, University of 0s10, Norway (1979).

6. FE Barber, DW Baker, DE Strandness, JM 0fstad, AD Mah1er: Duplex scanner II.

U7trason Symp Proc IEEE, Cat. 74 CHO 896-ISU Trans Sonics U1trasonics (1974) *

7. L Pourcelot: Echo-Doppler Systems - Applications for the detection of cardiovascular disorders. In: Echocardialogy with Doppler Applications and Real-time Imaging, Ed. N Bom.

245-256, Martinus Nijhoff, The Hague (1977).

8. M Brandestini: Topoflow - A digital full 1 range Doppler velocity meter. IEEE Trans Sonics U1trasonics SU-25: 287-293 (1978). 
9. APG Hoeks, RS Renenan, PA Peronneau: A multi-gate pulsed Doppler systen with serial data processing.

IEEE Trans Sonics U1trasomics SU-28: 242-247 (1981).

10. PA Peronneau, JP Bournat, A Bugnon, A Barbet, $M$ Xhaard: Theoretical and practical aspects of pulsed Doppler flowmetry: real-time application to the measure of instantaneous velocity profiles in vitro and in vivo. In: Cardiovascular applications of ultrasound, Ed. RS Reneman. 66-84, North-Holl and/American Elsevier, Amsterdam (1974).

11. BAd Angelsen, $K$ Kristoffersen: Discrete time estimation of the mean Doppler frequency in ultrasonic blood velocity measurements. IEEE Trans Biomed Eng BME-30: 207-214 (1983).

12. APG Hoeks, CJ Ruissen, P Hick, RS Reneman: Methods to evaluate the sample volume of pulsed Doppler systems. Ultrasound Med Biol 10: 427-43.4. (1984).

13. RS Reneman: What measurements are necessary for a comprehensive evaluation of the peripheral arterial circulation? Cardiovasc Dis 8: 435-454 (1981).

14. APG Hoeks, CJ Ruissen, P Hick, RS Reneman: Transcutaneous detection of relative changes in artery diameter.

U1trasound Med Biol 11: 51-59 (1985).

15. RS Reneman, APG Hoeks: Continuous wave and pulsed Doppler flow meters a general introduction. In: Echocardiology with Doppler applications and real time imaging, Ed. N Bom. 189-205, Martinus Nijhoff, The Hague (1977). 



\section{CHAPTER III}

SPECTRAL ANALYSIS OF THE DOPPLER SIGNAL

It has been established that disturbances in the flow pattern do occur at relatively slight degrees of artery narrowing 1,2,3. Therefore, detection of these disturbances can be considered as an important parameter in the diagnosis of arterial lesions at an early stage of the disease.

In the clinic these flow disturbances are generally detected with the use of spectral analysis of the Dappler signal. In this technique the amplitude of the respective frequencies present in a Doppler sigmal are assessed and displayed as an instantaneous function of time. The amplitude of a given frequency component is displayed in shades of grey. This can be achieved with the use of, for example, Fast Fourier Transform or time compression techniques. In this way the distribution of the velocities present in the recorded signal can be examined. An example is given in Fig 3.1. When in an examinated blood vessel nearly all red blood cells travel

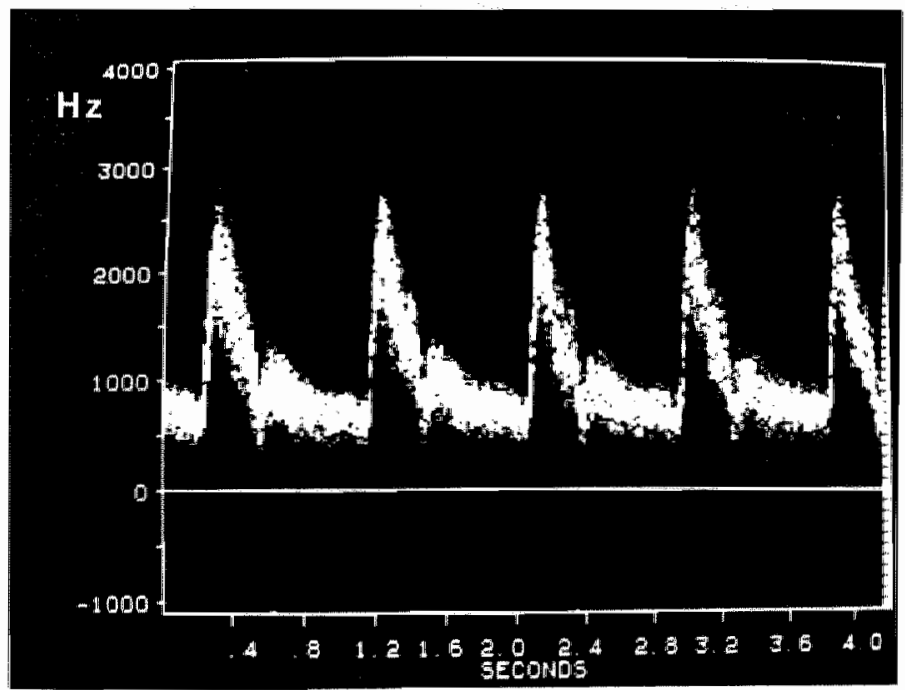

Fig. 3.1: Spectral anatyais of the Doppler signat recorded in the common arotid artery of a mate volumter of 43 yeare without detectable carotid artery disease. 
at the same velocity, spectral analysis of the Doppler signal recorded at this site ill show a rather narrow frequency distribution. In the case, however, that seweral blood cell velocities are present simultaneously in the recorded volume, spectral analysis will yield a wider frequency distribution resulting in "broader" spectra. The degree and extent of this spectral broadening is used in the non-invasive assessment of arterial diameter reduction in atherosclerotic vessel disease. Doppler signals that are recorded in undiseased arteries generally result in small bandwidth spectra, indicating undisturbed laminar fiow. Arterial stenosis will generate disturbances in this flow pattern, and therefore a wide range of blood cell velocities will be present, mesulting in spectral broadening.

It has been suggested that pulsed Doppler systens are more suitable than CW Doppler devices to detect minor vascular lesions with the use of Doppler audio spectrum analysis ${ }^{4,5}$. Because of the small sample volume in the former systems, they allow the recording of spectra in the centre of the artery and, hence, avoid interference with low velocities near the vessel wall. Therefore, the Doppler spectra as recorded with pulsed Doppler devices are more narrow than those recarded with $\mathrm{CW}$ systems (see Fig. 3.2). This may facilitate the diagnosis of atherosclerotic lesions associated with a slight degree of artery marrowing, because these lesions generate minor broadening of the spectrum during the deceleration phase of the cardiac cycle (Chapter IV), and this minimal broadening may be more easily detected in narrow bandwidth spectra.

Rather detailed information about disturbances in the flow pattern along stenosed arteries can be obtained by using a Continuous Wave Doppler device with velocity imaging and audio spectrum analysis 6 . This method also detects arteril wall vibration as induced by high velocity turbulence just distal to a stenosis. In this approach velocity imaging is used to locallize properly the site of recording of the audio spectrum in relation to the position of the stenosis. Another approach is to combine audio spectrum analysis with a single-channel pulsed Doppler system and to localize the site of sampling by using a B-mode image of the vessel wall $4,7,8,9$. Advantages of this approach are, that information can be obtained about the angle between the sound beam and the direction of blood flow. Moreover changes, if any, in the acoustic properties of the vessel wall may be detected and contamination of the velocity signal by unwanted signals, 


\section{Common Carotid A.}

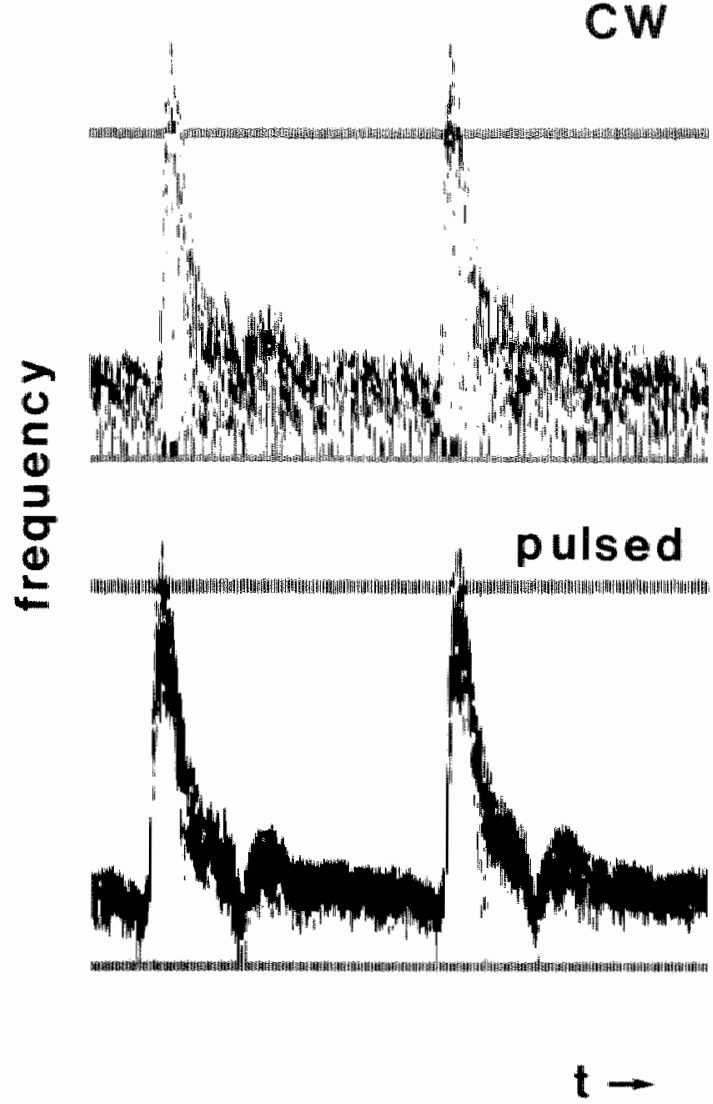

Fig. 3.2: Comparison of spectrat analyais of two Doppler signals recorded respectively with a Continuous Wave and a muttigated pulsed Doppler device in the common carotid artery in a male volunteer of 26 years without detectable carotid artery disease. 
like those from the vessel wall, can be largely prevented. A drawback of using simultaneously pulsed Doppler and B-mode imaging techniques is that the maximum detectable velocity, which is already limited in pulsed Doppler systems, is further reduced. This can cause unreliable readings, especially in the vicinity of stenotic lesions. This problem can be owercome by storing the B-mode image and recording the Doppler signal separately.

Although audio spectrum analysis yields valuable information about the flow disturbances in stenosed arteries, this method has its limitations. As mentioned before spectral broadening is generally used to diagnose disturbances in the flow pattern and to estimate the degree of carotid artery narrowing. Spectral broadening, however, does not necessarily mean pathology, as will be discussed in the next chapter. 


\section{REFERENCES}

1. DP Giddens, FR Mabon, RA Cassanova: Measurement of disordered flows distal to subtotal vascular stenoses in the thoracic aorta of dogs. Circ Res 39: 112-119 (1976).

2. RW Barnes, GE Bone, J Reinerson, EE Slaymaker, DE Hokansom, DE Strandness: Noninvasive ultrasonic carotid angiography: prospective vallidation by contrast arteriography.

Surgery 80: $328-335(1976)$.

3. W Sandmann, P Peronneau, G Schweins, J Bournat, J Hinglais: Turbulenzmessung mit dem Doppler-ultraschallverfahren: eime neue Methode der Qualitatskontrolle in der Arterienchirurgie. In: Ultraschall-Doppler Diagnostik in der Angiologie, Ed. A Kriesman. 77-81, Georg Thieme Verlag Stuttgart (1978).

4. WM Blackshear, DJ Phillips, BL Thiele et a1: Detection of carotid occlusive disease by ultrasonic imaging and pulsed Doppler spectrum analys is.

Surgery 86: 698-706 (1979).

5. RS Reneman, L Pourcelot, APG Hoeks: Prospects and conclusion. In: Doppler Ultrasound in the diagnosis of cerebrovascular disease. 271-289, Research Study Press, Chicester (1982).

6. RS Reneman, MP Spencer: Local Doppler audio spectra in nomal and stenosed carotid arteries in man. Ultrasound Med Biol 5: 1-11 (1979).

7. G Fell, DJ Phillips, PM Chikos, JD Harley, BL Thiele, DE Strandness: U1trasonic Duplex scanning for disease of the carotid artery. Circulation 64: 1191-1195 (1981).

8. PJ Breslau: Ultrasonic Duplex scanning in the evaluation of carotid artery disease.

Thesis. University of Limburg, Maastricht, The Netherlands (1982). 
9. Y Langlois, Go Roederer, A Chan et al: Evaluating carotid artery disease: the concordance between pulsed doppler/spectrum analysis and angiography.

U1trasound Med Biol 9: 51-63 (1983). 


\section{CHAPTER IV}

LIMITATIONS OF DOPPLER SPECTRAL BROADENING IN THE EARLY DETECTION OF CAROTID ARTERY DISEASE DUE TO THE SIZE OF THE SAMPLE VOLUME

\subsection{Introduction}

Disturbances in the flow pattern do occur at relatively slight degrees of artery narrowing ${ }^{1}$ so that the detection of these disturbances is commonly used in the diagnosis of arterial lesions at an early stage of the disease. In the clinic disturbances in the flow pattern are generally diagnosed by estimating the degree of broadening of the Doppler audio spectrum, using either continuous wave ${ }^{2,3,4}$ or pulsed Doppler systems $5,6,7$. This is generally performed by classifying the spectra into a number of categories of spectral broadening, as judged by the eye. Spectral broadening, however, also occurs when in the sample volume the velocity profile is parabolic rather than flat, the soundbeam is non-homogeneous or divergence of the beam occurs. The latter may be induced by vessel wall calcifications without narrowing of the artery ${ }^{8}$.

In Continuous Wave Doppler systems the dimensions of the sample volume are mainly determined by the width of the ultrasound beam, while in pulsed Doppler systems the size of the sample volume depends on both the beamwidth and the effective sample duration. Hence, in pulsed devices spectral broadening will occur when the sample volume increases relative to the vessel diameter. It also implies that the spectra recorded with Continuous Wave systems are broader than those recorded with pulsed devices. In the latter devices spectra are displayed of samples usually taken from the centre of the vessel where red blood cells are travelling at approximately the same high velocity in case of plug flow and even parabolic flow. In Continuous Wave systems velocities are sampled along the whole cross-section so that the lower velocities near the vessel wall are presented in the audio spectrum as well. Therefore, it has been suggested that pulsed Doppler systems are likely to be more suitable to detect spectral broadening than Continuous Wave systeris, especially in the presence of minor lesions ${ }^{5}$. But then the sample volume relative to the vessel diameter has to be small and 
sampling in the middle of the bloodstream has to be ascertained. A complicating factor in pulsed devices is that spectral broadening will be introduced by the finite size of the sample volume in the direction of the velocity (transit-time effect). The smaller this dimension is, the larger the spectral broddenfing will be. This type of spectral broadening, however, is related to the average frequency and relative to this frequency constant for a given system ${ }^{9}$.

It was the aim of the present investigation to evaluate the criteria of spectral broadening used in pulsed Doppler devices to diagnose minar disease in the cervical carotid arteries in relation to the size of the sample volume. For this purpose the Doppler audio spectra as recorded with an ATL Duplex scanner with a short focus scamhead and a specially designed multigate pulsed Doppler system ${ }^{9}$ with a significantly smaller sample volume than the Duplex scanner, were compared with each other. Besides, sampling in the centre of the vessel is ascertained with the multi-gate device. The Doppler audio spectra were recorded in asymptomatic volunteers of varying age, randomly selected through population registers.

\subsection{Materials and methods}

The measurements were performed on 146 healthy male volunteers, randomly selected through the population registers of small, average and large cities between May 1981 and May 1982. From all subjects informed consent. was obtained before they entered the study. The volunteers were allotted to five age groups: Group I 20-29 years, Group II 30-39 years, Group III $40-49$ years, Group IV 50-59 years and Group $V$ 60-69 years of age. They all had a physical examination, including cuff blood pressure measurements. A history was taken on symptoms in relation to atherosclerosis. None of them had a positive history of cerebral insufficiency such as amaurosis fugax or transient ischemic attacks. Fourteen volunteers complained about angina pectoris and 11 suffered from intermittent claudication (al1 above 50 years of age). Five of them had combined disease. Nomal blood pressure readings were found in the younger age groups, but above 50 years of age about $25 \%$ of the volunteers were hypertensive according to the criteria of the W.H.0. (Blood pressure $>140 / 90)$. The highest blood pressure found in these volun- 
teers was $170 / 105$. A carotid bruit (in the absence of heart murmurs) was found in 3 cases.

The Doppler examinations were performed with the volunteers in the supine position, with the head in the mid-position (multi-gate pulsed Doppler system) or tilted sonewhat to the contralateral side (Duplex scanner). The carotid arteries on either the right or the left side were investigated.

When using the multi-gate pulsed Doppler system the site of sampling was localized through a welocity image of the bifurcation. In the Duplex scanner this was achieved by the B-mode image. With both systems the Doppler spectra were recorded mid-stream in the common carotid artery (about 3 an proximal to the bifurcation) and proximally in the internal carotid artery (one $\mathrm{cm}$ distal to the bifurcation). In some volunteers additional recordings were made more distally in the internal carotid artery $(3-4 \mathrm{~cm}$ distal to the bifurcation). In the multi-gate system the angle between probe and wessel was kept as constant as possible and aimed at about $50^{\circ}$ with respect to the skin surface. In the Duplex scanner this angle was checked on the B-mode image and kept at $60^{\circ}$ with respect to the investigated artery. These angles were chosen to obtain the best signals with either of the devices.

Table 4.I: Characteristics of the multi-gate pulsed Doppler system.

\begin{tabular}{lll}
\hline Emission frequency & 6.1 & $\mathrm{MHz}$ \\
PRF & 18 & $\mathrm{kHz}$ \\
Duration of emission & $0.5-1 \quad$ us \\
Sample gate width & 0.5 & $\mathrm{us}$ \\
Sample distance & 0.5 & $\mathrm{~mm}^{2}$ \\
Sample volume & $1.2-1.7 \mathrm{~mm}^{3}$ \\
Number of gates & $64^{1)}$ \\
\hline
\end{tabular}

1) can be selected in multiples of 8 . 
The Duplex scanner used, was the ATL Mark $V$ with a short focus scanhead. The emission frequency of this system is $5 \mathrm{MHz}$. The multi-gate pulsed Doppler device has been described in Chapter II. The major characteristics of the system are given in Tabie $4 . I$.

The sample volumes of both systems were measured in our labaratories under comparable circumstances. Defining the sample valume as the volume at a given range where $90 \%$ of the backscattered energy is originating from, the sample volume of the Duplex scanner at a range of 15 mo turned out to be $4.9 \mathrm{~mm}^{3}$, while at a range of $20 \mathrm{~mm}$ the size of the sanple vollume was 4.6 $\mathrm{mm}^{3}$. In this condition the sample volume of the multi-gate pulsed Doppler system was $1.2 \mathrm{~mm}^{3}$ at a range of $15 \mathrm{~mm}$ and $1.7 \mathrm{~mm}^{3}$ at a range of $20 \mathrm{~mm}$ for a duration of entission of $1 \mu \mathrm{s}$.

The increase in sample volume at increasing range indicates the short range at which the transducer was focussed. The presented ranges were selected because of the level of the carotid arteries relative to the skin.

Al1 spectra were stored on a 4-channel tape recorder (Racal; 0 - $10 \mathrm{KHz}$ - $3 \mathrm{~dB}$ ) and analysed off-line with a Nicolet spectrum analyser (100 frequency bins, each $100 \mathrm{~Hz}$ ), providing anplitude as function of frequency. For display the amplitude of the spectrum was scaled with respect to the peak amplitude. The hard copies as produced by this analyser were similar for both systems. The spectra were read blindly, regarding system and subject, and classified by the author according to the criteria used by Strandness and co-investigators for pulsed Doppler instruments 10 . Their criteria as described for the ATL Duplex scanner, are depicted in Table 4.II. Since the enission frequency of the multi-gate system is higher than that of the Duplex scanner and the angle between vessel and probe is a bit steeper when using the former device, under normal conditions the maximum systolic peak frequency for this system was considered to be $6 \mathrm{kHz}$.

\subsection{Results}

Since the distribution of the various categories of spectral broadening was simflar in the volunteers suffering from intermittent claudication, angina pectoris or hypertension and in the volunteers without disease, all subjects were grouped for further analysis. 
Table 4.II: Grading of artery narrowing from the degree of spectral broademing according to Strandness (Breslau, 1982).

- normal

$-5-15 \%$ stenos is

- $16-49 \%$ stenosis

$-50-99 \%$ stenosis

- total occlusion
(A): no spectral broadening; Max, frequency $<4 \mathrm{kHz}$ त

(B): spectral broadening in deceleration phase of systole; max. frequency $<4 \mathrm{kHz}$

(C): spectral broadening throughout systole; $\max$. frequency $<4 \mathrm{kHz}$

(D): spectral broadening throughout systole/ increased frequencies in diastole; max. frequency $>4 \mathrm{kHz}$

(E): no signal

I $6 \mathrm{kHz}$ for multi-gate system (see section 4.2 ).

The classifications as were found with both systems in the common carotid artery are shown in Table 4.III. In the younger age groups the spectra were generally classified as $A$ 's, but above 50 years of age mainly $B$ classifications were found.

The classifications of the Doppler audio spectra as recorded proximally in the internal carotid artery are presented in Table 4. IV. The number of $B$ classifications in this artery was greater than in the common carotid artery, especially in the younger age groups. Below 40 years of age more spectra were classified as $B$, when they were recorded with the Duplex scanner. At older age $C$ and $D$ classifications were found with both systems.

Comparison of the spectra recorded proximally and distally in the internal carotid artery in the same volunteers revealed only minor differences between the classifications of the spectra recorded with the multigate pulsed Doppler systems. A tendency to higher classifications (more B's at younger age, and $C^{\prime} s$ and $D$ 's at older age) was seen when they were recorded with the Duplex scanner (Table 4.V). 
Table 4.11: Classifications of the Doppler audio spectra as recorded in the conmon carotid artery.

$$
\begin{aligned}
& \text { multi-gate } \\
& \text { pulsed Doppler }
\end{aligned}
$$

$$
\begin{array}{cc}
20-29 & A \\
(n=32) & B
\end{array}
$$

30-39 A

$(n=19) \quad B$

$40-49 \quad A$

$(n=13) \quad B$

$50-59 \quad A$

$(n=41) \quad B$

60-69 A

$(n=41) \quad B$
32

0

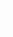

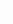

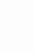


latter system with a sample volume of only $1.2-1.7 \mathrm{~mm}^{3}$ and sampling in the middle of the bloodstream was ascertained, the incidence of A classifications (normal spectra) was relatively low. The high incldence of $B$ classifications in young volunteers as obtained with the Duplex-scanner is in keeping with recent findings of knox and co-investigators 10 in a small group of asymptomatic volunteers.

Table 4.IV: Classifications of the Doppler audio spectra as recorded proximally in the internal carotid artery.

multi-gate

pulsed Doppler
ATL duplex

scanner $\begin{array}{cc}20-29 & A \\ (n=31) & B\end{array}$

$30-39 \quad A$

$(n=22) \quad B$

40-49 A

$(n=14) \quad B$

$A$

50-59 B

$(n=40) \quad C$

D

A

60-69 B

$(n=39) \quad C$

0
18

13

14

8

2

12

1

30

34

4

5

1

1

34

36

4

2

$\begin{array}{ccrr}20-29 & A & 18 & 6 \\ (n=31) & B & 13 & 25 \\ 30-39 & A & 14 & 7 \\ (n=22) & B & 8 & 15 \\ & & & 2 \\ 40-49 & A & 2 & 12 \\ (n=14) & B & 12 & 1 \\ & & & 34 \\ 50-59 & \text { B } & 5 & 5 \\ (n=40) & \text { C } & 30 & - \\ & \text { D } & 4 & 1 \\ & & 1 & 36 \\ 60-69 & \text { B } & & 2 \\ (n=39) & \text { C } & - & - \\ & \text { D } & 34 & \end{array}$


Table 4.V: Classifications of the Doppler audio spectra as recorded proximally and distally in the internal carotid artery in the same volunteers.

multi-gate pulsed

Doppler system

prox.

dist.

6

5

6

4

$(n=10) \quad B$

40-49 A

$(n=9) \quad B$

$\begin{array}{cc}50-59 & A \\ (n=27) & C \\ & C\end{array}$

A
$60-69 \quad B$

$(n=25) \quad C$

a

$20-29$
$(n=11) \quad B$

4
7

6

4

1

8

9

$\begin{array}{rr}1 & - \\ 21 & 21 \\ 4 & 4 \\ 1 & 2\end{array}$

4

2

$21 \quad 20$

5

3.5

ATL duplex scanner

prox.

dist.
7

9

8

9

22

19

5

7

1

$$
1
$$

22

2

21 
Additional support for the idea that the spectral broadening as found in the internal carotid artery in young asymptomatic volunteers, is caused by a too large sample volume relative to the vessel diameter is given by the increasing incidence of $B$ classifications when the spectra are recorded more distally in the same vessel, especially with the Duplex scanner (Table 4. V). At this site the artery is likely to be narrower. In these young wolunteers mainly A classifications were found with both systems in the common carotid artery, a larger diameter vessel.

Another limitation of too large a sample volume is the increased sensitivity to flow disturbances, introducing velocity gradients within the sample volume, as a result of inlet phenomena as can easilly occur proximally in the internal carotid artery. This may also contribute to the differences in classification between the Duplex scanner and the multi-gate pulsed Doppler system at this site.

At first sight better results could be obtained by further decreasing the size of the sample volume, especially along the ultrasound bean. Further reduction of the sample volume, however, results in deterioration of the signal to noise ratio and as discussed before, in spectral broadening due to transit-time effects.

The importance of a small sample volume and sampling in the middle of the bloodstream in the use of spectral broadening to detect minor lesions is illustrated in Figure 4.1. Even with a small sample volume and a sample distance along the ultrasound beam of $0.5 \mathrm{~mm}$, normal spectra (A classifjcations) are only found in the middle of the bloodstream, $i . e$. in the most central gates. Towards the vessel wall spectral broadening occurs due to the presence of velocity gradients within the sample volume, despite the relatively flat velacity profile in these arteries 11,12 .

The higher incidence rate of $B$ classifications and the presence of $C$ and $D$ classifications in the older age groups can probably not be explained by a more unfavourable relation between sample volume and vessel diameter, because the vessel diameter increases with increasing age (13\% from 20-69 years) ${ }^{13}$. The hilgher incidence of spectral broadening at older age might reflect the presence of vascular disease, although no definite conclusions can be drawn because no anglograms were made. Even the volunteers with classifications $C$ and $D$ were not submitted to angiography since they were asymptomatic. In case of vascular disease the spectral broadening as 

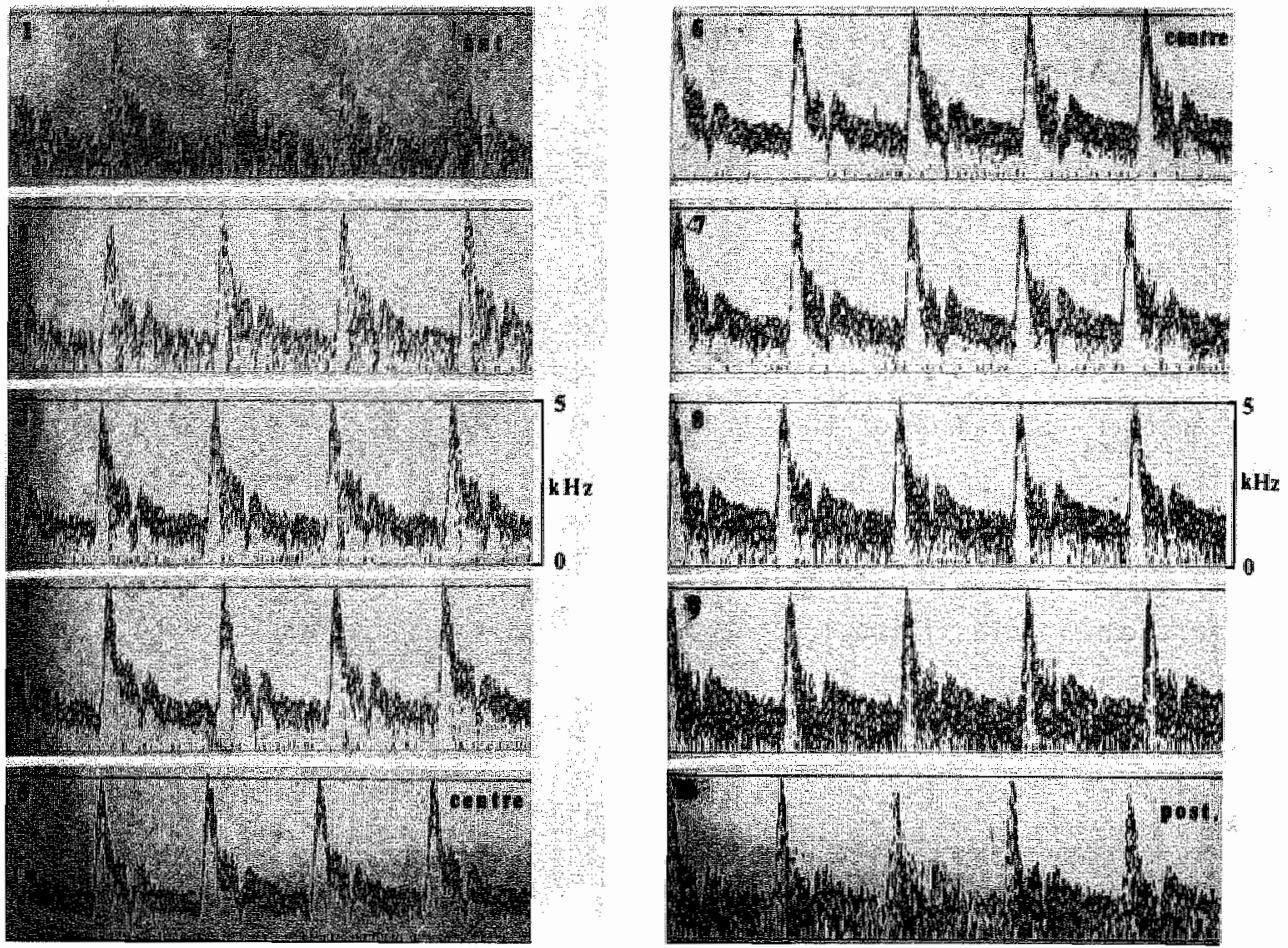

Fig. 4.1: Doppler audio spectra as recorded in the common carotid artery at successive sites along the ultrasound beam during consecutive cardiae oycles with the multi-gate pulsed Doppler fiystem without changing the position of the probe. Ant = anterior wall; post = postemior wati.

found in the alder age group does not necessarily have to be associated with narrowing of the artery because calcifications in the vessel wall may al so induce spectral broadening due to beam divergence ${ }^{8}$. Support for changes in vessel wall properties at alder age might be found in the loss of elastic properties of the vessel as indicated by the diminished relative diameter increase of the common carotid artery during the cardiac cycle above 40 years of age 14 .

In conclusion the findings in the present study indicate that for the detection of vascular lesions in the cervical carotid arteries at an early stage of the disease on the basis of spectral broadening, small sample volumes and sampling in the middle of the bloodstream are required. One may 
wonder whether for the internal carotid artery the sample volume cain be made sufficiently small to distinguish accurately normal from slightly diseased vessels.

Previously published as:

Limitations of Doppler spectral broadening in the early detection of carotid artery disease due to the size of the sample volume: Tiny van Merode, Paul Hick, Arnold PG Hoeks and Robert S Reneman. Ultrasound Med Bial 9: $581-586$ (1983). 


\section{REFERENCES}

1. DP Giddens, RF Mabon, RA Cassanova: Measurement of disordered flows distal to subtotal vascular stenoses in the thoracic aarta of dogs. Circ Res 39: 112-119 (1976).

2. RS Reneman, MP Spencer: Local Doppler audio spectra in normal and stenosed carotid arteries in man.

UTtrasound Med Biol 5: 1-11 (1979).

3. RW Barnes, SE Rittgers, WW Putney: Real-time Doppler spectrum analysis: predictive value in defining operable carotid artery disease. Arch Surg 117: 52-57 (1982).

4. JM van Baalen, JJ Jakimowicz, RS Reneman: Noninvasive evaluation of carotid artery stenosis - comparison of direct and indirect techniques. Vascular Surgery 18: 88-95 (1984).

5. WM Blackshear, DJ Phillips, BL Thiele, JH Hirsch, PM Chikos, MR Marinelli, CJ Ward, DE Strandness: Detection of carotid occlusive disease by ultrasonic imaging and pulsed Doppler spectrum analysis. Surgery 86: 698-706 (1979).

6. G Fell, DE Strandness: The duplex scanner - real time imaging combined with pulsed Doppler. In: Doppler Ultrasound in the Diagnosis of Cerebrovascular Disease, Ed. RS Reneman, APG Hoeks. Research Studies Press, Chichester (1982).

7. PJ Breslau: Ultrasonic Duplex scanning in the evaluation of carotid artery disease.

Thesis. Iniversity of Limburg, Maastricht, The Netherlands (1982).

8. MP Spencer: Ultrasonic detection of the non-stenotic plaque. In: Cerebrovascular Evaluation with Doppler Ultrasound, Ed. MP Spencer, JM Reid. Martinus Nijhoff Publishers, The Hague (1981). 
9. APG Hoeks: On the development of a multi-gate pulsed Doppler system with serial data-processing. Thesis. University of Limburg, Maastricht, The Netherlands (1982).

10. RA Knox, DJ Phillips, PJ Breslau, R Lawrence, J Primozich, DE Strandness: Empirical findings relating sample volume size to diagnostic accuracy in pulsed Doppler cerebrovascular studies. J $\mathrm{Cl}$ in U1 trasound 10: 227-232 (1982).

11. RS Reneman: What measurements are necessary for a comprehensive evaluation of the peripheral arterial circulation? Cardiovasc Dis 8: 435-454 (1981).

12. RS Reneman, $T$ van Merode, P Hick, APG Hoeks: Noninvasive detection of atherosclerotic lesions in cervical carotid arteries at an early stage of the disease.

J Cereb Blood Flow 2. Suppl 2: 32-34 (1982).

13. $K$ Fujishiro, $S$ Yoshimura: Haemodynamic changes in carotid blood flow with age.

Jikeihai Medical Journal 29: 125-138 (1982).

14. RS Reneman, T van Merode, APG Hoeks, P Hick: The on-line recording of velocity profiles and diameter changes in normal and stenosed cervical carotid arteries in man.

U1trasound Med Biol 8 Suppl 1: 166 (abstract) (1982). 

CHAPTER W

DIAGNOSTIC ACCURACY OF THE MULTI-GATE PULSED DOPPLER SYSTEM IN DETECTING MODERATE CAROTID ARTERY LESIONS. A COMPARISON WITH BIPLANE ARTERIOGRAPHY

Since the detection of minor and moderate carotid artery stenoses by Doppler examination cannot be based unambiguously on spectral analysis of the Doppler signal alone (Chapter IV), additianal criteria had to be found to diagnose these lestons.

We only considered spectral broadening (corresponding with a B-classification according to Strandness and collegues; Chapter IV) as abnormal, if associated with flow disturbances as observed in the nulti-gate pulsed Doppler examination. The flow pattern was considered to be abnomal when the flow profile was asymmetric at a site where normally a symmetrical profile is found and/or the instantaneous velacity wave forms, as recorded simultaneously at various sites along the ultrasound beam, showed irregularities, locally or along this beam.

This resulted in a modification of Strandness" classification for spectral analysis, as shown in Table 5.I. Needless to say that flow disturbances are generally present in the more severe lesions, i.e. the catagories $C$ and $D$.

In a prospective study on 70 carotid arteries in 35 patients from the neurological department of the University Hospital in Mastricht, the results as obtained with the multi-gate pulsed Doppler system, using the criteria as described in Table 5.I, were compared with those obtained with arteriography in the diagnosis of extracranial carotid artery disease.

All patients were submitted to biplane arteriography (Seldinger technique) of the carotid circulation, because of focal neurological symptoms. The further analysis was performed on 67 arteries, because one patient underwent unilateral carotid endarterectomy before the ultrasonic examination, and 2 arteries could not be investigated for technical reasons cone for equipment breakdown and one because of gross obesityl. The ultrasonic examination was performed and the degree of artery narrowing assessed (according to the classification described in Table 5.1) by the author, who was not informed of the results of the arteriograms. The usual routine for 
carotid evaluation with the multi-gate pulsed Doppler systam was followed (see Chapter IV).

The arterlograms were read by the hospital's radiologists, without knowledge of the outcome of the non-invasive examination. The lesions were classified as absent (normal), moderate stenosis (1-49\% diameter reduction), severe stenosis (50-99\% diameter reduction) and acclusion.

The results are depicted in Table 5. 11 . The overall diagnostic accuracy was $88 \%$. The calculation of the diagnostic accuracy $\left(P_{0}\right)$ is shown underneath Table 5.III. For all lesions the sensitivity was $92 \%$ and the specificity was $84 \%$. The positive predictive value and the negative predictive value were $87 \%$ and $90 \%$, respectively. When only the moderate lesions were regarded the accuracy was $84 \%$, with a sensitivity of $83 \%$ and a specificity of $84 \%$

By callculating the averall diagnostic accuracy the agreement between two diagnostic methods can thus be described, but in this way the marginal distribution of the data is not taken into account. A skewed data distribution with, for instance, many severe lesions, may flatter the outcome of the calculated diagnostic accuracy, even when minor lesions are missed to a relatively large extent. It is therefore better to calculate the chancecorrected measure of agreement, Kappa. Kappa 1,2 , is not only determined by the observed agreement, but also by the marginal distribution. Calculation of Kappa is presented in Table 5.III. It can be seen that the rather homogeneous data distribution in Table 5.11 results in only a moderate chancecorrection: the overall diagnostic accuracy remains good $(82.2$ rather than 88.0\%). For a comparable study in the internal carotid artery, that correlated the results of a combined single-gate pulsed Doppler/B-mode image (Duplex) technique with those of arteriography using a short focus scanhead and only the degree of spectral broadening as diagnostic criterion, the overall diagnostic accuracy was found to be $76.6 \% 3$. In this study, however, the calculated chance-corrected measure of agreement was only $68.2 \%$.

Based upon the present findings the diagnostic accuracy of the multigate pulsed Doppler system, cambining spectral analysis and directly recorded disturbances in the flow pattern, can be considered to be adequate for non-invasive diagnosis of both moderate and severe carotid artery disease. Accurate diagnosis of vascular lesions at relatively early stage of the disease will provide more insight into the natural history of the disease, and may be helpful in epidemiological studies. 
TABLE 5.I: Modified criteria according to Strandness for spectral analysis, adapted for the multi-gate pulsed Doppler system as used in this study (see for characteristics of the system Chapter II).

Norma]

(A) no spectral broadening; max. frequency $<6 \mathrm{kHz}$

$\left(\mathrm{B}^{-}\right)$spectral broadening in deceleration phase of systole; no associated flow disturbances; max. frequency $<6 \mathrm{kHz}$

$\leq 15 \%$ stenosis

$\left(B^{+}\right)$spectral broadening in deceleration phase of systole; max. frequency $<6 \mathrm{kHz}$; flow disturbances along the ultrasound beam or asymmetry of the velocity profile !

$16-49 \%$ stenosis

(C) spectral broadening throughout systole; $\max$. frequency $<6 \mathrm{kHz}$

$50-99 \%$ stenosis

(D) spectral broadening throughout systole/ increased frequencies in diastole; max. frequency $>6 \mathrm{kHz}$.

Total occlusion

(E) no signal.

I This subcategory is used in the study described in Chapter VI. 
IABLE 5.1I: The results of the multi-gate pulsed Doppler investigation when compared with biplane arteriography (Seldinger technique) as a gold standard.

DOPPLER

$\begin{array}{llll}\text { nomal } & 50 \%-99 \% & 100 \% & \text { TOTAL }\end{array}$

ANGIO

nomal 26

5

31

$<50 \%$

3

15

18

$50-99 \%$

14

14

$100 \%$

4

4

TOTAL

29

20

14

4

67

lesions $<50 \%$

Diagnostic accuracy

$88 \%$

$84 \%$

Sensitivity

$92 \%$

$83 \%$

Specificity

$84 \%$

$84 \%$

Pos. pred. value $87 \%$

Neg. pred. value 
TABLE 5.III: Comparison of the observed $\left(P_{0}\right)$ and the chance-corrected agreement $(K)$ for the data presented in Table 5.II.

a posteriori (Doppier examination)

$\begin{array}{lllll}\text { a priori normal } & <50 \% & 50-99 \% & 100 \% & \text { Marginals } \\ \text { (arteriography) } & & & & \end{array}$

$\begin{array}{lllll}\text { A } & \text { B } & C & 0 & M_{1}\end{array}$

normal

26

5

E $\quad F$

G $\quad \mathrm{H} \quad \mathrm{M}_{2}$

$<50 \%$

3

15

18

\begin{tabular}{llllll}
\hline I & J & $K$ & $\mathrm{~L}$ & $M_{3}$
\end{tabular}

$50-99 \%$

14

14

0

p

Q

R

$M_{4}$

$100 \%$

$M_{5}$

Marginals

29

$M_{6}$

$M_{7}$

N

4

4

$P_{0}: \frac{A+F+K+R}{N}=\frac{59}{67} \times 100 \%=88.0 \%$

$K=\frac{P_{0}-P_{C}}{1-P_{C}}$

$P_{c}=\frac{M_{1}}{N} \times \frac{M_{5}}{N}+\frac{M_{2}}{N} \times \frac{M_{6}}{N}+\frac{M_{3}}{N} \times \frac{M_{7}}{N}+\frac{M_{4}}{N} \times \frac{M_{8}}{N}=0.3276$

$K=\frac{0.8806-0.3276}{1-0.3276}=0.822$, i.e. $82.2 \%$ 


\section{REFERENCES}

1. J Cohen: A coefficient of agreenent for nominal scales. Educ Psyc 20: $37-46$ (1960).

2. HA Schouten: Measuring pairwise agreement among many observers. Biom J 22: 497-504 (1980).

3. PJ Breslau: Ultrasonic Duplex scanning in the ewaluation of carotid artery disease.

Thesis, University of Limburg, Maastricht, The Netherlands (1982). 
CHAPTER VI

SERUM HOL/TOTAL CHOLESTEROL RATIO AND BLOOD PRESSURE IN ASYMTOMATIC ATHEROSCLEROTIC LESIONS OF THE CERVICAL CAROTID ARTERIES IN MEN

\subsection{Introduction}

Risk factors for caratid artery lesions have been investigated extensively in the past decades. Especially high blood pressure, serum lipoprotein abnomalities and diabetes were found to be related to the risk of cerebrovascullar disorders like stroke and transient ischemic attacks 1-11. These investigations, however, were performed on patients suffering from these disorders, which means that information about risk factors has been obtained at a progressed stage of the disease. Besides, in most of these investigations the control subjects were assumed to be healthy, despite the fact that asymptomatic carotid artery lesions may be present in the age groups studied $12-14$.

In the present investigation arterial blood pressure as well as serum total cholesterol and high density Iipoprotein (HDL) cholesterol levels were assessed in asymptomatic subjects with atherosclerotic lesions of the cervical carotid arteries and in healthy subjects without cervical carotid artery lesions. The subjects were randomly selected through the population registers of small, average and large urban and rural towns, and screened for cervical carotid artery lesions using a high resolution multi-gate pulsed Doppler system 15-17 (See also Chapter II). Arterial lesions were diagnosed, using modified criteria of spectral broadening as developed for pulsed Doppler systems 18,19 and adapted to the characteristics of the mult-gate device (See Chapter V). The study was limited to men above the age of 50 years, because cervical carotid artery lestions are likely to occur infrequently below this age (Chapter IV). Men were selected since differences in HDL-cholesterol levels between patients and control subjects are often more pronounced in males than in females. 4 . The serum HDL cholesterol level and the HDL/tatal cholesterol ratio were used as indicators for dyslipoproteinemia because a low HDL-cholesterol level is considered to be an independent risk factor for atherosclerosis 4-8. Moreover, 
overnifht fasting is not required for accurate assessment of these biochemical variables 20,21 which is a major advantage in studies on nonhospltalized subjects.

\subsection{Materials and methods}

The study was performed on 100 male volunteers from the Maastricht area, varying in age between 50 and 69 years. Their names and addresses were randomly selected from the population registers of small, average and large urban and rural towns. Two hundred and fifty subjects were contacted ance to obtaln 100 volunteers. All respondents were included in the study. From all volunteers informed consent was obtained before they entered the study. A history was taken on symptoms related to atherosclerosis. They all had a physical examination, including cuff blood pressure measurenents in the supine position. In case of hypertensive blood pressure readings (see below), the measurements were repeated $2-3$ times and the lowest vallue was taken as the subject's reading.

The cerwical carotid arteries were screened for disease, using a high resolution multi-gate pulsed Doppler system (Chapter II) with the following characteristics: enission frequency $6.1 \mathrm{MHz}$, pulse repetition frequency 18 $\mathrm{KHz}$, emission duration $0.5-1.0 \mu \mathrm{s}$, sample interva $0.5 \mathrm{~mm}$ and number of gates 64. The sample volume of this system as measured in vitro 22 is 1.2 $\mathrm{mm}^{3}$ at a range of $15 \mathrm{~mm}$ and $1.7 \mathrm{~mm}^{3}$ at a range of $20 \mathrm{~mm}$ (see Chapter IV). The Doppler examinations were performed with the volunteers in the supine position with the head in the mid-position. Doppler signals were recorded midstream at various sites in the common, internal and external carotid arteries. The site of sampling was localized through a velocity image of the bifurcation. All Doppler signals were stored on a 4-channel tape recorder (Racal; $0-10 \mathrm{KHz}-3 \mathrm{~dB}$ ) and analyzed off-line with a Nicolet spectrum amalyzer (100 frequency bins, each $100 \mathrm{~Hz}$ ), providing amplitude as a function of frequency. For display the amplitude of the spectrum was scaled with respect to the peak amplitude. The spectra were classified according to modified criteria of spectral broadening as developed for pulsed Doppler systems 18,19 and adapted to the characteristics of our multi-gate device. Since doubt has been raised whether $B$ classifications allways represent 
cervical caratid artery lesions, as has been discussed in chapter IV, even when small sample volumes are used, only $B$ classifications associated with disturbed flow patterns as indicated by other criteria, were considered to be representative of vessel disease. The criteria include asymetry of the velocity profile and/or disturbed instantaneous velocity waveforms along the ultrasound beam, locally or along the whole vessel diameter (See Table 5.I). Velocity profiles at discrete time intervals during the cardiac cycle and instantaneous velocity wavevorms at various sites along the ultrasound beam can be recorded on-line with our multi-gate pulsed Doppler systen (Chapter II). In prospective studies the pulsed Doppler/spectrum analys is method to detect atherosclerotic lesions of the cervical carotic arteries has been compared with biplane arteriography 18,19 . These studies revealed that cervical carotid artery lesions associated with a degree of artery narrowing of 16-49\% (C classification) and 50-99\% (D classification) can be diagnosed accurately, provided that the sample volume of the Doppler system is small, as is the case in the present investigation. In our hands lesions can be diagnosed with a sensitivity of $92 \%$, a specificity of $84 \%$ and a diagnostic accuracy of $88 \%$ as compared to arteriography. See Chapter $V$.

Venous blood was taken from each person in a non-fasting condition for the estimation of total cholesterol and HDL cholesterol in whole serum. The concentration of total cholesterol in serum was measured after direct addition of Liebermann-Burchard reagent and the results were calibrated with human serum pools with known cholesterol concentrations as described by Katan and co-investigators 23 . Reproducibility for blind control sera provided by the Centers for Disease Control, Atlanta USA, was within 0.9\% and the accuracy was within $1.6 \%$ of the true (target) values. The concentration of cholesterol in HDL was measured after the precipitation of low and very low density 1 ipoprateins by heparin- $\mathrm{MnCl}_{2}{ }^{24}$. Reproducibility for blind control sera as obtaimed in the Center for Disease Control Survey of HDL-measurements ${ }^{25}$ was within $\pm 2.2 \%$ and this, with regard to the overall survey mean, was an average of $0-1 \%$. Bilood samples were taken scattered over the day. This is allowed because previous studies have shown that there are no detectable differences in the concentrations of total and HDL cholesterol with time of the day and the time interval since the last meal 20,21 . Differences between the mean values of the variables in the varlous groups were evaluated for statistical significance $(p<0.05)$ in an one-way 
analysis of wariance as implemented in a standard computer program (BMDP statistical software, University of California Press, Los Angeles, 1981, p. 106).

\subsection{Results}

In 5 of the 100 wolunteers the serum lipid concentrations could not be assessed for technical reasons. Two subjects were excluded from the study because of insulin-dependent diabetes mellitus.

Twenty-three of the remaining 93 subjects had an abnormal Doppler investigation $(30 \%$ in the 6 th age decade and $18 \%$ in the 7 th age decade, a non-significant difference; pearson $x^{2}$ test). The arteries involved and the degree of narrowing are given in Table 6.1 . In 21 cases lesions were found

Table 6.I Arteries involved and the degrees of artery narrowing in the 23 subjects with abnomal Doppler findings.

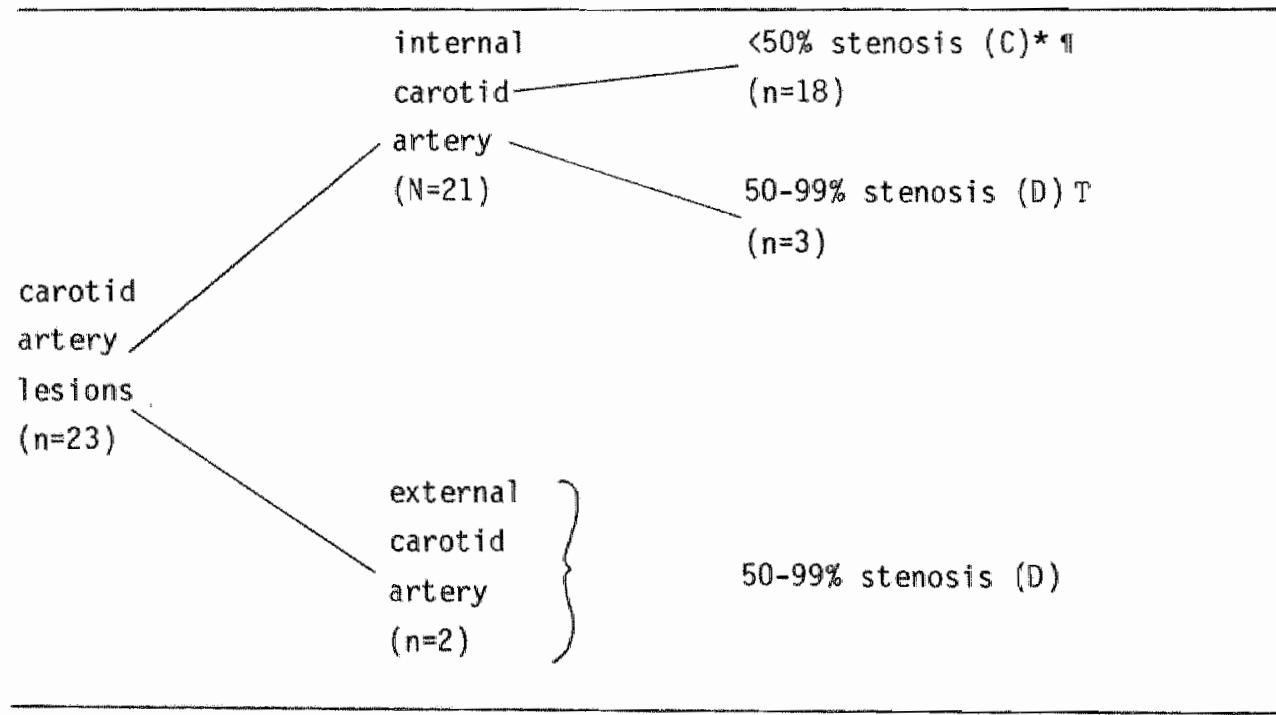

* Diameter reduction

"Including 5 patients with multi carotid artery disease.

No patients with multi carotid artery disease. 
in the internal carotid artery, while the external carotid artery was involved in 2 cases. In 5 subjects multi-vessel disease was observed. All volunteers were asymptomatic for carotid artery disease, which means a negative history of stroke, transient ischemic attacks or amaurosis fugax. The Doppler examination was nomal in the subjects that were excluded from the serum lipid estimation (see above). Hence, the frequency of asymptomatic carotid artery disease in the population under investigation was $23 \%$. of the 70 subjects with normal Doppler findings, 16 had a positive history of angina pectoris, myocardial infarction and/or intemittent claudication. Based upon these findings three groups were formed. One group of normal subjects consisted of 54 volunteers with nomal Doppler findings and no history of atherosclerotic disease (Group I). A second group consisted of 16 volunteers with normal Doppler findings, buth with a positive history of atherosclerotic disease (Group II). The third group consisted of the 23 subjects with abnormal Doppler findings (Group III). Seven of these subjects had a positive history of angina pectoris or intermittent claudication. Beta blocking agents were taken by one subject in Group I (Lopresor (metoprolo1)), 9 subjects in group II (6 Inderal (propranolo1), 2 Trasicor (oxprenolo1), 1 Aptine (alprenolo1)) and 2 subjects in Group III (Trasicor). Two subjects in each group took thiazides (Esidrex).

Twenty-five of the volunteers were hypertensive according to the criteria of the W.H.0. (blood pressure $>140 / 90$ ). The frequency of hypertension was significantily higher in the Groups II (40\%) and III (35\%) tham in Group I (19\%). No significant difference could be detected between the frequency in Group II and Group III. Diastolic blood pressure was significantiy higher in Group II $(87.6 \pm 9.9 \mathrm{mmHg} ; \bar{x} \pm s d)$ and Group III $(86.0 \pm 10.6 \mathrm{~mm} / \mathrm{lg})$ than in Group I $(81.5 \pm 8.7 \mathrm{mmHg})$. The diastolic blood pressure readings in the Groups II and III were not significantly different. No significant differences could be detected between the systollic blood pressure readings in the three groups. In all subjects in Group I with blood pressure $>140 / 90$, the blood pressure was lower than $160 / 95$ and hence their hypertensive status could be considered borderline. Three subjects in Group II and 3 subjects in Group III were definitely hypertensive (blood pressure > 160/95). There was no significant difference in the frequency of hypertenston between the 6th and 7 th age decade in the Groups I and III, but a higher frequency of hypertension in the 6th age decade in Group II (Pearson $x^{2}$ 
Table 6.11 Serum total and HDL cholesterol concentrations (mol/1) and HDL/total cholesterol ratio in nomal subjects (Group I), subjects with a positive history of atherosclerosis, but without detectable cervical carotid artery lesions (Group II) and subjects with asymptomatic cervical carotid artery lesions (Group III). Values are given in $\bar{x} \pm s d$.

$\begin{array}{lll}\text { Group I } & \text { Group II } & \text { Group II I } \\ (n=54) & (n=16) & (n=23)\end{array}$

Total cholesterol

$6.02 \pm 0.85$

$6.25 \pm 0.93$

$6.61 \pm 1.04$ *

HDL cholesterol

$1.30 \pm 0.39$

$1.05 \pm 0.22 \%$

$1.18 \pm 0.27$

$\mathrm{HOL} /$ total

cholesterol ratio

$0.22 \pm 0.06$

$0.17 \pm 0.06$

$0.18 \pm 0.05 \pi$

* Significantly higher than in Group I.

"Significantly lower than in Group I.

test). The groups were comparable as far as age and heart rate are concerned.

The serum total and HDL cholesterol concentrations as well as the HDL/total cholesterol ratio in the various groups are shown in Table 6.I1. The total cholesterol level was significantly higher in Group III than in Group 1, while the HDL cholesterol level was significantly lower in Group II than in Group I. The HDL/total cholesterol ratio was significantly lower in the Groups II and III than in Group I. No significant differences could be detected between the Groups II and III. The serum total and HDL cholesterol concentrations, and the HDL/total cholesterol ratio were similar for hypertensive and non-hypertensive subjects (Table 6.III). 
Table 6. III Serum total and HDL cholesterol concentrations (mono//1) and HOL/total cholesterol ratio in nomotensive and hypertensive subjects $(\bar{x} \pm s d)$.

Nomotensive

Hypertensive

$(n=68)$

$(n=25)$

Total cholesterol

$6.14 \pm 0.83$

$6.20 \pm 1.10$

HDL cholesterol

$1.23+0.38$

$1.21 \pm 0.29$

HDL/total cholesterol ratio

$0.20 \pm 0.06$

$0.20 \pm 0.06$

\subsection{Discussion}

In the present study serum total cholesterol was found to be higher and the serum HDL/total cholesterol ratio lower in subjects with asymptomatic cervical carotid artery lesions than in age matched subjects devoid of obvious atherosclemosis as evidenced by a normal Doppler examination and a negative history of symptoms related to atherosclerosis. In the former subjects the frequency of hypertension and the diastolic blood pressure level were higher than in the control subjects. These findings support the idea that at least in men a low serum HDL/total cholesterol ratio $3-8$ and high blood pressure $2,9,11$ can be considered as risk factors for atherosclerotic lesions of the cervical carotid arteries, especially since these aberrations are already observed at an early stage of the disease. In the present investigation, after a11, all subjects were asymptamatic for cerebrovascular disease, while $78 \%$ of the lesions were associated wth less than 50\% narrowing of the artery (Table 6.I). That these risk factors are related to atherosclerosis is supported by the finding that the serum lipid disturbances, the frequency of high blood pressure and the diastolic blood pressure level were simillar in the group with asymptomatic cervical carotid 
artery lesions (Group III) and in the group of subjects with a history of ischemic heart disease and/or intemittent claudication (Group II), but with a normal Doppler examination. Furthemore, 30\% of the subjects in Group III also had a history of ischemic heart disease of intermittent claudication. These findings also imply that the risk factors under investigation are indiscriminate as far as the 10calization of atherosclerosis is concerned. A major advantage of the use of the serum HDL/total cholesterol ratio as risk factor in epidemiologic studies over other lipids is that overnight fasting is not required to estimate this ratio accurately 20,21. Several subjects, especial1y in Group II, were taking beta-blocking agents or thiazides. Whether this has influenced the resuits as abtained in the present investigation is not known because the effect of these compounds on serum lipids is stil11 a matter of debate $5,26-29$.

In the present investigation the Doppler spectral classifications $A$ and classifications $B$ with normal velocity profiles and instantaneous velocity waveforms were grouped and assumed to be representative of normal arteries, despite the fact that $B$ classifications per se have been considered to be associlated with very minor lesions. In Chapter $I V$, however, it was indicated that $B$ classifications per se do not necessarily reflect cervical carotid artery disease, especially in the internal carotid artery where the flow conditions are rather complicated, even under normal circumstances 30 . On the other hand, the inclusion of subjects with very minor caratid artery lesions in the group of normals cannot be excluded when $A$ and some $B$ classifications are combined.

The frequency of asymptomatic cervical carotid artery lesions of $23 \%$ as found in this study compares favorably with the results obtained by Martin and co-investigators 13 in post-morten studies, but is significantiy higher than the incidence of $5.9 \%$ found by Hennerici and his colleagues 12 in neuralogically asymptomatic at-risk patients. The latter investigators, however, only considered patients with a degree of carotid artery narrowing of more than $50 \%$. The incidence of lesions in this category was $5 \%$ in our study, a value in close agreenent with the one described by Hennerici.

In summary the findings of the present study support the idea that a low serum HDL/tatal cholesterol ratio and high blood pressure have a high degree of association with atherosclerotic lesions of the cervical carotid arteries. This association is already apparent at an early stage of the disease. 
Previously published as:

Serum HOL/total cholesterol ratio and blood pressure in asymptomatic atherosclerotic lesions of the cervical carotid arteries in men. Tiny van Merode, Paul Hick, Arnold PG Hoeks and Robert 5 Reneman. Stroke 16: 34-38. (1985). 


\section{REFERENCES}

1. A Randrup, H Pakkenberg: Plasma triglyceride and cholesterol levels in cerebrovascular disease.

J Atheroscler Res 7: 17-24 (1967).

2. GW Duncan, RS Lees, RG Ojemann, SS David: Conconmitants of atherosclerotic carotid artery stenosis.

stroke 8: 665-669 (1977).

3. S Roessner, KG Kjellin, KL Mettinger, A Siden, CE Soederstraem: Dyslipo-proteinemia in patients with ischemic cerebro-vascular disease: A study of stroke before the age of 55 .

Atherosclerosis 30: 199-209 (1978).

4. CR Sirtori, G Gianfranceschi, I Gritti, G Nappi, G Brambilla, P Paoletti: Decreased high density lipopratein cholesterol levels in male patients with transient ischemic attacks.

Atherosclerasis 32: 205-211 (1979).

5. 4 Taggart, RW Stout: Reduced high density lipoprotein in stroke: relationship with elevated triglyceride and hypertension. Eur J Clin Invest 9: 219-221 (1979).

6. A Murai, T Tanaka, T Miyahara, M Kameyama: Lipoprotein abnormalities in the pathogenesis of cerebral infarction and transient ischemic attack. Stroke 12: $167-172$ (1981).

7. AR Nubiola, L Masana, S Masdeu, J Rubies-Prat: High-density lipoprotein cholesterol in cerebrovascular disease. Arch Neurol 38: 468 (1981).

8. S Roessner: Serum lipoproteins and ischemic vascular disease: on the interpretation of serum lipid versus serum lipoprotein concentrations. J Cardiovasc Phamacol 4 (suppl 2): \$201-\$205 (1982). 
9. B Herman, ACM Leyten, JH vam Luyk, GWGM Frenken, AAw op de Coul, BPM Schulte: An evaluation of risk factors for stroke in a Dutch cormunity. Stroke 13: $334-339$ (1982).

10. JT Salonen, P Puska, J Twomilehto, K Homan: Relation of blood pressure, serum lipids and smoking to the risk of cerebral stroke. Stroke 13: $327-334$ (1982).

11. WH Barker, KS Feldt, JH Feibel: Community surveillance of stroke in persons under 70 years old: contribution of uncantrolled hypertension. Am J Public Health 73: 260-265 (1983).

12. MG Hennerici, A AuTich, W Sandmann, HJ Freud: Incidence of asymptamatic extracranial arterial disease.

Stroke 12: $750-758$ (1981).

13. MU Martin, JP Whisnant, GP Sayre: Occlusive vascular disease in the extracranial cerebral circulation. Arch Neurol 5: 530-538 (1960).

14. JM Kroener, PL Dorn, PM Shoor, IG Wickbom, EF Bermstein: Prognosis of asymptomatic ulcerating carotid lesions. Arch Surg 115: $1387-1392$ (1980).

15. APG Hoeks, RS Reneman, PA Peronneau: A multigate pulsed Doppler system with serial data processing. IEEE Trans Sonics U1trasonics SUJ-28: 242-247 (1981).

16. APG Hoeks: On the development of a multi-gate pulsed Doppler system with serfal data processing. Thesis, University of Limburg, Mastricht, The Netheriands (1982).

17. APG Hoeks, H Peeters, C Ruissen, RS Reneman: A novei frequency estimator for sampled Doppler signals. IEEE Trans Biomed Eng BME-36: 212-220 (1984). 
18. Y Langlois, GD Roederer, A Chan, DJ Phillips, KW Beach, D Martin, PM Chilkos, DE Strandness: Evaluating carotid artery disease. The concordance between pulsed doppler/spectrum analys is and angiography. U1trasound Med Biol 9: 51-63 (1983).

19. PJ Breslau; Ultrasonic Duplex scanning in the evaluation of carotid artery disease.

Thesis, University of Limburg, Maastricht, The Netherlands (1982).

20. KH Mayer, J Stam7er, AR Dyer, DM Berkson: Epideniological findings on the relationship of time of day and time since last meal to 5 clinical variables: serumcholesterol, hematocrit, systolic and diastolic blood pressure, and heart mate.

Prev Med 7: 22-27 (1978).

21. Lo Henderson, AL Saritel1i, E La Garde, PN Herbert, RS Shulman: Minimal within day variation of high density lipoprotein cholesterol and apoprotein $A-1$ levels in normal subjects.

J Lipid Res 21: 953-955 (1980).

22. APG Hoeks, CJ Ruissen, P Hick, RS Reneman: Methods to evaluate the sample volume of pulsed doppler systems.

ultrasound Med Biol 10: 427-434 (1984).

23. MB Katan, J van der Haar, D Kromhout, FJM Schouten: Standardization of serum cholesterol assays by use of serum calibrators and direct addition of Liebermann-Burchard reagent.

Clinical Chem 28: 683-688 (1982).

24. C Kies, LS Lin, HM Fox, M Korslund: Blood serum fatty acid patterns of adolescent boys as influenced by source of dietary fat: Corn oil/butter oil, safflower oil/beef tallow.

J Food Sci 43: 598-602 (1978).

25. Ad Vergroesen, MJ Gottenbos: Introduction. In: The role of fat in human nutrition, Ed. AJ Vergroesen. Acadenic Press New York (1978). 
26. JH Bauer, CS Brooks, I Weinstein et al: Effects of diuretic and propranolol on plasma lipoprotein lipids.

Clin Phamacol Ther 30: 35-43 (1981).

27. RP Ames, P Hill: Antihypertensive therapy and the risk of coronary heart disease.

J Cardiovasc Pharmacol 4: \$ 206-\$212 (1982).

28. G Gemma, G Montanari, G Suppa, A Paralovo, G Franceschini, 0 Mantero, CR Sirtori: Plasma lipid and lipoprotein changes in hypertensive patients treated with propranolol and prazosin.

J Cardiovasc Pharmacol 4: \$233-\$237 (1982).

29. P Leren, I Eide, OP Foss, A Helgeland, I Hjermann, I Holme, Se Kjeldsen $P G$ Lund-Larsen: Antihypertensive drugs and blood lipids: the 0slo study.

J Cardiovasc Pharmacol 4: S222-S224 (1982).

30. DJ Phillips, FM Greene, Y Langlois, GO Roederer, DE Strandness Jr: Flow velocity patterns in the carotid bifurcations of young, presumed normal subjects.

U1trasound Med Bial 9: 39-49 (1983). 
CHAPTER VII

THE DETECTION OF FLOW DISTURBANCES AND RELATIVE ARTERIAL DIAMETER CHANGES DURING THE CARDIAC CYCLE

\subsection{The recording of velocity patterns}

With the multi-gate pulsed Doppler device velocity profiles at discrete time intervals during the cardiac cycle cam be recorded on-line. Under normal conditions the velocity profile in the common carotid artery is symmetric and flat, representing plug flow. In young adults the relative diameter increase during systole is in the order of $10 \%$ (see chapter $\llbracket X$ ). In older, healthy volunteers these values are around 5-6\%.

Indicative of vascular lesions in this artery are (1) asymetry of the velacity profile at sites where the profile is normally symmetric, (2) asymmetric widening of the velocity profile during systole, (3) a narrow velacity profine in combination with high peak velocities during systole, and (4) distortion of the velocity waveform and oscillation on these tracings, locally in the artery or along its cross-section, representing the presence of turbulence.

\subsection{Velocity patterns in the carotid artery bifurcation}

Since disturbances in the flow pattern do occur at relatively slight degrees of artery narrowing, the detection of these disturbances is commonly used to diagnose arterial lesions at an early stage of the disease. In the clinic disturbances in the flow pattern are generally detected and quantified by estimating the degree of broadening of the Doppler audio spectrum. Spectral broadening, however, does not necessarily mean pathology because it may be induced by several other factors (Chapter IV). Besides, it has been shown in model studies $1,2,3$ and in excised human carotid arteries ${ }^{4}$, that the flow patterns in carotid artery bifurcations, devoid of stenosis and atherosclerotic lesions, are complicated. Areas of recirculation and flow separation are observed on the side opposite to the flow 


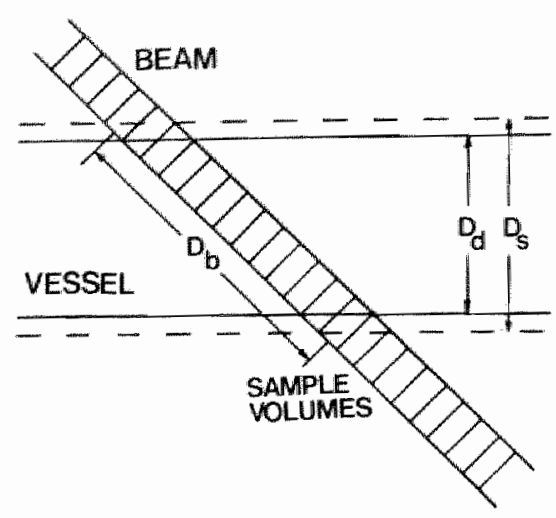

Fig. 7.1: Schematic mepresentation of the ultrasound beam of the multi-gate puliaed Doppler system when investigating a vessel.

$D_{b}=$ estimated vessel diameter based on the presence of high amplitude low frequency signals along the uttrasound beam.

$D_{0}=$ true vesael diameter during systole.

$D_{d}^{s}=$ true vessed diameter during diastote.

divider, while the highest axial blood flow velocities are found on the side of the flow divider. These nomally occuring flow patterns will probably induce spectral changes that are difficult to distinguish from those induced by minimal to moderate atherosclerotic lesions, generally located proximally in the internal carotid artery. Because of the more detalled and direct information about the velocity patterns in arteries, as obtained with multi-gate pulsed Doppler systems, one may assume that these systems are more accurate in diagnosing minimal to moderate atherosclerotic lesions than other Doppler devices. To be able to prove or disprove this assumption detalled information about the flow patterns in normal carotid artery bulbs in man is requilired. 
7.3 The use of relative arterial diameter changes

As mentioned in Chapter II, the multi-gate pulsed Doppler system al lows the transcutaneous recording of the changes in artery diameter during the cardiac cycle, simultaneousiy with the velocity profile in that artery.

Based on the instantaneous envelope of the low frequency Doppler signals, the sample volumes corresponding with the vessel walls can be selected (see Fig. 7.1). Since the angle of observation influences the assessment of the artery diameter (d) and the displacement of the vessel walls $(\Delta d)$ along the ultrasound beam to the same extent, the relative arterial diameter changes during the cardiac cycle $\left(=\Delta d / d^{\star} 100 \%\right)$ are independent of the angle of observation.

In-vitro studies ${ }^{5}$ showed that under all experimental conditions the intra-observer variability in detecting these relative arterial diameter changes remains below $0.5 \%$ (absolute bias). For an angle of observation of $60^{\circ}$ the absolute bias in the estimate of the peak value of the change in arterial diameter during the heart cycle is even less, about $0.25 \%$, irrespective of the diameter and its true relative change. The inter-observer variability is somewhat higher, but remains below $0.5 \%$ except for large diameter tubes $(>9.5 \mathrm{~mm})$.

For the usual conditions in in-vivo examinations these results are favorable. The detection procedure only provides reliable results if the vessel walls remain in the selected sample volumes. Under normal conditions, however, the tracking range of the system is adequate to accomodate carotid artery evaluation. The tracking range can still be expanded by elongating the duration of emission, causing an increase in the sample size. This, however, is at the expense of the resolution of the system. The non-invasive assessment of vessel wall properties in humans becomes feastble with these features and, hence, flow patterns and information about arterial wall properties can be recorded simultaneously in patients with carotid artery disease.

The flow patterns and relative arteriall diameter changes in the normal carotid artery bulb in man are described in Chapter VIII. The age related changes in carotid artery wall properties in normotensive males, as measured non-invasively, are presented in Chapter IX. The detection of minimal to moderate atherosclerotic lesions on the basis of disturbances in the 
flow pattern and relative arterial diameter changes are given in Chapter $x$, while the carotid artery wall properties in borderline hypertensive subjects are described in Chapter XI. 


\section{REFERENCES}

1. BK Bharadvaj, RF Mabon, DP Giddens: Steady flow in a model of the human carotid bifurcation. Part I-Flow visualization.

J Bionech 15: $349-362$ (1982).

2. BK Bharadvaj, RF Mabon, DP Giddens: Steady flow in a model of the humam carotid bifurcation. Part II-Laser Doppler anemometer measurenents. J Biomech 15: 363-378 (1982).

3. DN Ku, DP Giddens: Pulsatile flow in a model carotid bifurcation. Arteriosclerosis 3: $31-39$ (1983).

4. Motomiya, T Karino: Flow patterns in the human carotid artery bifurcation.

Stroke 15: $50-56(1984)$.

5. APG Hoeks, Cu Ruissen, P Hick, RS Reneman: Transcutaneous detection of relative changes in artery diameter.

UTtrasound Med Bioll 11: 51-59 (1985). 
CHAPTER VIII

FLOW NELOCITY PATTERNS IN AND DISTENSIBILITY OF THE CAROTID ARTERY BULB IN SUBJECTS OF VARIOUS AGES WITHOUT DETECTABLE CAROTID ARTERY DISEASE

\subsection{Introduction}

In a recent study relating data derived from autopsy specimens to flow patterns and shear stresses as assessed in model bifurcations 1,2, Zarins and colleagues ${ }^{3}$ showed that in the carotid artery bulb maximal intimal thickening and atherosclerotic plaque formation occurs in regions of flow separation and reduced shear stress. These regions were lacated on the side oppposite to the flow divider. Regions with predominantly axial and unidirectional flow velocities, and high shear stresses, located on the side of the flow divider, are relatively devoid of these wall changes. A zone of recirculation in the carotid artery bulb opposite to the flow divider was also observed in studies performed on excised human carotid artery bifurcations 4 . In these investigations flow patterns were studied under conditions of steady flow, while undistensible materials and Newtonian fluids were used, conditions quite different from the situation in vivo. Although preliminary model studies indicate that the flow pattern in the carotid artery bulb is rather similar under steady and pulsatile flow conditions 5,6 , certain differences have to be appreciated ${ }^{6}$.

In the present study we investigated the flow velocity patterns in the carotid artery bulb of volunteers of varying age, using a high resolution multi-gate pulsed Doppler system 7,8,9. With this system velocity profiles at discrete time intervals during the cardiac cycle and instantaneous velocity waveforms at various sites along the ultrasound beam can be recorded on-line. In addition, the system provides on-line information about the relative diameter changes of arterles duming the cardiac cycle 10 giving insight into the distensibility of these vessels. See also Chapter II. 


\section{2 materials and methods}

The study was performed on 20 male, normotensive (cuff blood pressure in the supine position $<140 / 90 \mathrm{~mm} H \mathrm{Hg}$ ) volunteers with a negative history of cardiovascular diseases. They were picked aselectively from a group of 80 subjects randomly selected from population registers for other purposes. All invited subjects participated in the study. In none of them could cervical carotid artery disease be detected, using the ultrasound Doppler criteria as previousily described (Chapter $V$ ). Two groups of volunteers were investigated. Growp I consisted of 11 subjects (aged 20-30 years; $\bar{x}=24.6$ years; and Group II of 9 subjects (aged $50-60$ years; $\bar{x}=53.7$ years). From all volunteers informed consent was abtained before they entered the study.

The principle and features of the high resolution multi-gate pulsed Doppler system have been described in detail before (Chapter II). For adequate interpretation of the data and accurate measurements one has to be informed of the site of velocity assessment in relation to the position of the flow divider, the angle between the axes of the common and internal carotid arteries and the angle of interrogation. Hence, in the present study the multi-gate pulsed Doppler systen was connected to an ATL Mark $V$ B-mode imager with a short focus scanhead. In this configuration the multigate device, which functionally replaces the single gate Doppler device of the ATL system, has the following characteristics: pulse repetition frequency $16 \mathrm{kHz}$, emission frequency $5.2 \mathrm{MHz}$, emission duration $1.2 \mu \mathrm{s}$, sample interval $0.6 \mathrm{~mm}$, number of gates 64 and lower cut-off frequency $250 \mathrm{~Hz}$. The sample wolume of the multi-gate system in this combination as measured in vitro ${ }^{11}$ was $1.75 \mathrm{~mm}^{3}$ at a range of $15 \mathrm{~mm}$ and $1.35 \mathrm{~mm}^{3}$ at a range of $20 \mathrm{mmll}$.

The investigations were performed with the volunteers in the supine position with the head tilted somewhat to the contralateral side. Only the left carotid artery bifurcation was examined because of a llonger entrance length (no anonymous artery) as compared to the right side. The velocity profiles at discrete time intervals during the cardiac cycle, the instantaneous velocity tracings along the ultrasound beam and the relative diameter changes of the artery during the cardiac cycle ( $\Delta \mathrm{d} / \mathrm{d}$ * $100 \%$ ) were recorded on-line at the following sites. In the common carotid artery (about 3 cm proximal to the tip of the flow divider), in the carotid artery 

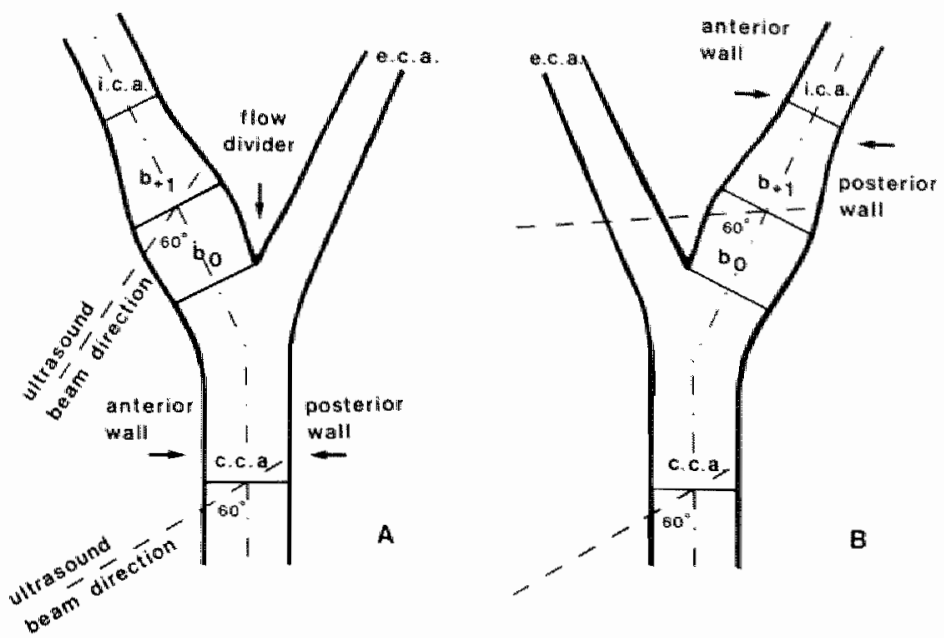

Fig. 8.1: Schematic representation of the sites of recording. The situation for measurements in the plane of the bifurcation and interrogation at an angle of $60^{\circ}$ with the vesset axis is depteted, when the intemal carotid artery (i.c.a.) is anterior (= superficial, A) or postemion (B) to the extemal carotid artery (e.c.a.). In this direction mainly axial flow velocity components are recorded. e.c.a. = conmon carotid artery; $b=$ the butb at the level of the tip of the flow divider; $b_{+1}=$ the butb one em more distalty.

bulb at the level of the tip of the flow divider $\left(b_{0}\right)$ and ane an more distally $\left(b_{+1}\right)$ as well as in the internal carotid artery $13-4 \mathrm{~cm}$ distal to the tip of the flow divider) (Figure 8.1). For recording of the velocity information the vessels were interrogated in the plane of the carotid artery bifurcation at angles of $60^{\circ}$ (Figure 8.1) and $90^{\circ}$ with the vessel axis (Figure 8.2), and perpendicular to the plane of the bifurcation (Figure 8.2). The latter is an approximation because the system used does not allow visual control in this position. Interrogation at an angle of $60^{\circ}$ mainly provides information about the axial flow component, but radial and tangential components, if any, are recorded as wel1. Perpendicular interrogations principally measure the radial component of flow. In our system positive velocities have to be interpreted as flow away from the probe. The relative diameter changes were recorded in the plane of the bifurcation at 


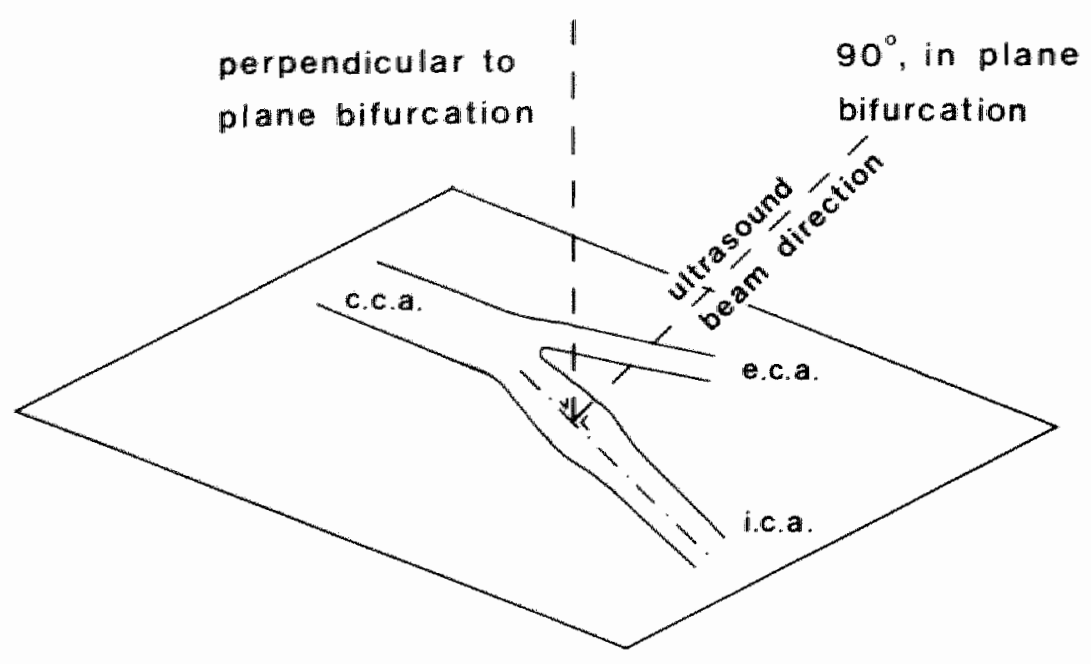

Fig. 8.2: Schematic representation of the interrogations in the plane of the bifurcation at an angle of 900 with the vesset arits and perpendicular to this plane. Ir these dimeatione mainly radial flow velocity componente are recorded. Abbreviations as in Fig. 8.1 .

an angle of $60^{\circ}$. This direction was used because the assessment of vessel wall displacement is based upon the detection of low frequency Doppler signals, originating from the sample volumes coinciding with the anterior and posterior walls 10 . To ensure that the initial relative change at the beginning of the cardiac cycle is constant, it is reset to zero by a trigger derived from the $R$-wave of a standard lead of the ECG. This trigger was also used to mark the start of the cardiac cycle when velocities were recorded. The absolute diameters, which were also measured in the plane of the blfurcation at an angle of $60^{\circ}$, were assessed from the A-mode of vessel wall displacement as detemined with the multi-gate system. This A-mode is different from the $A$-mode as known in echo systems because of the rejection of stationary signals (cut-off frequency $5 \mathrm{~Hz}$ ). The A-mode is displayed continuously on a CRT. The relative diameter changes ( $\Delta d / d * 100 \%$ ) are independent of the angle of interrogation and can be determined with an absolute accuracy of $0.5 \% 10$, comparing favorably to the relative peak excursions observed (see section 8.3). The absolute artery diameters as obtained are dependent on the angle of interrogation and hence were multiplied by $0.87\left(=\sin 60^{\circ}\right)$. 
The velocity profiles, the instantaneous velocity tracings and the relative diameter changes could be observed on-line on a CRT. The trigger derived from the R-wave of the ECG was displayed as well. The vartables as recorded during several consecutive cardiac cycles (usually ten) only showed minimal variations on a beat to beat basis (Figure 8.3). From this series three cycles were selected, plotted on a $x / y$ recorder (Philips) and used for further anaiysis. This procedure was followed for each sampling position and each sampling angle. The reproducibility of the variables as measured at a giwen position and under a certain angle is usually good. only a limited number of velocity profiles during one cardiac cycle, gene-
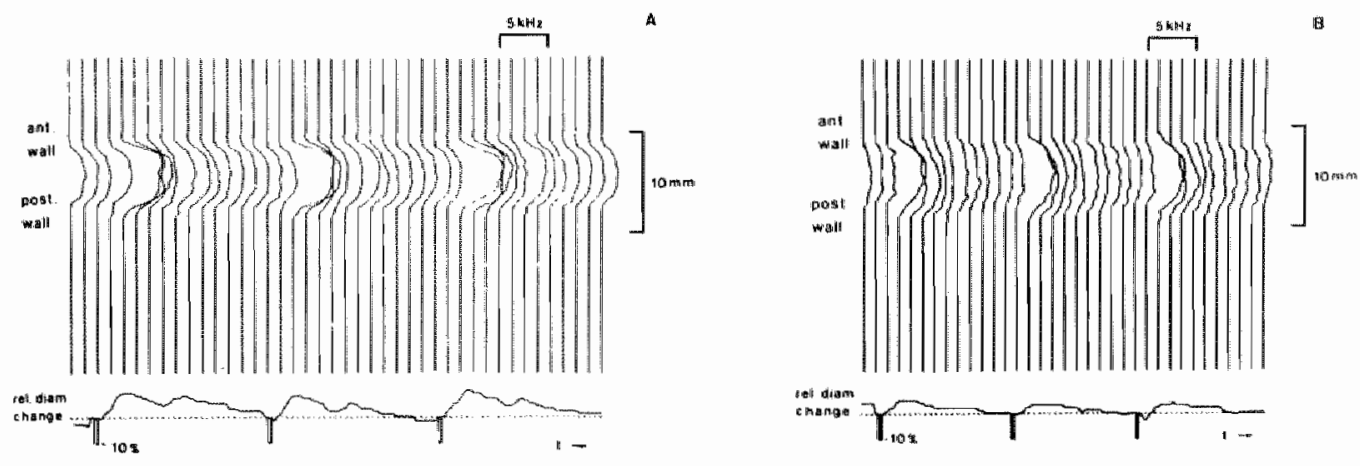

tot ditam
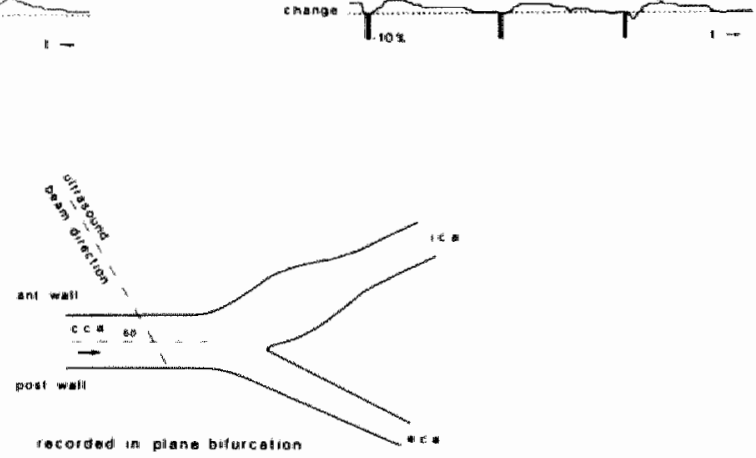

Fig. 8.3: The axial velocity profiles at discrete time intervals during the cardiac cycle and the relative diameter changes during this cycte as bimiltaneously recorded in the comon carotid artery of a younger (A) and an older (B) volunteer. Three consecutive ardiac aycles are depicted. The negative deflection represents the trigger demived from the R-wave of the ECG. Wote the symmetric and flat velocity profiles which show orly sitint variations on a beat to beat basis. Whe arrow in the schematic drawing indicates the direction of flow. Abbreviations as in Fig. 8.1. 
rally 10-20 out of 256, is presented for the sake of clarity. The velocity profiles at discrete time intervals during the cardiac cycle and the relative diameter changes during this cycle as simultaneously recorded in the comon carotid artery are shown in Figure 8.3. The quadrature audio signal of the sound gate and the pulse code of the $R$ wave of the ECG were stored on a tape recorder (Racall: $0-10 \mathrm{kHz}-3 \mathrm{~dB}$ ) for off-line spectrum analysis, using a Medasonics spectrum amalyser.

Only instantaneous velocity waveforms that were consistent in several gates and in all cardiac cycles recorded, were considered as real velocity patterns. Differences in absolute diameters, rellative diameter changes during the cardiac cycle and pulse pressures between the two groups were evaluated for statistical significance by applying Student's pooled t test. Differences in the amplitude of relative diameter changes and absolute diameters between common caratid artery and the carotid artery bulb within each group were evaluated for statistical significance, using a paired Student"s t test.

\subsection{Results}

The pulse pressure as measured in the brachial artery with the cuff method was $45.0 \pm 10.5 \mathrm{~mm} \mathrm{Hg}$ in Group I and $42.2 \pm 8.7 \mathrm{~mm} \mathrm{Hg}$ in Group II, a non-significant difference.

In the younger volunteers (Group I) the internal carotid artery was situated anterior (= superficial) to the external carotid artery in 5 cases and posterior to this artery in the remaining 6 cases. The angle between the axis of the internal carotid artery and the extended axis of the common carotid artery was $10.8 \pm 5.2^{\circ}(\bar{x} \pm s d)$. In the older volunteers (Group II) the internal carotid artery was anterior to the external carotid artery in 7 cases and posterior to this artery in only 2 cases. In this group the angle between the axis of the internal carotid artery and the extended axis of the common carotid artery was $12.6 \pm 3.5^{\circ}(\bar{x} \pm s d)$.

The absolute diameters and the relative diameter changes during the cardiac cycle in the groups I and II are presented in Table 8.I. At all levels the average artery diameter tended to be larger in Group II than in Group I, but the widening at the level of the bulb, relative to the more 
Table 8.I: Absolute diameters (d) and relative diameter changes during the cardiac cycle $(\Delta d / d * 100 \%)$ in Group I $(20-30$ years; $n=11)$ and Group II $(50-60$ years; $n=9)$. Mean values and standard deviations are presented.

C.C.A. $-b_{0}-b_{+1} b_{\max }$ I.C.A.

Group I

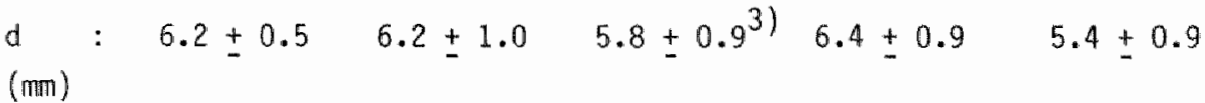

$\Delta d / d: 9.6 \pm 1.3^{1)} 11.0 \pm 2.1^{1)} 10.4 \pm 2.3^{1)} 11.7 \pm 1.8^{1) 4} 9.0 \pm 2.9^{21}$ $(\%)$

Group II

d : $\quad 6.4 \pm 1.0 \quad 6.9 \pm 1.0 \quad 7.1 \pm 0.8 \quad 7.1 \pm 1.1 \quad 6.2 \pm 0.6$ (minn)

$\Delta \mathrm{d} / \mathrm{d}: \quad 5.6 \pm 0.9 \quad 3.9 \pm 1.9^{5)} \quad 4.0 \pm 2.0 \quad 4.4 \pm 1.6^{6)} \quad 4.9 \pm 1.0$ $(\%)$

C.C.A. = common carotid artery; $b_{0}$ and $b_{+1}=$ proxinally and distally in the carotid artery bulb, respectively (see Figure 1); $b_{\max }=\max i m a l$ value in the bulb at either $b_{0}$ or $b_{+1} ; \mathbb{I} . C . A_{\text {. }}=$ internal carotid artery.

1), 2) and 3) significantly different from group (II); 1) $p<0.0001$;

2) $p<0.005$; 3) $p=0.01$.

4), 5) and 6) significantly different from the C.C.A. in this group; 4) $p(0.001 ; 5) p(0.01 ; 6) p<0.05$

distal part of the internal carotid artery, was similar in both groups; 14.8\% in Group I and $14.5 \%$ in Group II. At all levels the relative diameter increase during the cardiac cycle was significantiy larger in Group I than in Group II. In Group II the diminished relative magnitude of arterial wall displacenent during the cardiac cycle was relatively most pronounced in the 
Table 8.11: Flow patterns as recorded in the carotid artery bulb in Group I $(20-30$ years; $n=11)$ and Group $I I(50-60$ years: $n=9)$

- Highest velocities near

flow divider

$10 / 11 \quad(90.9 \%) \quad 6 / 9(66.7 \%)$

- Signs of flow separation and recirculation opposite to flow divider
- axial or radial
$11 / 11(100.0 \%)$
$5 / 9(55.6 \%)$
- axial and radial
$8 / 11 \quad(72.7 \%)$
$2 / 9(22.2 \%)$

carotid artery bulb. In Group I the relative diameter increase during the cardiac cycle was more pronounced in the bulb than in the common carotid artery, while the opposite was observed in Group II.

In the common carotid artery the velocity profile as recorded in the axial direction was generally symmetric and no retrograde flow was observed in this direction at any time during the cardiac cycle, in either Group I or Group II (Figure 8.3). The axial velocity profile as recorded in the carotid artery bulb was generally skewed with the highest velocities on the side of the flow divider (Figure 8.4; Table 8.II). This skewness was most pronounced early in systole. Skewness of the axial velocity profile was associated with retrograde flow on the side of the bulb opposite to the flow divider (Figure 8.4 ) in $81.8 \%$ of the cases in Group 1 , but only in $33.3 \%$ of the cases in Group II. Retrograde flow started during the deceleration phase and changed into forward flow again later during the cardiac cycle (Figure 8.5). The triphasic pattern of the velocity waveform is indicative of flow separation and recirculation. Skewed velocity profiles as well as flow separation and recirculation could be observed proximally $\left(b_{0}\right)$ or distally in the bulb $\left(b_{+1}\right)$, or at both levels. In this small population the presence or absence of skewness of the axial velocity profile was not 

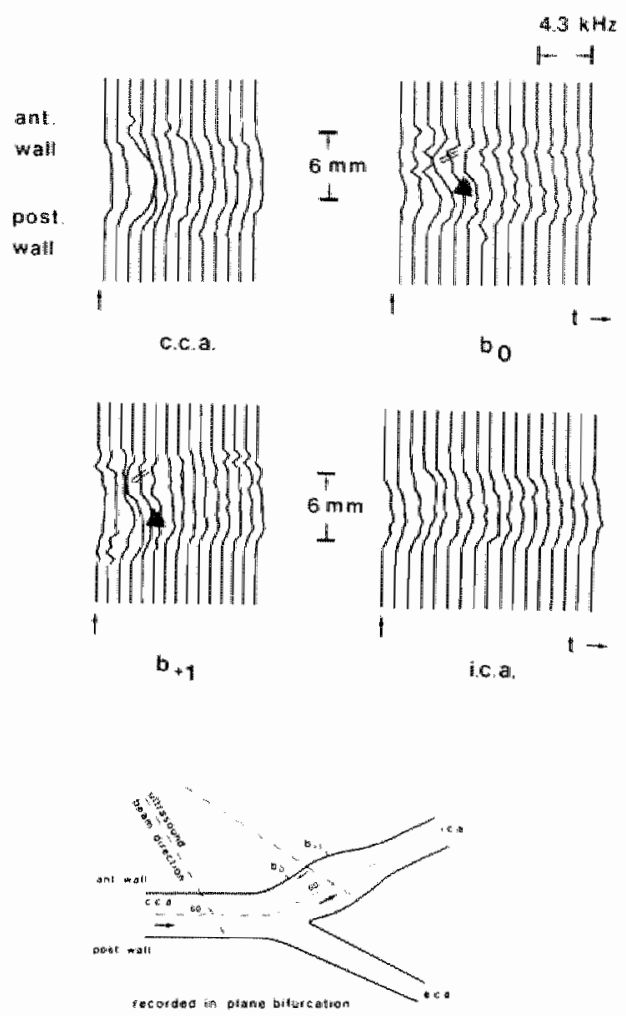

Fig. 8.4: The axiat veloctty profiles at discrete time intervals during the cardiac cycle as recorded in the common (c.c.a.) and intemal carotid (i.c.a.) arteries and proximally ( $b$ ) and more distally $(b, j)$ in the bulb of a young subject. The arrow represents the trigger derived from the R-wave of the ECG. Note the skewed velocity profile (arrow head) taurars the flow divider and retrograde flow (open arrow) on the oppobite side in systole at both levels in the bulb. Retrograde flow is not observed in the common and intemal carotid arteries. The arrows in the schematical drawing indicate the direction of flow. Abbreviations as in Fig. 8.1 .

clearly related to the angle between the axes of the common and internal carotid arteries. The axial velocities in the carotid artery bulb as measured by the mean frequency processor in the Doppler system, were low (peak 

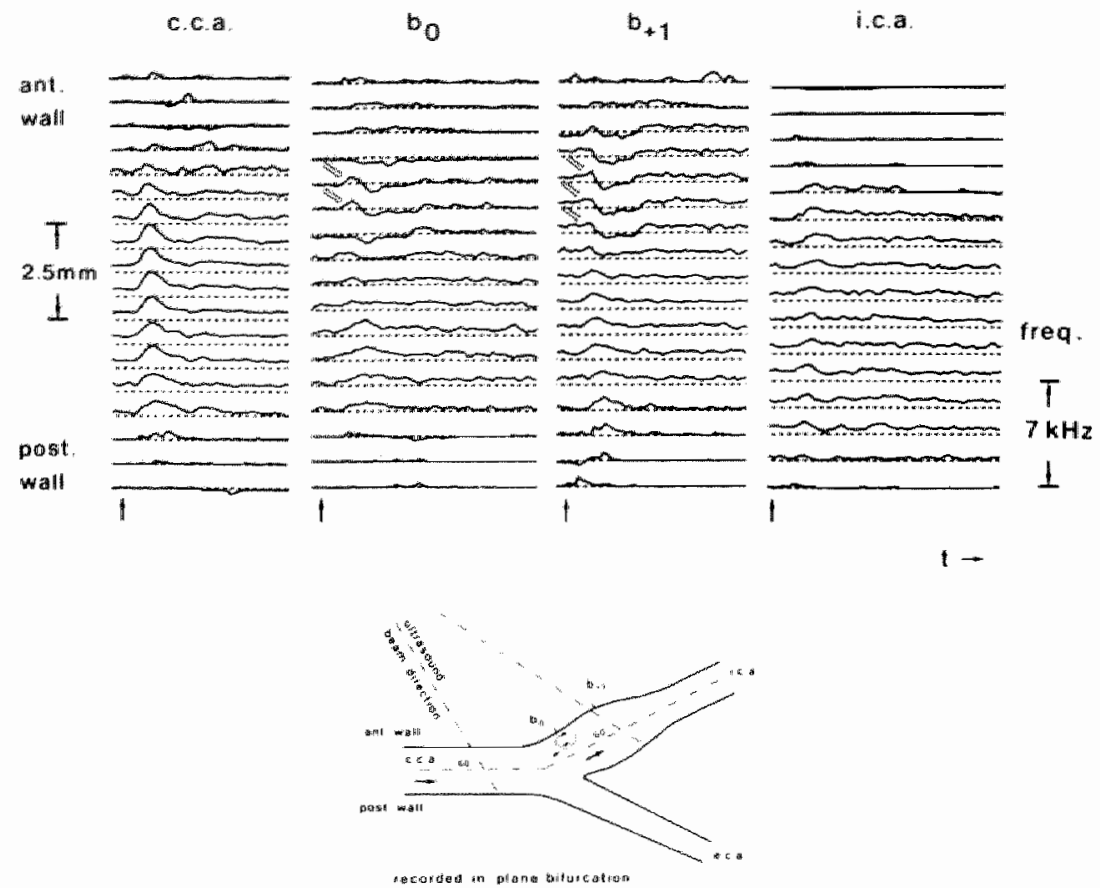

Fig. 8.5: The instantaneous velocities as recorded at vamious sites along the ultrasound beam at the same sites and in the same subject as in Fig. 8.4. The arrow represents the trigger derived from the $R$-wave of the ECG. Note the triphasic patterm of the velocity waveform in the butb on the side opposite to the flow divider (open arrow) with forward flow early in systole followed by retrograde flow, starting during the deceleration phase, and forward flow again later during the cardiac cycle. This patem is indicative of flow separation and reciroutation as depicted in the achematical drawing. In this drating recirculation is only shown at the tevel of $b$. The arrow in the schematical drawing indicates the main $d$ irection of flow. Abbreviations as in Fig. 8.1.

average velocities around $\mathrm{l} \mathrm{kHz}$ ). No differences between the two age groups could be detected. In all but one case in Group I the axial velocity profile was symmetric again in the internal carotid artery. At this site retrograde flow was never observed.

In the common and internal carotid arteries the instantaneous velocity as recorded along the ultrasound beam at an angle of $90^{\circ}$ in the $p l$ ane of 
the bifurcation, representing the radial flow component, was non-pulsatile in nearly all cases. In the common carotid artery the average velocity in this direction was often just above or below zero, while inconsistenties between consecutive gates could be observed. In the internal carotid artery the average radial velocities were generally higher and clearly above zero. Similar patterns were observed when the instantaneous velocity was recorded perpendicular to the plane of the bifurcation. In this direction, however, the radial component of flow was occasionally more pulsatile. In the carotid artery bulb a variety of velocity patterns was observed when recording in the radial direction. The instantaneous velocity could be pulsatile or nom-pulsatile. Under pulsatile conditions the direction of flow was either from the probe or showed a triphasic pattern with flow away from the probe early in systole followed by flow towards the probe, starting during the deceleration phase, and flow away from the probe again later during the cardiac cycle (Figure 8.6). The latter pattern was only found on the side opposite to the flow divider. This indicates that at this site blood is also recirculating in the radial direction. In the carotid artery bulb flow separation and recirculation on the side opposite to the flow divider was more common and more pronounced in the younger than in the older volunteers (Table 8.11). The flow patterms most commonly observed in the carotid artery bifurcation are depicted schenatically in Figure 8.7 .

\subsection{Discussion}

A]though three dimensional phenomena are described on the basis of two dimensional measurements the data as abtained in the present study provide insight into the complicated flow pattern in the carotid artery bulb in man. In the bulb of young, asymptomatic wolunteers without evidence of cervical carotid artery lesions, the axial velocity profile is generally skewed with the highest velocities near the flow divider. This skewness is most pronounced early in systole. Flow separation generally occurs on the side opposite to the flow divider as indicated by the occurence of retrograde flow in the axial direction at this site in the bulb. The periad of retrograde flow is usually followed by forward flow later during the cardiac cycle. These observations in combination with the commutating fiow in 
bo

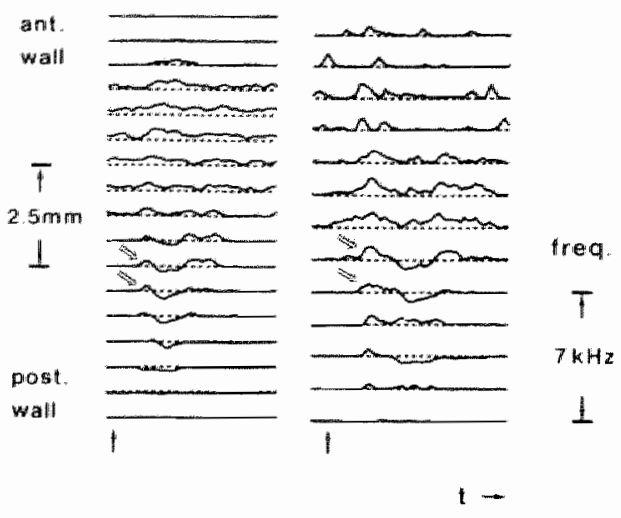

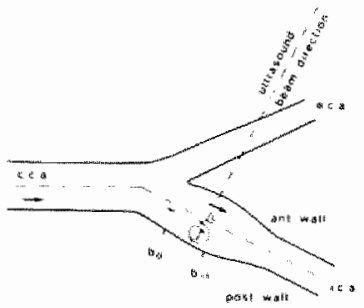

tocoseded an ohand butuecation

Fig. 8.6: The radial instantaneous velocities as recorded at various sites along the ultrasound beam in the plane of the bifurcation, proximalty $\left(b_{0}\right)$ and distally $\left(b, b^{\prime}\right)$ in the bulb. The arrow represents the trigger derived from the $R$-wave of the ECG. Note the triphasic pattern of the vetoctty waveform on the side opposite to the flow divider (open arrow) with flow away from the probe earty in systole followed by flow towards the probe, starting during the deceleration phase, and flow away from the probe again later during the cardiac cycle. This pattern is indicative of flow separation and recirculation as depicted in the schematical drawing. In this drawing reairoulation is only shown at the level of $b+1$. The arrow in the schematical drawing indicates the main direction of flow. Abbreviatione as in Fïg. 8.1. 


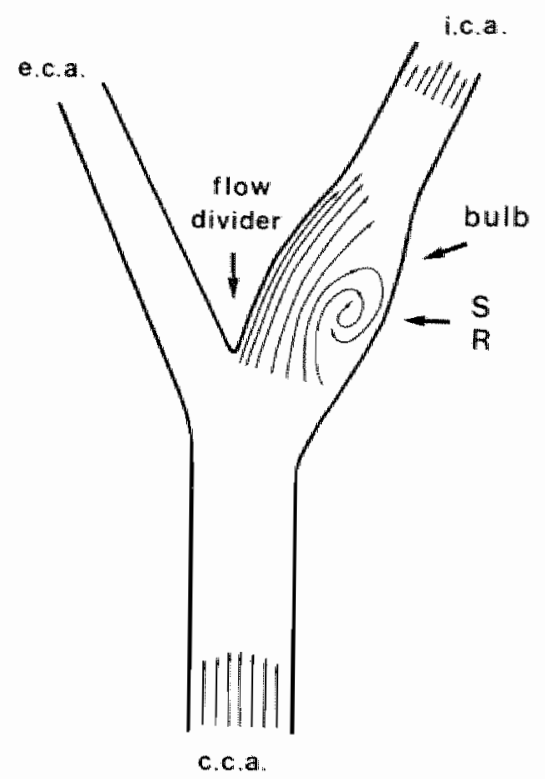

Fig. 8.7: Schematic representation of the axial velooity pattems most commonly obm served in the carotid artery bifurcation. The vezocity profite is flat and symetric in the common carotid artery (c.c.a.) and flat, but occasionally sigighty aeymmetric in the intemal carotid artery (i.c.a.). In the carotid artery butb the velocities are highest near the flow divider, while flow separation (S) and recirculation (R) are abserved on the side apposite to this divider. Recirculation is not seen early in systole. Fllow separation and recirculation are less common and lese pronoumced in the older volun teens. Abbreviations as im Erg. 8.1.

the radial direction are indicative of areas of recirculation on the side opposite to the fiow divider. The finding that blood recirculates in both the axial and radial direction suggests the presence of helical flow. The observation that in both the axial and radial direction retrograde flow does not start before the deceleration phase suggests that flow separation is not continuously present throughout the cardiac cycle. 
Since the velocity differences abserved in the radial direction are very small, the question can be raised whether these differences are real or a consequence of changes in the angle of incidence between the ultrasound beam and the direction of blood flow. This question is pertinent because deviation of $5^{\circ}$ from the normal induces an axial Doppler shift in the radial recording of $261 \mathrm{~Hz}$ in case of a maximum frequency of $3 \mathrm{kHz}$, a realistic figure considering the peak average frequency of $1 \mathrm{kHz}$ found in the bulb (see section 8.3) Moreover, slight deviations from $90^{\circ}$ may easily occur when recording perpendicular to the plane of the bifurcation because the Doppler system used does not provide visual control in this position. Despite these considerations the alternating velocity direction as observed in the radial recording opposite to the flow divider, is likely to be real because it is consistently present in only a limited number of gates. When resulting from differences in angulation, the axially induced velocity changes are expected to occur in most of the gates and would be more pronounced near the flow divider where the axial velocities are highest. Besides, similar velocity changes are observed at the same site in the vessel when recordings are made at an angle of $90^{\circ}$ in the plane of the bifurcation, a sampling position which can be accurately controlled on the CRT.

The flow patterns as found in the carotid artery bulb of young volunteers are similar to those observed in a model under pulsatile fiow conditions, but using undistensible material and Newtonian fluids ${ }^{6}$. In this model a continuously changing region of separation was abserved opposite to the flow divider with vortices varying in size and energy level. High axial velocities near the flow divider and areas of flow separation and reversal on the side of the bulb opposite to this divider were also observed under conditions of steady flow in rigid models 1,2 and in witro situdies on undistensible vessels 4 . In this situation, however, the region of separation is fixed and a well-defined stable secondary flaw structure can be observed.

In the carotid artery bulb of the older volunteers the axial velocities are generally also higher near the flow divider, but flow separation and recirculation on the side opposite to this divider are less common and less pronounced than in the younger subjects. This difference between younger and older volunteers cannot readily be explained on the basis of a more 
favorable diameter transition from common to internal carotid artery in the younger volunteers. In this group the transition was more gradual than in the older subjects in whom the carotid artery bulb was slightly wider than the common carotid artery, a situation favoring recirculation. It cannot be excluded that in the older volunteers the carotid artery bulb is smaller than measured due to intimal thickening on the side opposite to the flow divider ${ }^{3}$, creating a situation less favorable for recirculation. The diameter of the cervical carotid arteries as found in the present study, however, are in good agreement with those measured in postmortem specimens 3,4 and only slightly smaller than the diameters obtained from angiograms ${ }^{1}$ and ultrasound pulsed echo techniques 12 , considering the accuracy of the various methods. The tendency to larger diameters at alder age is in keeping with the findings of Fujishiro and Yoshimura 13.

The skewness of the axial velocity profile in the carotid artery bulb can be considered as a curvature effect because the internal carotid artery branches from the common carotid artery at an angle. The average axial velocities as measured in the carotid artery butb of both young and old subjects, are relatively low, which is in agreement with previous results obtained with CW Doppler systems 14.

A striking difference between the older and younger volunteers is the reduction in artery wall displacenent during systole, especially at the level of the carotid artery bulb, in the older age group. In both age groups the relative increase in diameter of the common carotid artery during systole is in good agreement with the value previously published from our laboratory 15 . The average relative dianeter increase in the younger volunteers as found in these studies is smaller (9.6\% vs 14.2\%) than that reported by Arndt and his coll leagues 12 . This difference may be explained by the amplitude dependency of the pulsed echo displacenent technique as used by these investigators. Amplitude dependency can easily lead to overestimation of the relative diameter changes. The displacement method employed in the present study is amplitude independent over a wide range of amplitudes 10 . Since the pulse pressure as measured in the brachial artery is not significantly different in both age groups, ane may assume that the reduction in artery wall displacement during systole at older age reflects a reduced arterial distensibility. It is unlikely that diminished distensibility as such can be held responsible for the less 
pronounced and less commonly observed flow separation and recirculation on the side of the bulb opposite to the flow divider in the older age group. These phenomena, after all, have been clearly demonstrated in models and in vitro studies, using rigid materials with the same properties along the bifurcation (sèe above). When assuming a constant pulse pressure along the common and internal carotid arteries, differences in increase in relative diameter during systole may be interpreted as differences in distensibility. Hence, in the younger volunteers the buib can be considered to be more distensible than the common carotid artery. The opposite is observed in the older subjects. These differences in distensibility at the transition from cominon to internal carotid artery may explain the differences in flow separation and recirculation between both age groups. Further investigations are required to rate these findings at their true value.

The difference in distensibility between the common carotid artery and the carotid artery bulb in the younger subjects can probably not be explained on the basis of structural differences because the wall of this artery and the wall of the major part of the bulb have a mainly elastic structure ${ }^{16}$. The wall of the bulb, however, is thinner ${ }^{16}$ so that larger wall tensions are developed at comparable pressures and diameters. The more pronounced distensibility of the carotid artery bulb likely facilitates the functioning of the baroreceptors, which are mainly located in the proximal part of the bulb ${ }^{16}$. In this light the reduced distensibility of the bulb at older age might explain the decreased baroreceptor sensitivity at this age 17 .

The rather flat axial velocity profiles in the common and internal carotid arteries in both age groups confirm earlier reports from Keller and co-investigators 18 and our own laboratory 19,20 . The fast deceleration of blood flow in the middle third of the common carotid artery after the systolic peak as observed by the former investigators, is not seen in the axial velocity profiles as recorded in the present study. This can be explained by a difference in the site of measurenent because we recorded our velocity profiles about $3 \mathrm{~cm}$ proximal to the tip of the flow divider and the fast deceleration could only be observed over a distance of approximately $2 \mathrm{~cm}$ from this divider ${ }^{18}$. The continuous flow in the internal carotid artery as recorded at an angle of 90 degrees in the plane of the bifurcation and perpendicular to this plane, indicates the presence of a 
continuous radial flow component in this artery, especially since the behavior of velocities is coherent in adjacent gates. This radial flow component probably is a curvature effect. The less consistent and less pronounced contunuous flow component in the radial direction in the cammon caratid artery is likely to be an artifact. These low velocities, after all, cannot be measured unambiguously at the cut-off frequency of $250 \mathrm{~Hz}$ as used in our instrument. The slight pulsatility occasionally seen in the radial flow component as recorded perpendicular to the plane of the bifurcation, may be explained by a deviation of the angle of interrogation from 90 degrees, which results in the recording of axial flow velocity components as wel1. The existence of areas of recirculation in the conmon and internal carotid arteries is very unlikely because neither retrograde flow in the axial direction nor commutating flow in the radial direction could be observed in these vessels.

It has been shown that in the carotid artery bulb atherosclerotic lesions are most commonly found opposite to the side of the flow divider ${ }^{3}$. Although from the present study no conclusions can be drawn about the relation between flow velocity patterns and the formation of atheroscleratic lesions, the findings favor the idea that the formation of these lesions is associated with low rather than high wall shear stress $3,6,21,22,23$ and with areas of flow separation and deviation from axially orientated, unidirectional flow 3,6 .

Detection of disturbances in the flow pattern have been widely used to diagnose carotid artery lesions using either CW 24,25 or pulsed Doppler systems $26,27,28$ combined with audio spectrum amalysis. The normally occurring, complicated flow patterns in the carotid artery buib, however. induce spectral changes (Figure 8.8) which are probably difficult to distinguish from those induced by atherosclerotic lesions. The Doppler spectra as depicted in this figure are similar to those recentiy reported by Phillips and his colleagues 29 in a presumed normal, young valunteer. Since in asymptomatic volunteers the velocity pattern is undisturbed in the internal carotid artery $3-4 \mathrm{~cm}$ distal to the flow divider, one may argue that disturbances in the flow patterm as induced by vascular lestons in the carotid artery bulb, can be diagnosed at the former site. One should rea1 ize, however, that so far downstream to a lesion flow disturbances, even those 3 nduced by lesions associated with more than $60 \%$ diameter reduction, 

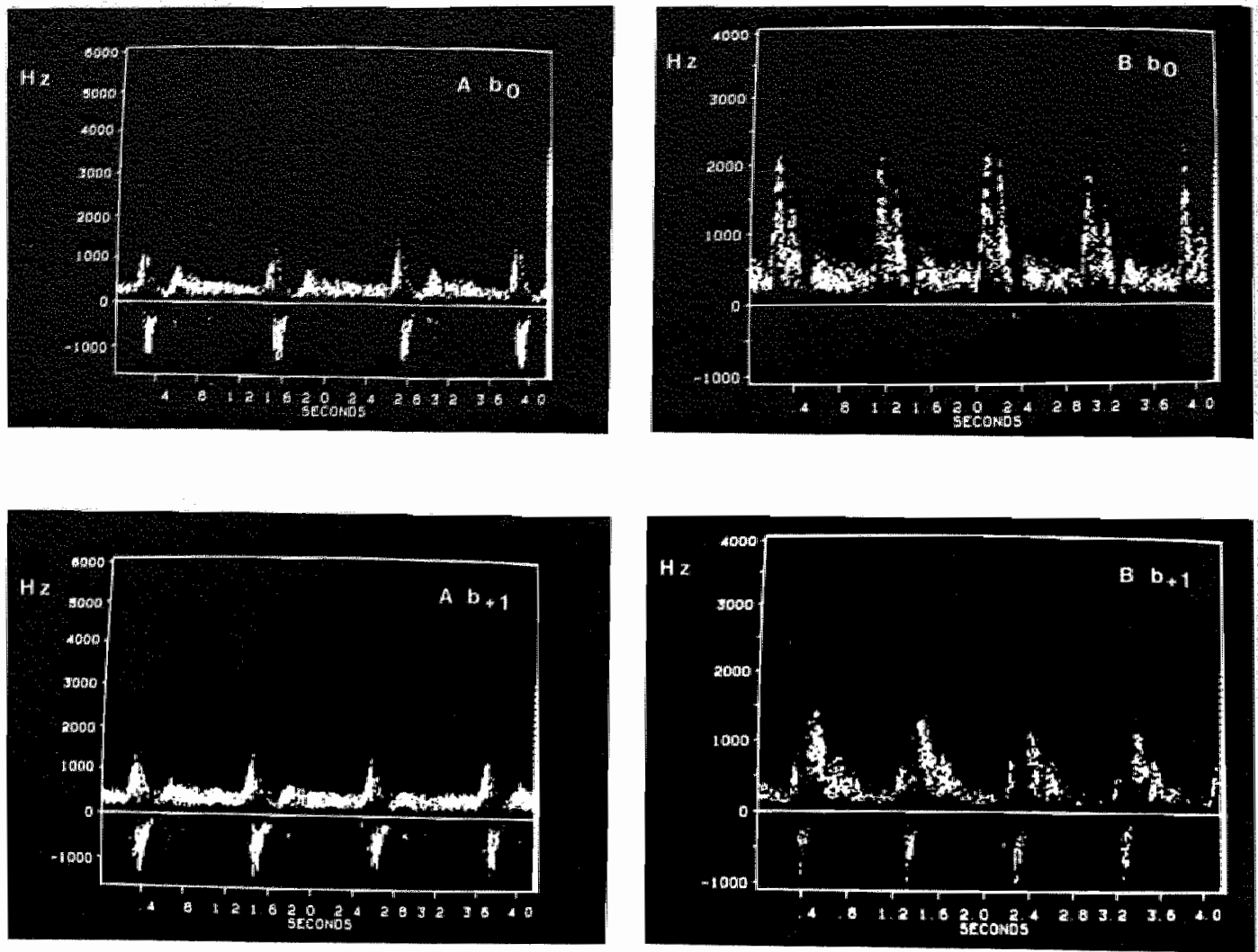

Fig. 8.8: The Doppler audio spectra as recorded proximally $(b)$ and more distat$l y\left(b_{+1}\right)$ in the camotid artery butb of a younger $(A)$ and an older $(B)$ volunteer. In these spectra frequemey is depicted as an instantaneous function of time, white the intensity of the pattem represents the amplitude of the frequencies, indicating the number of med biood celts moving at a given velocity.

have disappeared ${ }^{14}$. An additional problen is that the sample volume cannot be made sufficlently small to distinguish mormal from slightly diseased arterles on the basis of spectral broadening when measuring at this site in the internal carotid artery (Chapter IV).

In conclusion the findings in the present study demonstrate that in the carotid artery bulb of volunteers without detectable lesions of the cervical carotid arteries the axial velocities are highest on the side of the flow divider, while regions of flow separation and recirculation are ob- 
served on the side opposite to this divider. Flow separation and recirculation are less pronounced and less common at older age. Flow separation is not continuously present throughout the cardiac cycle. The findings in younger subjects corroborate previous observations in model and in vitro studies. The distensibility of the cervical caratid arteries is significantly diminished at older age, especially at the level of the bulb. It is possible that the diminished flow separation and recirculation in the older volunteers result from alterations in distensibility at the transition from common to internal carotid artery with increasing age.

Previously published as:

Flow velocity patterns in and distensibility of the carotid artery buib in subjects of various ages. Robert S. Reneman, Tiny van Merode, Paul Hick, Arnold P.G. Hoeks. Circulation 71: 500-509 (1985). 


\section{REFERENCES}

1. BK Bharadwaj, RF Mabon, DP Giddens: Steady flow in a model of the human carotid bifurcation. Part I-Flow visualization.

$J$ Biamech 15: 349-362 (1982).

2. BK Bharadvaj, RF Mabon, DP Giddens: Steady flow in a model of the human caratid bifurcation. Part II-Laser-Doppler anemometer measurements. J Biomech 15: 363-378 (1982).

3. CK Zarins, DP Giddens, BK Bharadvaj, VS Sottiurai, RF Mabon, S Glagov: Carotid bifurcation atherosclerosis - Quantitative correlation of plaque localization with flow velocity profiles and wall shear stress. Circ Res 53: 502-514 (1983).

4. M Motomiya, T Karino: Flow patterns in the human carotid artery bifurcation.

Stroke 15: 50-56 (1984).

5. FW LoGerfo, MD Nowak, WC Quist, HM Crawshaw, BK Bharadvaj: Flow studies in a model carotid bifurcation. Arteriosclerosis 1: 235-241 (1981).

6. DN Ku, DP Giddens: Pulsatile flow in a model carotid bifurcation. Arteriosclerosis 3: 31-39 (1983).

7. APG Hoeks, RS Reneman, PA Peronneau: A multigate pulsed Doppler system with serlal data processing.

IEEE Trans Sonics U1trason SU-28: 242-247 (1981).

8. APG Hoeks: On the development of a multi-gate pulsed Doppler system with serial data-processing.

Thesis, University of Limburg, Maastricht, The Netherlands (1982). 
9. APG Hoeks, HPM Peeters, CJ Ruissen, RS Reneman: A novel frequency estimator for sanpled Doppler signals.

IEEE Trans Bioned Eng BME-31: 212-220 (1984).

10. APG Hoeks, CJ Ruilssen, P Hick, RS Reneman: Transcutaneous detection of relative changes in artery diameter.

U1trasound Med Biol 11: 51-59 (1985).

11. APG Hoeks, CJ Ruissen, P Hick, RS Reneman: Methods to evaluate the sample volume of pulsed Doppler systems.

U1trasound Med Biol 10: 427-434 (1984).

12. J0 Arndt, J Klauske, F Mersch: The diameter of the intact carotid artery in man and its change with pulse pressure.

Pftuegers Arch 301: 230-240 (1968).

13. K Fujishiro, S Yoshimura: Haemodynamic changes in carotid blood flow with age.

Jikeinai Med J 29: 125-138 (1982).

14. RS Reneman, MP Spencer: Local Doppler audia spectra in normal and stenosed carotid arteries in man.

Ultrasound Med Biol 5: 1-11 (1979).

15. RS Reneman, $T$ van Merode, APG Hoeks, $P$ Hick: The on-line recording of velocity profiles and diameter changes in normal and stenosed cervical caratid arteries in man.

U1trasound Med Biol 8, Suppl 1: 161 (abstract) (1982).

16. G Muratori: Histological observations on the structure of the carotid sinus in man and mammals. In: Baromeceptors and Hypertension, Ed $P$ Kezdi.

Pergamon Press, Oxford-New York (1967). 
17. B Gribbin, TG Pickering, P Sleight, R Peto: Effect of age and high blood pressure on baroreflex sensitivity in man.

Circ Res 29: 424-431 (1971).

18. HM Keller, WE Meier, M Anliker, DA Kumpe: Noninvasive measurement of velocity profiles and blood flow in the common carotid artery by pulsed Doppler ultrasound.

Stroke 7: $370-377$ (1976).

19. RS Reneman: What measurements are necessary for a comprenensive evaluation of the peripheral arterial circulation.

Cardiovasc Dis 8: $435-454$ (1981)?

20. RS Reneman, $T$ van Merode, P Hick, APG Hoeks: Noninvasive detection of atherosclerotic lesions in cervical carotid arteries at an early stage of the disease.

J Cereb Bload Flow Metabol 2, Supp1 1: 32-34 (1982).

21. CG Caro, RM Nerem: Transport of ${ }^{14} \mathrm{C}-4$-cholesterol between serum and wall in the perfused dog common carotid artery.

Circ Res 32: 187-205 (1973).

22. MH Friedman, GM Hutchins, CB Bargeron, OJ Deters, FF Mark: Correlation between intimal thickness and fluid shear in human arteries. Atherasclerosis 39: 425-436 (1981).

23. M Kaermes, A svindland, L Walloe, So Wille: Localization of early atherosclerotic lesions in an arterial bifurcation in humans. Acta Pathol Microbiol Scand [A] 89: 35-40 (1981).

24. RW Barmes, SE Rittgers, WW Putney: Real-time Doppler spectrum analysis: predictive value in defining operable carotid artery disease. Arch Surg 117: 52-57 (1982). 
25. JM van Baalen, JJ Jakimowicz, RS Reneman: Nonimwasive evaluation of carotid artery stenosis-comparison of direct and indirect techniques. Vasc Surg 18: 88-95 (1984).

26. WM Blackshear, DJ Phillips, BL Thiele, JH Hirsch, PM Chikos, MR Marinelli, CJ Ward, DE Strandness: Detection of carotid acclusive disease by ultrasonic imaging and pulsed Doppler spectrum analysis. Surgery 86: 698-706 (1979).

27. PJ Breslau: Ultrasonic duplex scanning in the evaluation of carotid artery disease.

Thesis, University of Limburg, Maastricht, The Netherlands (1982).

28. $Y$ Langlois, Go Roederer, A Chan, DJ Phillips, KW Beach, D Martin, PM Chikos, DE Strandness Jr: Evaluating carotid artery disease - The concordance between pulsed Doppler/spectrum analysis and angiography. vitrasound Med Biol 9: $51-63$ (1983).

29. DJ Phillips, FM Greene Jr, Y Langlois, GO Roederer, DE Strandness Jr: Flow velocity patterns in the carotid bifurcations of young, presumed normal subjects.

UTtrasound Med Biol 9: 39-49 (1983). 
CHAPTER IX

AGE RELATED CHANGES IN CAROTID ARTERY WALL PROPERTIES IN NORMOTENSIVE PRESUMED NORMAL MALES

\subsection{Introduction}

It has been known for quite some time that aging alters the histological structure of arterial walls 1 and, hence, will change its dymamic properties. Most of the information available on arterial wall properties has been obtained from excised vessels or vessel strips $2,3,4,5$ or data derived from experiments on anesthetized animals $2,3,6,7$ despite the fact that arteries show a stiffer behavior in vitro than in vivo 8 and anesthesia may affect vascular smooth muscle tone ${ }^{9}$. Therefore, the information derived from these studies is not necessarily representative of the situation in intact man. Systematic investigation of changes in arterial wall properties with age in man has been hampered by the lack of adequate noninvasive methods. The properties of human carotid arteries have been assessed non-invasively 10 , but in this study age related changes were not considered. Age-related changes were considered in a study in man, in which femoral artery wall properties were determined with a non-invasive technique ${ }^{11}$. This investigation revealed that the elastic properties of the femoral arteries are limited (average relative diameter increase in systole less than $3 \%$ at young age) and that these arterles become stiffer at older age.

It was the aim of the present investigation to study the changes in distensibility (the relative increase in arteriai diameter during systole normalized with respect to the arterial pulse pressure) and cross-sectional compliance (distensibility multiplied by the arterlal diameter) of the common carotid artery with age. This artery was chosen because in intact man no information is available about the age related changes in vessel wall properties of the common carotid artery, which is known to be more elastic (average relative diameter increase in systole 9.6\% (Chapter VIII) to $14.2 \%$ in than the femoral artery. The relative diameter changes of the common carotid artery during the cardiac cycle were recorded on-line with a 
high resolution multi-gate pulsed Doppler systen (Chapter II). This system also allows the on-line recording of velocity profiles 12,13 . From the width of these profiles arterial dianeters along the ultrasound beam can be determined. Arterial pulse pressure was estimated from brachial artery cuff blood pressure measurements. The study was perfomed on healthy, male volunteers, randomly selected through the population registers of small, average and large urban and rural towns, and varying in age between 20 and 69 years. The study was 1 imited to volunteers older than 19 years of age because at this age the vascular system was assumed to be mature. Multivariate analysis techniques were used because such parameters as arterial pulse pressure and arterial diameter may also vary with age, while the variables measured may be interrelated.

\subsection{Materials and methods}

\subsubsection{Volunteers and methods of investigation}

Hundred and sixty eight male volunteers from the Maastricht area, varying in age between 20 and 69 years, entered the study. Their names and addresses were randomly selected from the population registers of small, average and large urban and rural towns. Three hundred and thirty subjects were contacted once to obtain 168 volunteers. A11 respondents were included in the investigation. From all volunteers informed consent was obtained before they entered the study. A history was taken on symptons related to atherosclerosis. They all had a physical examination, including brachill artery cuff blood pressure measurements in the supine position. The measurements were repeated 2 or 3 times and the lowest value was taken as the subject's reading. The arterial pulse pressure $(\Delta P)$, that is the difference between systolic and diastolic blood pressure, was estimated from this pressure reading. Only volunteers with blood pressure lower than 140/90 mon $\mathrm{Hg}(18.7 / 12 \mathrm{kPa})$ were allowed to enter the study. According to this criterion 30 subjects were excluded. Sixteen volunteers with a history of cardiovascular disease were also excluded. Cervical carotid artery disease was diagnosed in 23 subjects (all above 50 years of age), using the ultrasound Doppler criteria as previously described in Chapter VI. They were also excluded so that the study was ultimately performed an 99 subjects. 
Common Carotid A

$\sqrt[5 k+k]{1}$
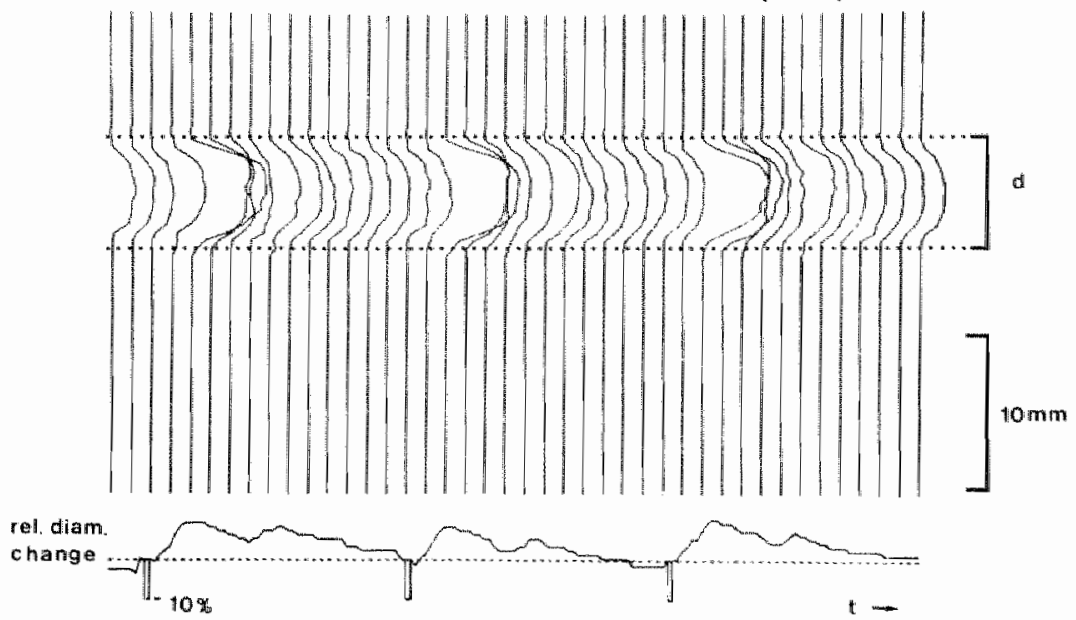

Fig. 9.1: The velocity profites at discrete time intemals duming the cardiac cycte as reconded in the common carotid artery of a volunteer, 27 years of age. The dotted lines indicate the width of the profiles during systote from which the intemat artery diameter was estimated. The relative arterial diameter changes duming systole are depicted as wett. The negative deflection represents the trigger of the R-wave of the ECG. $d=$ diameter.

The ultrasound investigations were performed with the subjects in the supine position with the head tilted slightly to the contralateral side. Either the right or the left common carotid artery was examined. The side of investigation was selected randomly. The relative diameter changes ( $\Delta d / d$ * 100\%) of the common carotid artery during the cardiac cycle were recorded on-line with a high resolution multi-gate pulsed Doppler systen (see Chapter II and Fig. 9.1). These diameter changes were recorded in the plane of the carotid artery bifurcation. The assessment of wessel wall displacement is based upon the processing of low frequency Doppler signals, originating from the sample volumes coinciding with the anterior and posterior walls. To ensure that the initial relative change at the beginning of the cardiac cycle is constant, it is reset to zero by a trigger derived from the R-wave of a standard lead of the ECG. The ECG was also used to calculate heart rate. The relative arterial diameter changes are independent of the angle 
of interrogation and can be determined with an absolute accuracy of $0.5 \%$ (Chapter II), comparing favorably to the peak excursions observed. The multi-gate pulsed Doppler system also allows the on-line recording of velocity profiles in arteries, that is the velocity distribution aver the cross-sectional area of the vessel, at discrete time interwals during the cardiac cycle (Chapter VIII). From the width of these velocity profiles the internal diameter of an artery can be assessed rather accurately (Fig. 9.1). The diameters presented refer to the systalic phase of the cardiac cycle. Since the arterial diameter, as obtained in this way, is dependent on the angle of interrogation the values measured were corrected assuming an angle of observation of $60^{\circ}$. The relative arterial diameter changes during the cardiac cycle and the diameter af the common carotid artery were determined approximately $3 \mathrm{~cm}$ proximal to the carotid artery bifurcation. The site of measurement was localized through a velocity image of the bifurcation 14 .

\section{2 .2 Calculations}

The distensibility coefficient (DC) of an artery can be assessed from the rellative arterial diameter change during systole by rewriting the expression

$$
D C=\frac{\Delta V / V}{\Delta P}
$$

where $V=$ volume of the artery and $\Delta V=$ the increase in volume for a given increase in pressure during systole (= pulse pressure; $\Delta \mathbb{P}$ ).

It is assumed that the increase in volume is caused by distension of the artery (i.e. the increase in cross-sectional area A) rather than elongation. The assumption that the increase in volume does not result from elongation seems to be reasonable because under normal circumstances lengthening of the artery during systole is not obserwed on B-mode images, as indicated by the absence of displacement of the tip of the flow divider at the carotid artery bifurcation in the cranial direction, relative to a certain spot in the common carotid artery. Because relative changes in arterial diameter of maximally $15 \%$ are anticipated, a first order approximation for $\triangle A$ can be employed to modify expression (1): 


$$
\begin{aligned}
D C & =\frac{\Delta A / A}{\Delta P} \\
& =\frac{2 \pi d \cdot \Delta d / m d^{2}}{\Delta P} \\
& =\frac{2 \Delta d / d}{\Delta P}
\end{aligned}
$$

where $d=d$ ameter and $\Delta d=$ increase in diameter during the cardiac cycle.

Equation (2) was used for calculation of the distensibility coefficient because the variables in this equation could be measured.

The cross-sectional compliance (CC) of an artery can be derived from the dynamic capacitance $\Delta V / \Delta P$ by rewriting this relation as follows:

$$
\begin{aligned}
C C & =\frac{\Delta A}{\Delta P} \\
& =\frac{\pi d \cdot \Delta d}{2 \Delta P} \cdot \frac{d}{d} \\
& =\frac{\Delta d / d}{2 \Delta P} \cdot \pi d^{2}
\end{aligned}
$$

Equation (3) was used to calculate cross-sectional compliance because the variables in this equation could be measured. The same assumption was made as in the derivation of the distensibility coefficient. The cross-sectional compliance as assessed, is highly dependent on the angle of interrogation because the diameter and, hence, the angle, appears in the squared form in this equation.

\subsubsection{Data analysis and statistics}

The velocity profiles and the relative arterial diameter changes during the cardiac cycle could be observed on-line on a cathode ray tube (CRT). The trigger derived from the $R$-wave of the ECG was displayed as well. From the variables as recorded during consecutive cardiac cycles, at least three cycles were selected and plotted on a $x / y$ plotter (Philips). The data was only used for further analysis when the velocity profiles and the relative arterial diameter changes in these cycles were consistent for at least three consecutive cardiac cycles (Fig. 9.1). This criterion was met in 80 of the 99 volunteers. The values shown represent an average of at least three cycles.

The changes in distensibility coefficient and cross-sectional compliance with age, if any, were evaluated for statistical significance. To 


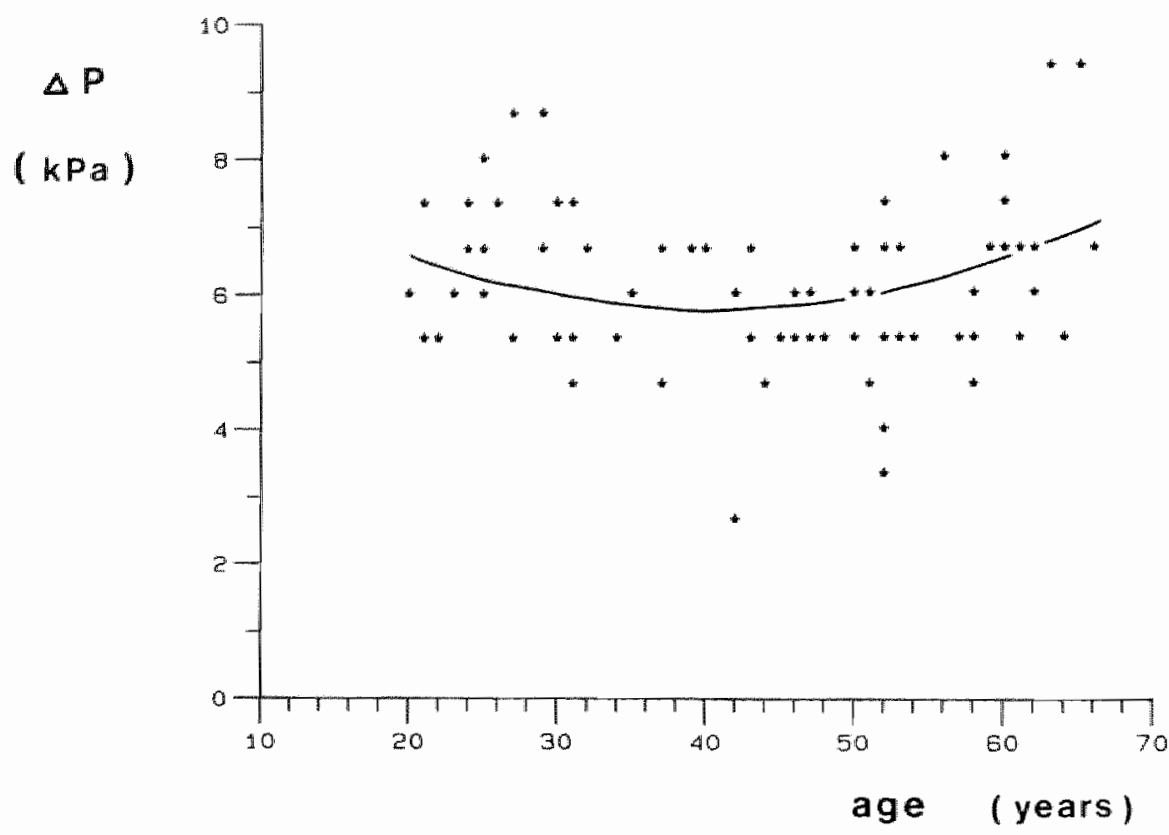

Fig. 9.2: The pressume putse (DP) as a function of age. The curve represents the direct effect of age on $\triangle P$; the other independent variables being kept at their mean level.

abtain better insight into these possible changes we also investigated the dependency on age of the variables measured like $\Delta d / d, d, \Delta P$ and diastolic arterial pressure. The dependency of heart rate on age was investigated as well because the diastolic arterial pressure level and, hence, $\triangle P$, is partially determined by heart rate ${ }^{15}$. Besides, possible relations between the various variables were evaluated for statistical significance to exclude disturbing effects of these variables on the analysis of the changes. with age.

To assess whether the age-related changes in the various variables were statistically significant a set of simultaneous linear equations was fitted to the data by using LISREL $V$, a standard computer program to analyze multivariate data 16 . Since initial analysis revealed a curved relation between $\Delta p$ and age (Fig. 9.2), a second order term (age - average age) ${ }^{2}$ was added to the model of analysis. Standard regression coefficients, i.e. 
slopes corrected for differences in variance between dependent and independent variables, and their significance levels were obtained from the LISREL program. A linear regression analys is of the changes in distensibllity coefficient and crosssectional compliance with age and age squared was performed with BMDP $1 R{ }^{17}$, also providing estimations of the standard regression coefficients and the corresponding levels of significance. The data presented in this chapter might differ a little from those published before (see p. 112) because of a slightly different approach in the analysis.

\subsection{Results}

The distensibility coefficient and cross-sectional compliance decreased highly significantly with age, although the reduction in the latter variable was less pronounced (Figs 9.3 and 9.4). These significant changes were only observed for the linear age component (Table 9.I). The relative arterial diameter increase during systole diminished highly significantly with age, reaching a plateau from the sixth age decade (Fig. 9.5). The latter is reflected in a significant positive coefficient of the quadratic age component (Table 9.I). The average relative arterial diameter increase was $9.3 \%$ in the third and $5.5 \%$ in the seventh decade, which is a $41 \%$ reduction. The arterial diameter and heart rate tended to increase with age, but these changes did not reach the level of significance (Table 9.I). AP turned out to be significantly $U$-shaped related with age; $\Delta P$ increased with age from the fourth decade (Fig. 9.2). Diastolic arterial pressure did not change with age.

A slight, but significant negative relationship was observed between the relative arterial diameter increase during systole on the one hand and diastolic pressure ( $p<0.05$; standard regression coefficient: -0.19$)$ and heart rate $(p<0.01$; standard regression coefficient: -0.23$)$ on the other. $\Delta P$ tended to increase with the relative arterial diameter increase during systole (standard regression coefficient: 0.29 ), but this relationship did not reach the level of significance. 
Table 9.I: Changes in distensibility coefficient (DC), cross-sectional compliance (CC), relative artery diameter increase during systole $(\Delta d / d * 100 \%)$, artery diameter $(D)$, heart rate $(H R)$, pulse pressure $(\Delta P)$ and diastolic arterial pressure (diast $P$ ) with age. The standard regression coefficients and the levels of significance are presented, for both the linear and the quadratic age component. $\mathbb{N S}=$ nat significant.

\section{linear component}

$$
\text { regr. caeff }
$$

$\mathrm{DC}$

$c c$

$\Delta d / d^{*} 100 \%$

D

HR

$\Delta \mathrm{P}$

diast $P$

0.01 p value

$<0.001$

$<0.001$

$<0.001$

NS

NS

NS

NS quadratic component

regr. coeff

p value

0.02

NS

NS

0.02

0.22

$<0.01$

NS

NS

$<0.05$

0.26

$<0.05$

NS

\subsection{Discussion}

The findings in the present non-invasive study indicate that common carotid artery distensibility decreases linearly with age, starting in the third decade of life. That the decrease in distensibility coefficient indeed represents reduced arterial wall elasticity is supported by the observation that the relative arterial diameter increase during systole diminishes highly significantly with age despite the fact that pulse pressure increases from the fourth age decade. The reduction with age of the 


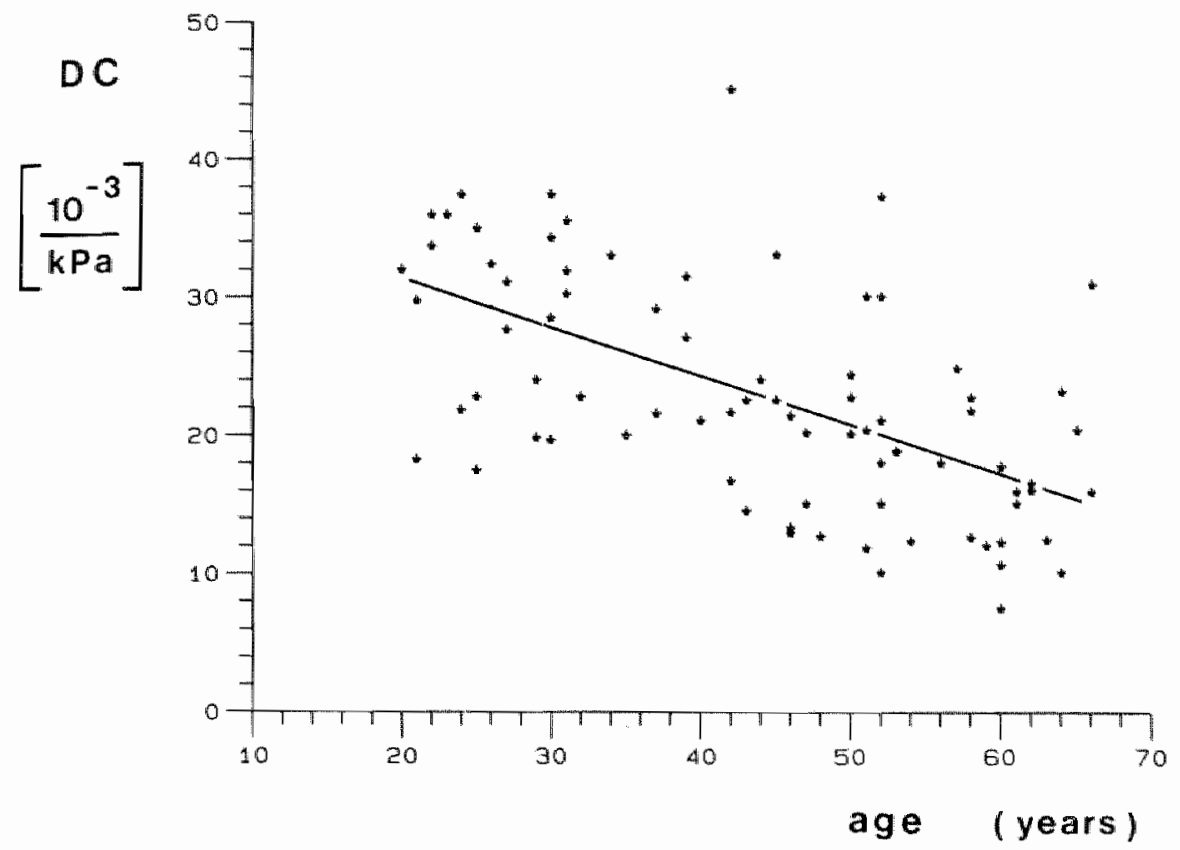

Fig. 9.3: Distensibility coeffictent (DC) as a function of age. The straight line represents the zinear regression of DC with age.

relative arterial diameter increase is less linear than the decrease in distensibility and cross-sectional compliance and reaches a plateau from the sixth age decade. A decrease in vessel wall elasticity at older age has also been described for stiffer vessels, like the femoral artery 11 . The early decrease in artery wall distensiblility, as found in the present study, is in agreement with the experimental finding that artery wall elasticity is diminished in relatively young sheep as compared with newborn 1 ambs 18 .

The relative increase in common carotid artery diameter during systole in the younger volunteers (average increase in third decade: $9.3 \%$ ) is in good agreenent with the value in Chapter VIII, but is smaller than the value reported by Arndt and his colleagues 10 . This difference may be explained by the amplitude dependency of the pulsed echo displacenent technique as used by these investigators. Amplitude dependency can easity lead to overestimation of the relative arterial diameter changes. The 


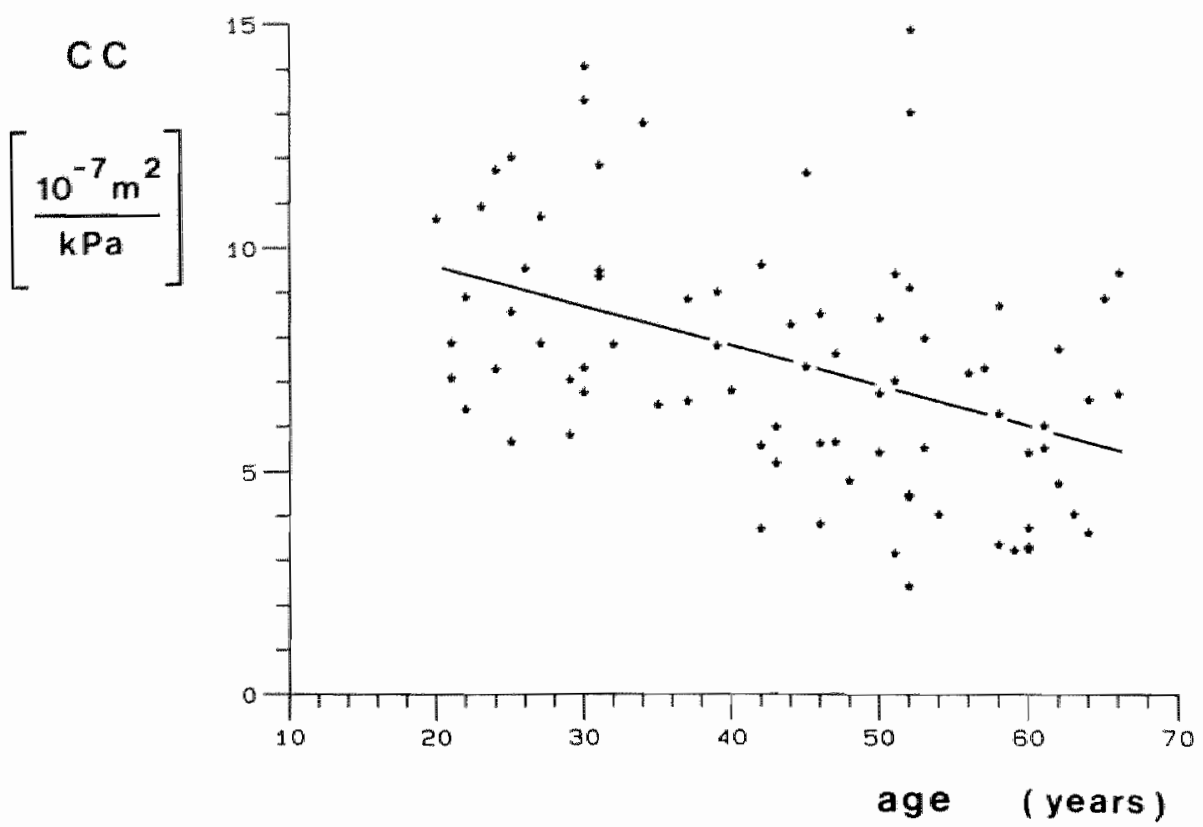

Fig. 9.4: Crobe-bectionat Compliance (CC) as a function of age. The straight line represents the linear regression of $\mathrm{CC}$ with age.

displacement method employed in the present study is amplitude independent over a wide range of amplitudes ${ }^{19}$.

The increase in pulse pressure from the fourth age decade can be explained by the decrease in artery wall distensibility. It should be noted that this study cannot be conclusive about the changes in pulse pressure as a function of age because hypertensive subjects were excluded from the study.

Common carotid artery cross-sectional compliance also decreases as a function of age, albeit that the reduction of this parameter with age is less pronounced than the decrease in distensibility. This is likely to be a consequence of the tendency of the common carotid artery diameter to increase with age. This increase was also observed in previous studies on the fenoral artery 11 and the carotid artery bifurcation (Chapter VIII). There are indications that the increase in arterial diameter with age is more 
pronounced in proximal arteries 4. The larger spread in cross-sectional compliance than in distensibility coefficient (cf Figs. 9.3 and 9.4) can be explained by variations in the angle of interrogation because cross-sectional compliance, as assessed in the present study, is dependent on this angle (see methods).

The weak, but significant, negative relation between the relative increase in common carotid artery diameter during systole and heart rate could be explained by the physiological dependency of diastolic arterial pressure on heart rate ${ }^{15}$. A lower heart rate will lead to a reduction of diastolic arterial pressure and, hence, a diminished diastolic arterial diameter. As a consequence the rellative arterial diameter increase during systole will be more pronounced. This idea is supported by the finding that there is indeed a slight, but significant negative relationship between this variable and diastolic arterial pressure. The changes in heart rate

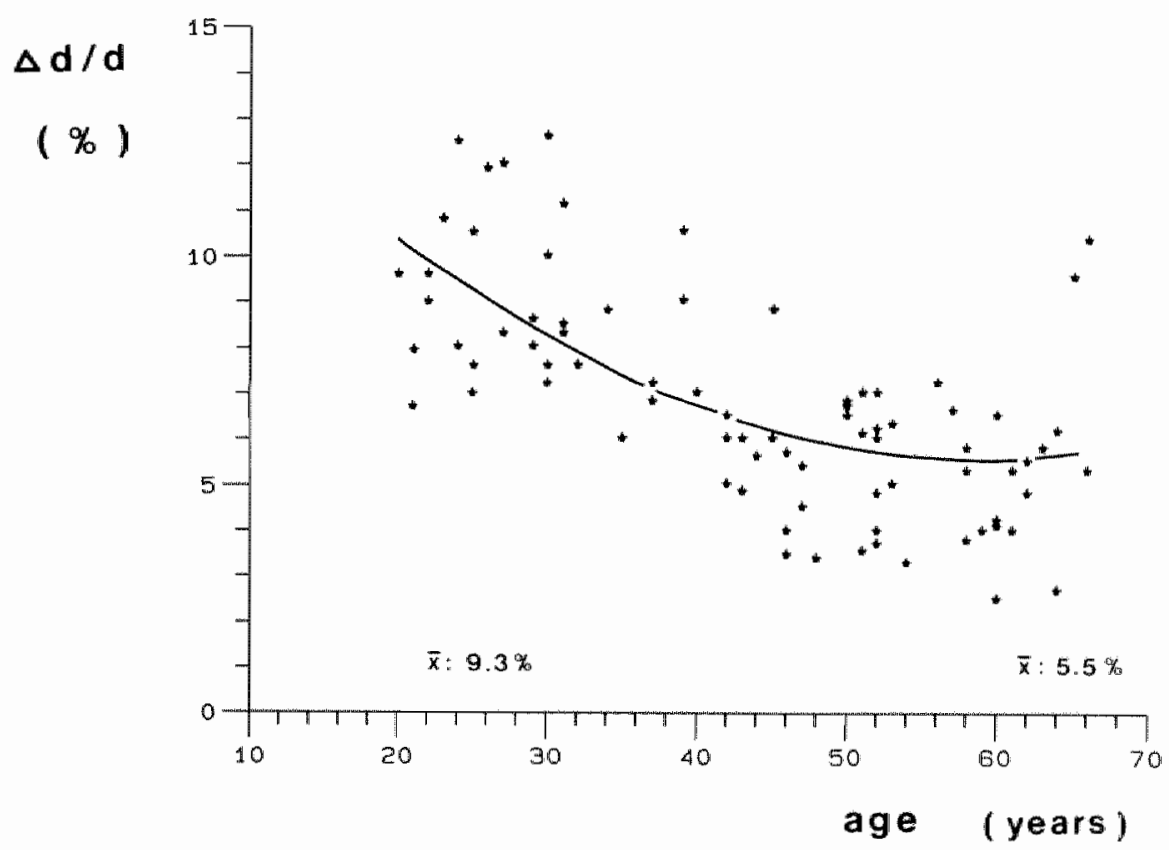

Fig. 9.5: The relative artemal diameter increase in syetole (Dd/a) as a function of age. The curve mepresents the direct effect of age on $\Delta d / d$; the other independent vamiables being kept at their mean tevel. 
and, hence, diastolic arterfal pressure, however, are not reflected in a change in pulse pressure.

A critique on the method, as used in the present investigation, is that pulse pressure was measured in the brachial rather than the common carotid artery. This was necessary because a non-invasive method to assess pressure in the latter artery is not available. In this approach it is assumed that the pulse pressure in the brachial artery as well as its changes with age are representative of those in the common carotid artery. An indication of the first assumption is the posftive, but non-significant, relationship between pulse pressure and the relative diameter increase of the common carotid artery during systole. Whether the decrease in wall elasticity, an important deteminant of pulse pressure, with age is similar in the brachial and common carotid arteries is unknown. However, the reduction in relative arterial diameter increase during systole with age is similar in the relatively stiff femoral artery $35 \%$ reduction from under 35 till over 60 years ${ }^{11}$ ) and the relatively elastic common carotid artery (39\% reduction from 20 till 69 years; this chapter). This and the rather similar arterial wall properties of the brachial and femoral arteries indicate that the wall elasticity in the brachial and the carotid artery diminish with age to a similar extent.

In conclusion the findings in this study indicate that common carotid artery distensibility and cross-sectional compliance decrease linearly with age, although the reduction in the latter parameter is less pronounced, probably as a consequence of an increase in arterial diameter with age.

Previousily published as:

Age related changes in carotid artery wall properties in men. Robert 5 . Reneman, Tiny van Merode, Paul Hick, Arno M.M. Muytjens and Arnold P.G. Hoeks. Ulltrasound Med Biol 12: 465-471 (1986). 


\section{REFERENCES}

1. RR Kohn: Heart and Cardiovascular System. In: Handbook of the blology of aging. Eds. Caleb E Finch, Leonard Hayflinck. Van Nostrand Reinhold Company, New York (1977).

2. DH Berget: Cardiovascular fluid dynamics. Academic Press, New York. $(1972)$.

3. DA McDonald: Blood flow in arteries. Williams and Wilkins, Baltimore. (1974).

4. BM Learoyd, MG Taylor: Alterations with age in the viscoelastic properties of human arterial walls.

Circ Res 18: 278-292 (1966).

5. MR Roach: The static elastic properties of carotid arteries from fetal sheep.

Can J Physiol Pharmacol 48: 695-708 (1970).

6. GR Nicolosi, HP Pieper: Nature of aortic smooth muscle responses to changes in venous return studied in intact dogs.

Am J Physiol 221: 1209-1216 (1971).

7. M Pagani, PJ Schwartz, VS Bishop, A Malliani: Reflex sympathetic changes in aortic diastolic pressure-diameter relationship.

An J Physiol 229: 286-290 (1975).

8. BS Gow, Co Hadfield: The elasticity of canine and human coronary arteries with reference to postmortem changes.

Circ Res 45: 588-594 (1979).

9. BT Altura, BM Altura: Pentobarbital and contraction of vascular smooth muscle.

Am J Physiol 229: $1635-1640$ (1975). 
10. J0 Arndt, $J$ klauske, F Mersch: The diameter of the intact carotid artery in man and its change with pulse pressure.

Pfluegers Arch 301: 230-240 (1968).

11. DJ Mozersky, DS Sumner, DE Hokanson, DE Strandness: Transcutaneous measurement of the elastic properties of the human femoral artery. circulation 46: 248-955 (1972).

12. APG Hoeks, RS Reneman, PA Peronneau: A multigate pulsed Doppler system with serial data processing.

IEEE Trans Sonics U1trasonics SU-28: 242-247 (1981).

13. APG Hoeks, HPM Peeters, CJ Ruissen, RS Reneman: A novel frequency estimator for sampled Doppler signals.

IEEE Trans Biomed Eng BME-31: 212-220 (1984).

14. RS Reneman, MP Spencer: Local Doppler audio spectra in normal and stenosed carotid arteries in man.

Ultrasound Med Biol 5: 1-11 (1979).

15. RF Rushmer: Cardiovascular dynamics. W.B. Saunders Company, Philadelphia, London, Toronto. (1970).

16. KG Joreskng, D Sorbom: Lisrel V user"s guide. National Educational Resources, Inc., Chlcago. (1981).

17. WJ Dixon, MB Brown: Biomedical computer program P-series (BMDP-81). University of California Press, Berkeley CA. (1981).

18. M Pagani, I Mirsky, H Baig. WT Manders, P Kerkhof, SF Vatner: Effects of age on aortic pressure-diameter and elastic stiffness-stress relationships in unanesthetized sheep.

Circ Res 44: 420-429 (1979). 
19. APG Hoeks, CJ Ruissen, P Hick, RS Reneman: Transcutaneous detection of relative changes in artery diameter. Ultrasound Med Biol 11: $51-59$ (1985). 

CHAPTER X

THE DIAGNOSIS OF MINOR CAROTID ARTERY STENOSIS BY THE USE OF FLOW VELOCITY PATTERNS IN AND DISTENSIBILITY OF THE CAROTID ARTERY BULB

As has been mentioned in Chapter VIII, a complicating factor in diagnosing minor (1-29\% diameter reduction) to moderate (30-50\% diameter reduction) lesions is that they are generally located at bifurcations where the flow pattern is complicated already. Therefore, in our laboratory diagnosis of these lesions with the use of a multi-gate pulsed Doppler system has been recently based upon

- deviations from the normally occurring flow patterns. For example, the presence of recirculation in areas generally devoid of this disturbance, like near the flow divider, or recirculation at this site as well as opposite to the divider. At younger age the absence of backflow is indicative of a vascular lesion.

- diminished vessel wall displacement during the cardiac cycle at the level of the bulb as compared to the displacement of the common and internal caratid arteries considering the age of the patient.

For the moderate and severe (50-99\% diameter reduction) lesions additional information was obtained from the changes in the Doppler audio spectrum. For proper localization of the site of measurement the multi-gate pulsed Doppler system has to be combined with a B-mode imager. Moreover, this imager provides additional information about the presence of a lesion, if any. Based upon the findings in nommal subjects and in a series af patients with various degrees of disease at the carotid artery bifurcation criteria to diagnose carotid artery disease and to estimate its severity (i.e. no lesion, minor lesion, moderate lesion, severe lesion and occlusion) were formulated (Table 10.1).

In a pilot, prospective study on 43 carotid arteries (23 patients), these criteria were evaluated, with the use of biplane carotid arteriography as a gold standard.

The 23 patients from the neurological department of the University Hospital in Maastricht were examined with the multi-gate pulsed Doppler system, using the criteria described in Table 10.I. All patients were 
submitted to biplane arteriography (Seldinger technique) of the carotid circulation, because of focal neurological symptoms. Omly 43 sides were used for analysis because two patients were submitted to unilateral endarterectomy of the carotid artery just prior to the Doppler examination, and in another patient on one side the arteriogram could not be interpreted.

The ultrasonic examination was performed and the degree of carotid antery disease was assessed by the author, who was not informed of the results of the arteriograms. The usual routine as described in the chapters IV and VIII was followed. With the B-mode imager employed (a mechanical sector scanner; ATL Mark V), not all soft tissue plaques were readily detected. Therefore, only calcified plaques with acoustical shadowing, as detected on the B-mode image, were considered in the diagnostic criteria as presented in Table 10.I. In this approach thrombotic lesions without calcifications could have been easily missed. The results obtained are probably subject to improvement by using a high resolution B-mode imager.

The arteriograms were read by one of the Hospital's neurologists, without knowledge of the outcome of the non-invasive evaluation. The lesions were classified as absent (normal), minor (1-29\% diameter reduction), moderate (30-49\% diameter reduction), severe (50-99\% diameter reduction) or total occlusion. All lesions were localized in the carotid artery bulb, al though some more severe lesions extended further downstream in the internal carotid artery. The results are depicted in Table 10.11. Minor lesions could be diagnosed with a diagmostic accuracy of $95.3 \%$, a sensitivity of $90.0 \%$ and a specificity of $90.0 \%$.

These results in diagnosing minor lesions are rather good, and compare favorably with ather studies on the detection of minor carotid artery disease $1,2,3$ as far as the diagnostic accuracy is concerned. The sensitivity and specificity in the detection of minor lesions in these studies, however, range from $45.0 \%$ and $33.3 \% \mathrm{l}$, to $80.3 \%$ and $67.1 \%^{3}$, respectively.

Although the results of this pllot study are rather promising, more experience with this approach is required to rate these findings at their true value. The use of a high resolution B-mode imager will probably further enhance the diagnostic accuracy. An extended prospective study has already been started. 
Table 10.I: Criteria to detect carotid artery disease with the multi-gate pulsed Doppler system

no Tesion

(nomal)

minor lesion

(1-29\% diameter reduction)
: no plaque on B-hode image

: backflow in carotid artery bulb on side opposite to flow divider. In older subjects backflow can be absent.

: relative increase in dianeter of the carotid artery bulb during systole not or only slightly diminished as compared to that in common carotid artery, considering the age of the patient.

: on B-mode image no or small plaque

: no backflow in the carotid artery bulb on the side opposite to the flow divider (in younger subjects) or at a non-specific site, for instance, on side of flow divider

: rellative increase in diameter of the carotid artery bulb during systole greatly diminished as compared to that in the common carotid artery, considering the age of the patient.

moderate lesion

$(30 \%-50 \%$

diameter reduction)
: on B-mode image often small plaque, however, may be absent

: backflow carotid artery bulb at non-specific site or at more sites

: relative increase in diameter of the carotid artery bulb during systole greatly diminished as compared to that in the common caratid artery, considering the age of the patient

: spectral analysis of the Dappler signal of the proximal internal carotid artery shows moderate spectral broadening (C classification according to the modified criteria of Strandness (Chapter V)). 
severe lestion

(>50\% diameter reduction)
: on B-mode image plaque

: flow pattern in the carotid artery bulb greatly disturbed, with areas of recirculation just distal to the site of the lesion

: no relative increase in diameter of the carotid artery bulb during systole

: spectral analysis of the Doppler signal of the proximal internal carotid artery shows severe spectral broadening with increased maximal frequencies (D classification according to the modified criteria of strandness (Chapter W)).

occlusion
: no signal from the internal carotid artery can be detected. 
TABLE 10.II: The results, as obtained with the multi-gate pulsed Doppler examination, compared with those obtained with biplane arteriography in a prospective study.

\section{$\underline{\text { DOPPLER } \rightarrow}$}

\begin{tabular}{|c|c|c|c|c|c|}
\hline ANGIO & normal & $1-29 \%$ & $30-49 \%$ & $50-99 \%$ & occlusion \\
\hline nomal & 17 & 1 & & & \\
\hline $1-29 \%$ & 1 & 9 & & & \\
\hline $30-49 \%$ & 1 & & 4 & & \\
\hline $50-99 \%$ & & & & 8 & \\
\hline acclusion & & & & & 2 \\
\hline
\end{tabular}

For minor lesions (1-29\% diameter reduction):

diagnostic accuracy

$95.3 \%$

sensitivity

$90.0 \%$

specificity

$90.0 \%$ 


\section{REFERENCES}

1. Y Lanilois, 60 Roederer, A Chan, DJ Phillips, KW Beach, D Martirn, PM Chikos, DE Strandness: Evaluating carotid artery disease. The concordance between pulsed Doppler/spectrum analysis and angiography. U1trasound Med Biol 9: 51-63 (1983).

2. RA Knox, FM Green, K Beach, DJ Phillips, PM Chikos, DE Strandness: Computer based classification of carotid arterial disease: a prospective as ses sinent.

Stroke 13: 589-594 (1982).

3. GO Roederer, YE Langlois, KA Jager, JF Primozich, KW Beach, DJ Phillips, DE Strandness: The natural history of carotid arterial disease in asymptomatic patients with cervical bruit.

Stroke 15: 605-613 (1984). 
CHAPTER XI

VESSEL WALL PROPERTIES OF THE CAROTID ARTERY IN NORMOTENSIVE AMD BORDERLINE HYPERTENSIVE MALE SUBJECTS OF VARIOUS AGES

\subsection{Introduction}

In man arterial hypertension has been widely recognized as a concomitant factor in atherosclerosis $1,2,3,4$, while histological studies revealed morphological changes in the arterial wall of hypertensive subjects, even at an early stage of the disease $5,6,7$. These changes in arterial wall structure likely lead to changes in the dynamic properties of the artery wall and indeed the results of studies published so far seem to support the idea of diminished arterial wall distensibility in hypertensive subjects $8,9,10,11$. In most of these studies, however, invasive techniques or exposed arteries were used to assess vessel wall properties 8,9,10. Even more important is that in most of these studies changes in vessel wall properties with age were not considered, despite the fact that vessel wall distensibility and compliance diminish with increasing age 12,13. (See also Chapter IX).

It was the aim of the present investigation to study the distensibility (the relative increase in arterial diameter during systole divided by the arterial pulse pressure) and cross-sectional compliance (distensibflity multiplied by the absolute arterial diameter) of the conmon carotid artery assessed non-invasively in nomotensive and borderline hypertensive male subjects of comparable age. The study was perfarmed on younger and on alder subjects. The borderline hypertensive state was chosen because it is considered to be an early stage or a mild form of the disease, and it is still a matter of debate whether these borderline hypertensive subjects have to be treated.

The common carotid artery was chosen for this study because this artery is accessible to ultrasound, while it is known to be more elastic (average relative diameter increase in systole $9.6 \%$ (Chapter VIII) to $14.2 \% 14$ ) than, for instance, the femoral artery. The relative diameter changes of the common carotid artery during the cardiac cycle were recorded on-line 
with a high resolution multi-gate pulsed Doppler system ${ }^{15}$. This systen also allows the on-line recording of velocity profiles 16,17 as described in detail in Chapter II. From the width of these profiles absolute internal arterial diameters can be detemined. Arterial pulse pressure was estimated from brachial artery cuff blood pressure measurements and cross-sectional compliance and arterial distensibility were calculated as previously described in detail in Chapter IX.

\subsection{Materials and methods}

The male subjects, who entered the study, originated from two different sources. The younger volunteers (aged 20-35 years) were randomly selected from a population study on different aspects of borderline hypertension. which has been described in detail before 19 . This group has been followed for several years (start July 1977) and consisted of borderline hypertensive $(n=25)$ and normotensive control subjects $(n=25)$. In this population study mormotension was defined as blood pressure values lower than or equal to $125 / 85 \mathrm{mmHg}$ after 2 minutes standing. These values were measured two times at an interval of 1 week. Borderline hypertensive subjects had blaod pressure values higher than or equal to $140 / 90$, but lower than $160 / 100 \mathrm{mmHg}$ at two measurenents performed at an 1 week interval.

From these subjects 28 volunteers were asked randomly to volunteer in the present study. A11 28 volunteers $(13$ normotensive and 15 borderline hypertenstwe subjects) agreed to participate.

Since no such population of older borderline hypertensive subjects was available, a different approach was enployed for this age group. These volunteers were selected from a study on age-related changes in carotid artery wall properties (see Chapter IX), as performed on male subjects without detectable carotid artery disease and a negative history of cardiac, renal, cerebrovascular or peripheral vascular disease. The volunteers enrolled in the original study were randamly selected from the population registers of large, medium and sma 11 , rural and urban cities. The age group of 50-69 years was used for the present study. From this group of 44 volumteers 9 were borderline hypertensive; the renaining 35 subjects served as controls. A11 nomotensive subjects had a blood pressue lower than 140/90 
$\mathrm{mm} H \mathrm{Hg}$. Borderline hypertension was defined as a cuff blood pressure higher than or equal to $140 / 90$, but lower than $160 / 100 \mathrm{~mm} H \mathrm{Hg}$. From all volunteers informed consent was obtained before they entered the study.

The ultrasound investigations were performed with the subjects in the supine position with the head tilted slightly to the contralateral side. Either the right or the left common carotid artery was examined. The artery to be investigated was randomly selected. The relative diameter changes $(\Delta d / d * 100 \%)$ of the common carotid artery during the cardiac cycle were recorded on-line with a high resolution multi-gate pulsed Doppler system as described in chapter II. These diameter changes were recorded in the plane of the carotid artery bifurcation.

The assessment of vessel wall displacement is based upon the processing of low frequency Doppler signals, originating from the sample volumes coinciding with the anterior and posterior walls. To ensure that the initial relative change at the beginning of the cardiac cycle is constant, it is reset to zero by a trigger derived from the R-wave of a standard lead of the ECG. The ECG was also used to calculate heart rate. The relative arterial diameter changes are independent of the angle of interrogation and can be determined with an absolute accuracy of $0.5 \%{ }^{15}$, comparing favorably to the peak excursions observed. The multi-gate pulsed Doppler system also allows the on-line recording of velocity profiles in arteries, that is the velocity distribution over the cross-sectional area of the vessel, at discrete time intervals during the cardiac cycle 16,17 . From the width of these velocity profiles the internal diameter of an artery can be assessed rather accurately (Fig. 9.1). The diameters presented refer to the systolic phase of the cardiac cycle. Since the arterial diameter, as obtained in this way, is dependent on the angle of interrogation, the values measured were corrected assuming an angle of observation of $60^{\circ}$. The relative arterial diameter changes during the cardiac cycle and the diameter of the common carotid artery were determined approxinately $3 \mathrm{~cm}$ proximal to the carotid artery bifurcation. The site of measurement was localized through a velocity image of the bifurcation 18 .

At the time of the examination brachial artery cuff blood pressure measurements were performed with the subject in the supine position. The measurements were repeated 2-3 times and the lowest value was taken as the subject's reading. The arterial pulse pressure $(\Delta P)$, that is the difference 
between systallic and diastolic blood pressure, was estimated from this pressure reading.

The peak systolic value of $\Delta d / d$, and the absolute diameter (d) and $\Delta P$ values were used to calculate the distensibility coefficient (DC) and cross-sectional compliance (CC), as previously described in detail (Chapter IX), with the use of the following equations:

$$
\begin{aligned}
& D C=\frac{2 \Delta d / d}{\Delta P} \\
& C C=\frac{\Delta d / d}{2 \Delta P} \pi d^{2}
\end{aligned}
$$

In both age groups differences between the wariables and parameters in the hypertensive and control subjects were evaluated for statistical significance with the use of the Mann-Whitney test. A p value $<0.05$ was considered to be a significant difference. Comparisons between the older and younger borderline hypertensive subjects were not performed because of the different origin of the subjects in the two age groups.

\subsection{Results}

\section{Young subjects}

The blood pressure values in all subjects and in those participating in the present study are presented in Table 11.I. No significant differences could be detected between the subpopulation and the whole population. The blood pressure values were significantly higher in the borderline hypertensive than in the control subjects.

At the time of the Doppler measurements (sept ' 83 - jan '84), in the younger subjects systolic and diastolic blood pressure were significantly higher in the borderline hypertensive than in the normotensive control subjects, but $\triangle P$ was not significantly different in both groups (Table 11.11). 
The $\Delta d / d, D C$ and $C C$ were significantly lower in the borderline hypertensive subjects than in the control subjects. No significant differences could be detected between the common carotid artery diameter and heart rate values in both groups. The groups were also comparable for age. (Table 11.II).

\section{OId subjects}

In these subjects systolic and diastolic blood pressure as well as pulse pressure $(\Delta P)$ were significantly higher in the borderline hypertensive than in the comtrol subjects. The distensibility coefficient (DC) was significantly diminished in the borderline hypertensive group, but $\Delta \mathrm{d} / \mathrm{d}$ and CC did not show a statistically significant difference between the borderline hypertensive and normotensive subjects, although $\Delta d / d(p=0.449)$ and $C C$ $(p=0.0626)$ tended to be lower in the borderline hypertensive group (Table 11. III). No significant differences could be detected between the common carotid artery diameter, heart rate and age in both groups (Tab1e 11.III).

\subsection{Discussion}

The findings in the present study show that both the distensibility coefficient and the cross-sectional compliance of the comnon carotid artery are significantly diminished in young subjects with borderline hypertensian as compared to age-matched control subjects. In older subjects with borderline hypertension the distensibility coefficient and the cross-sectional compliance of the comnon carotid artery are also lower than in age-matched control subjects, although the difference in the latter paraneter just did not reach the level of significance $(p=0.06)$.

Because the older and younger volunteers originated from two different sources, no comparison was made between the data in the older and younger age groups.

The diminished distensibility and cross-sectional compliance likely result from a decrease in arterial wall elasticity in both young and old subjects because the relative increase in common carotid artery diameter 
TABLE 11.1: Systolic $\left(P_{S}\right)$ and diastolic blood pressure $\left(P_{D}\right)$, and pulse pressure ( $\triangle P$ ) in nomotensive $(N)$ and borderline hypertensive (B) subjects as recorded at enrollment in the population study in all volunteers (A) and in those participating in the present study $(P)$. Mean values \pm S.D.

\begin{tabular}{lcccc}
\hline & $\begin{array}{c}N \\
(n=25)\end{array}$ & $\begin{array}{c}B \\
(n=25)\end{array}$ & $\begin{array}{c}N \\
(n=13)\end{array}$ & $\begin{array}{c}B \\
(n=15)\end{array}$ \\
\hline$P_{S}(\mathrm{mmHg})$ & $120 \pm 1$ & $148 \pm 1^{1)}$ & $122 \pm 4$ & $143 \pm 7^{1)}$ \\
\hline$P_{0}(\mathrm{mmHg})$ & $81 \pm 1$ & $95 \pm 1^{1)}$ & $73 \pm 4$ & $91 \pm 5^{1)}$ \\
\hline$\Delta P(\mathrm{mmHg})$ & $39 \pm 1$ & & & $52 \pm 7$ \\
\hline
\end{tabular}

1) statistically significantly higher than in normotensive volunteers $p<0.001$

during systole is significantly diminished in borderline hypertensives, despite the fact that their pulse pressure is similar to or higher than that in nornal control subjects. The reduced arterial wall elasticity is apparently not compensated for, because the common carotid artery diameters are not significantly different in borderline hypertensive and control subjects.

Although these findings indicate a stiffer behavior of the arterial wall in borderline hypertensive than in normotensive subjects, at both young and old age, the differences between borderline hypertensives and normotensives are less pronounced in the older subjects. This may be explained by the fact that distensibility and cross-sectional compliance of 
the common carotid artery significantly dininish with age (See Chapter IX). and that these alterations partly mask the differences between borderline hypertensive and normotensive subjects in the older age group.

When comparing the results of this study with those of other investigations, one has to consider differences in methodology to assess artery wall properties. Most investigators, however, seem to agree upon a decrease in arterial compliance in hypertensive subjects $8,10,11$. The results of the present study corroborate with those of Simon et al 10 and Safar et al 11 , who also used non-invasive Doppler measurements to calculate arterial compliance.

Gribbin et al ${ }^{8}$ found higher pulsewave velocity values in subjects with high blood pressure and, hence, less distensible arteries. They concluded that this was a consequence of the elevated distending pressures in these subjects and not a result of irreversible structural changes in the arterial wall, because no difference was found between hypertensive and nomal subjects at identical arterial distending pressures. The experimental procedure, however, included invasive techniques and the age of the subjects was not taken into account. Simon et al ${ }^{10}$ assessed forearm arterial compliance from simultameous blood pressure and blood flow measurements, using a pulsed Doppler device. A reduced forearm arterial compliance was found in hypertensive subjects, which was associated with a significant increase in brachial artery diameter with more severe hypertension. The investigators suggested that this is a mechanism to prevent forearm arterial compliance to decrease further when blood pressure is chronically elevated. In their study arterial blood pressure and arterial diameter returned to normal, but forearm arterial compliance remained diminished after administration of dihydralazine, indicating the existence of structural changes in the arterial wa11.

A critique on the method, as used in the present investigation, could be that pulse pressure was measured in the brachial rather than the conmon carotid artery. This was necessary because a non-invasive method to assess pressure in the latter artery is not awailable. In this approach it is assumed that the pulse pressure in the brachial artery is representative of that in the common carotid artery. An indication of this assumption is the pasitive, but non-significant, relationship between this pulse pressure and the relative diameter increase of the common carotid artery during systole 
TABLE 11.II: Age, systolic $\left(P_{S}\right)$ and diastalic $\left(P_{0}\right)$ arterial blood pressure, arterial pulse pressure $(\Delta P)$, peak relative arterial diameter increase during systole ( $\Delta d / d)$, arterial diameter $(d)$, distensibility coefficient (DC), and cross-sectional compliance (CC) in young (20-35 years) normotensive control $(n=13)$ and borderline hypertensive subjects $(n=15)$. Mean values \pm S.D.

\section{Normotensives}

Age

(years)

$P_{\mathbb{D}}$

$(\mathrm{mmH} H \mathrm{~g})$

$P_{S}$

(mnHg)

$\Delta \mathrm{P}$

(mmHg)

Heart rate

(beats $\cdot \min ^{-1}$ ),

$\Delta d / d$

(野)

d

(mm)

D.C.

$\left(10^{-3} / \mathrm{KPa}\right)$

C.C.

$\left(10^{-7} \mathrm{~m}^{2} / \mathrm{kPa}\right)$
$30 \pm 4$

$31 \pm 4$

$71.2 \pm 6.5^{1)}$

$84.3 \pm 7.8$

$128.1 \pm 8.0^{1)}$

$140.7 \pm 9.4$

$55.8 \pm 9.3$

$56.3 \pm 7.7$

$66 \pm 12$

$70 \pm 7$

$6.4 \pm 0.7$

$6.3 \pm 0.6$

$7.3 \pm 1.4^{1)}$

$6.1 \pm 1.1$

$20.0 \pm 5.1^{11}$

$16.3 \pm 3.0$

$6.5 \pm 1.7^{1)}$

$5.0 \pm 1.0$

1) Significantly different from borderline hypertensives $(P<0.05)$ 
TABLE 11.III: Age, systolic $\left(P_{S}\right)$ and diastolic $\left(P_{0}\right)$ artertal blood pressure, arterial pulse pressure $(\triangle P)$, peak relative arterial diameter increase during systole $(\Delta d / d)$, arterial diameter (d), distensibility coefficient (DC), and cross-sectional compliance (CC) in older (50-69 years) nornotensive control $(n=35)$ and borderline hypertensive subjects $(n=9)$. Mean values $\pm S . D$.

Normotensives

$P_{D}$

$(\mathrm{mm} H \mathrm{Hg})$

$P_{S}$

$(\mathrm{mmHg})$

$\Delta P$

$(\mathrm{mmHg})$

Heart rate

(beats.min ${ }^{-1}$ )

$\Delta d / d$

(\%)

d

(nm)

D.C.

$\left(10^{-3} / \mathrm{kPa}\right)$

C.C.

$\left(10^{-7} \mathrm{~m}^{2} / \mathrm{kPa}\right)$
$80.0 \pm 6.7^{1)}$

$57 \pm 5$

$57 \pm 6$

Borderline

hypertensives

$93.9 \pm 6.0$

$126.6 \pm 8.9^{1)}$

$151.1 \pm 9 \cdot 3$

$46.3 \pm 9.7^{1)}$

$57.2 \pm 10.0$

$72 \pm 7$

$75+1.0$

$5.5 \pm 1.7$

$4.9 \pm 1.6$

$6.5 \pm 0.7$

$6.6 \pm 0.8$

$\left.18.5 \pm 6.7^{1}\right)$

$13.2 \pm 5.0$

$6.2 \pm 2.8^{21}$

$4.5 \pm 2.1$

1) Significantly different from borderline hypertensives $(p<0.05)$

2) Difference did not reach the level of significance $(p=0.06)$ 
that was found in the study described in Chapter $I X$, examining age-related changes in distensibility and cross-sectional compliance in a similar way.

Another problem is that the borderline hypertensive subjects in the younger age group shomed mean blood pressure values as measured in this study, that can hardly be classified as borderline hypertension (see Table 11. II). These volunteers, however, have been followed with yearly blood pressure measurements since 1977. At these occasions, the blood pressure values in the 15 young subjects were generally classified as borderline hypertensive, although in some volunteers (about 40\%) blood pressure values below $140 / 90 \mathrm{miHg}$ were occasionally measured. The nearly normotensive mean blood pressure values, as measured during the present study, can be probably explained by a longer resting period prior to the measurements and that they were performed in the supine position. In the original population study blood pressure values were recorded standing. Especially diastalic blood pressures tend to be lower when measured in the supine position. Despite these relative slight differences in arterial blood pressure the carotid artery shows a stiffer behavior in borderline hypertensive than in normal subjects, which raises the question whether the changes in vessel wall properties in borderline hypertensives are really a result of the elevated arterial blood pressure.

In conclusion the findings in this study indicate that arterial distensibility and cross-sectional compliance are diminished in borderline hypertensive subjects, at both younger and older age. In the younger subjects this reduction is very likely originating from changes in arterial wall elasticity, because no differences in pulse pressure and arterial diameter were found between the normotensive and borderline hypertensive subjects. In older subjects the situation is probably more complicated, because of the significant differences in pulse pressure between the normotensive and borderline hypertensive subjects. At this age the vessel wall properties are likely to be influenced by age related changes (See Chapter IX). 


\section{REFERENCES}

1. GW Duncan, RS Lees, RG 0jemann, SS David: Concommitants of atherosciem rotic carotid artery stenosis.

Stroke 8: 665-669 (1977).

2. B Herman, ACM Leyten, JG van Luyk, GWGM Frenken, AAW op de Coul, BPM Schulte: An evaluation of risk factors for stroke in a Dutch community. Stroke 13: $334-339(1982)$.

3. IT Salonen, P Puska, J Tuomilehto, K Homan: Relation of blood pressure, serum lipids and smoking to the risk of cerebral stroke. Stroke 13: $327-334$ (1982).

4. WH Barker, KS Feldt, JH Feibel: Community surveillance of stroke in persons under 70 years old: contribution of uncontrolled hypertension. Am J Public Health 73: 260-265 (1983).

5. CK Zarins, DP Giddens, BK Bharadvaj, VS Sottiuraï, RF Mabon, S GIagov: Carotid bifurcation atherosclerosis. Quantitative correlation of plaque localization with flow velocity profiles and wall shear stress. Circ Res 53: 502-514 (1983).

6. P Grottum, A Svindland, L Walløe: Localization of early atherosclerotic lesions in the right carotid bifurcation in humans. Acta Path Microbiol Immunol Scand [A] 91: 65-70 (1983).

7. GW Pickering. In: High Blood Pressure. Churchi11 London (1968).

8. B Gribbin, TG Pickering, P Sleight: Arterial distensibility in normal and hypertenstive man.

clinical Science 56: 413-417 (1979).

9. MA Green, R Friedlander, AJ Boltax, CG Hadjigeorge, GA Lustig: Distensibility of arteries in human hypertension. In: Proc Soc Exp Biol Med 121: 580-585 (1966). 
10. ACh Simon, S Laurent, JA Levenson, JE Bouthier, ME Safar: Estimation of forearin arterial compliance in nomal and hypertensive men. Cardiovasc Res 17: $331-338$ (1983).

11. ME Safar, PA Peronneau, JA Levenson, JA Toto-Moukouo, ACh Simon: Pulsed Doppler: Dianeter, blood flaw velocity and wolumic flow of the brachial artery in sustained essential hypertension.

Circulation 63: 393-400 (1981).

12. K Fujishiro, 5 Yoshimura: Haemodynamic changes in carotid blood flow with age.

Jikeikai Medical Journal 29: 125-138 (1982).

13. DH Bergel: The dynamic elastic properties of the arterial wall. J Physiol 156: 458-469 (1961).

14. J0 Arndt, J Klauske, $F$ Mersch: The diameter of the intact carotid artery in man and its change with pulse pressure.

Pfluegers Arch 301: 230-240 (1968).

15. APG Hoeks, CJ Ruissen, P Hick, RS Reneman: Transcutaneous detection of relative changes in artery diameter.

U1trasound Med Biol 11: 51-59 (1985).

16. APG Hoeks, RS Reneman, PA Peronneau: A multigate pulsed Doppler system with serial data processing.

IEEE Trans Sonics Utrason SU-28: 242-247 (1981).

17. APG Hoeks, HPM Peeters, CJ Ruissen, RS Reneman: A novel frequency estimator for sampled Doppler signals.

IEEE Trans Biomed Eng BME-31: 212-220 (1984).

18. RS Reneman, MP Spencer: Local Doppler audio spectra in normal and stenosed carotid arteries in man.

H1trasound Med Biol 5: 1-11 (1979). 
19. JW Henquet, T Kho, M Schols, H Thijssen, KH Rahn: The sympathic nervous system and the renin-angiotensin system in borderline hypertension. Clinical Science 60: 25-31 (1981). 
CHAPTER XII

\section{GENERAL DISCUSSION}

Non-invasive detection of carotid artery disease has become an important diagnostic tool in patients with cerebrovascular disorders. One of the techniques most commoniy used is the recording of blood flow velocity signals by means of Doppler ultrasound. In this technique a beam of ultrasonjic waves (at the $\mathrm{MHz}$ level) is transmitted from a vibrating crystal diagonally through the vessel wall into the blood stream. The ultrasound backscattered from particles in the flowing blood, mainly the red blood cells, is shifted in frequency by an amount prapartional to the velocity of these particles. This frequency shift, which is in the audio range, is retrieved by mixing the transmitted and received signals. The Doppler signal does not contain one single frequency, but a spectrum of frequencies (the Doppler spectrum). In Continuous Wave Doppler systems the ultrasonic waves are transmitted continuously and another crystal operates as receiver. In pulsed Doppler devices usually one crystal operates alternately as transmitter and recelver: the crystal recelves the backscattered ultrasound during the interval between pulses. Pulsed Doppler systams can be divided into single gate and multi-gate pulsed Doppler devices.

Continuous Wave Doppler systems are very accurate in diagnosing moderate to severe lesions in the carotid artery ( $>50 \%$ diameter reduction), but for minor ( $<30 \%$ diameter reduction) to moderate ( $<50 \%$ diameter reduction) stenosis the accuracy drops markedly.

Minor lesions of the extracranial caratid artery are commonly diagnosed by detecting disturbances in the flow pattern, as induced by these lesions. These disturbances can be diagnosed by estimating the degree of broadening of the Doppler audio spectrum, generally obtained with a device combining a B-mode imager and a single gate pulsed Doppler system (Duplex scanner'). Spectral broadening, however, also occurs when in the sample volume the welocity profile is parabolic rather than flat, the sound beam is nonhomogeneous or divergence of the beam occurs. Besides, in pullsed Doppler systems spectral broadening may occur because of the fintte size of the sample wolume inducing transit time effects. 
In this thesis, the limitations of Doppler spectral broadening as a diagnostic tool in the detection of minor carotid artery disease with the use of pulsed Doppler systems were studied in relation to the size of the sample volume. The results of this study indicate that for the detection of atherasclerotic lesions in the cervical carotid arteries at an early stage of the disease on the basis of spectral analysis of the Doppler signal, small sample volumes and sampling in the centre of the vessel are required and that it is rather doubtful whether these lesians can be diagnosed accurately, even when these requirements are met.

Detailed information about flow patterns in nomal and diseased carotid arteries can be obtained with multi-gate pulsed Doppler systens. A special$1 y$ designed multi-gate pulsed Doppler system does not only allow the simultaneous, on-line recarding of the velocity distribution along the ultrasound beam in the vessel as an instantaneous function of time and, hence, the velocity profile, but also the relative changes in arterial dianeter during the cardiac cycle. The information obtained with multi-gate pulsed Doppler devices contributes to a more accurate detection of minor to moderate carotid artery lesions, especially since Doppler audio spectra can be recorded simultaneously with these systems. The small size of the sample volume of the multi-gate pulsed Doppler system, as used in our studies, results in small bandwidth spectra in the nomal carotid artery and facilitates the detection of slight spectral broadening in early carotid artery disease.

By combining spectral analysis of the Doppler signal and the detection of flow disturbances in the carotid artery we developed a modified approach to the diagnosis of atherosclerotic lesions with the use of the multi-gate pulsed Doppler system. Based on this approach, the diagnostic accuracy, sensitivity and specificity $(84 \%, 83 \%$ and $84 \%$, respectively) in detecting moderate carotid artery lesions was found to be satisfactory as compared with biplane arteriography. Therefore, we felt justified to emplay this method in an epidemiological study on the prevalence of carotid artery disease in relation to risk factors in presumed normal male subjects, randomly selected from population registers. The prevallence of moderate ( $<50 \%$ diameter reduction) to severe ( $>50 \%$ diameter reduction) asymptomatic carotid artery disease was found to be higher than expected (23\% of the volunteers examined). The HDL/total cholesterol ratio was lower and the 
frequency of high blood pressure higher in the volunteers with than in those without asymptomatic carotid artery disease.

For the detection of minor lesions, however, this approach still has its limitations, especially when they are located in the carotid artery bulb. In-vitro and in-vivo studies, after ali, showed complicated flow patterns and recirculation zones in the carotid artery buib under normal circumstances. In a study on 20 volunteers of various age without detectable carotid artery disease, axial velocities in the bulb were found to be highest an the side of the flow divider, while regions of flow separation and recirculation were observed on the side opposite to this divider. Flow separation and recirculation were not continuously present throughout the cardiac cycle and were less pronounced and less common in older subjects. In younger volunteers the relative increase in arterial diameter during systole was larger in the carotid artery bulb than in the common carotid artery. In older subjects the reverse situation was found; in this age group the distensibility of the carotid arteries was significantly decreased in older subjects, especially in the bulb, as compared to the young volunteers. The diminished flow separation and recirculation in the older subjects might result from these alterations in distensibility at the transition from common to internal carotid artery with increasing age. Whether the diminished distensibility in the carotid artery bulb at older age is a consequence of minimal disease of the carotid artery bulb cannot be excluded because for ethical reasons no arteriagrams were made in these presumed healthy, neurologicaliy asymptomatic volunteers. Besides, minimal carotid artery disease can easily be missed with arteriography as well.

The complicated flow patterns, as occurring under normal circumstances in the carotid artery bulb, result in changes in the Doppler spectrum, which are difficult to distinguish from those induced by minor carotid artery lesions, quite often localized in the bulb. Taking into account the limitations of spectral broadening (see page 138), it is rather unlikely that the diagnosis of minor atherosclerotic lesions on the basis of changes in the Doppler spectrum alone can be performed with an acceptable degree of accuracy.

Beside the detailed information about flow patterns in arteries, multigate pulsed Doppler systens provide information about vessel wall properties. From the relative arterial diameter changes, the absolute diameter 
and the arterial pulse pressure (systolic minus diastalic pressure), as measured at the arm, distensibility and cross-sectional compliance of the arterial wall can be estimated. Since it is likely that vessel wall properties change ith age, distensibility and cross-sectional compliance of the conmon carotid artery were studied as a function of age in 80 presumed healthy volunteers, varying in age between 20 and 69 years. Both distensibility and cross-sectional compliance decreased linearly with age, starting In the third age decade. The reduction of the cross-sectional compliance was less pronounced, probably as a consequence of an increase in arterial diameter with age. In this way older subjects may be able to store volume energy despite a decrease in arterial wall distensibility.

In a study on 72 volunteers of varying age, the effect of borderline hypertension on vessel wall properties was investigated. In borderline hypertensive subjects, distensibility and cross-sectional compliance were found to be decreased as compared with age-matched normotensive subjects.

Based upon our observation of the flow patterns in the carotid artery bulb and the vessel wall properties of the carotid artery bifurcation under nomal circumstances as well as the changes in these properties with age, a new method to detect minor carotid artery disease ( $30 \%$ diameter reduction) in the carotid artery bulb was developed. A largely diminished increase in arterial diameter during systole in the carotid artery bulb, as compared to that in the common carotid artery, and the absence of recirculation or the presence of recirculation at a non-specific site in the carotid artery bulb, were used as criteria for the existence of minor disease in the carotid artery bulb. Additional information about the carotid artery bifurcation was obtalned with a B-mode imager. In a pllot study on 43 arteries the diagnostic accuracy, sensitivity and specificity in the diagnosis of these lesions was found to be $95.3 \%, 90.0 \%$ and $90.0 \%$, respectively, as compared with bipllane arteriography. When more experience has been gathered with this approach, non-invasive diagnosis of minor carotid artery disease becomes feasible in patients with or without focal neurogical symptoms. Especially when the multi-gate pulsed Doppler system is combined with a high resolution $B$-mode imager, the diagnostic potential of this approach is promising.

In conclusion, the use of a multi-gate pulsed Doppler system in the evaluation of carotid artery disease allows accurate detection of minor, 
noderate and severe stenosis, and enables non-invasive assessment of vessel wall properties. The relatively high costs, as compared with continuous Wawe Doppler systems, and the skil1 requilred to ensure relliable results will probabiy limit the use of multi-gate pulsed Doppler systems to advanced vascular laboratories. Continuous Wave Doppler systems are low in cost, but not very accurate in detecting moderate and minor lesions. Duplex scanmers, requiring at least the same investments as multi-gate pulsed Doppler systems, are probably inadequate for accurate detection of minor carotid artery disease.

Future investigations may include more extensive population studies, for instance, on risk factors for carotid artery disease, and experimental research on atherogenesis in the carotid artery bifurcation. The presence of recirculation zones in the nomal carotid artery bulb and their rellation to the development of atherosclerotic lesions at these sites (in areas with low axial shear stress), for example, needs further investigation. Recent ly 20-flow mapping systems have been developed. In these sophisticated multigate pulsed Doppler systens the velocity distribution is displayed in a color coded fashion superimposed on the simultaneously assessed 2-D echo image. These systems have the advantage that flow disturbances, occurring at bifurcations under normal circumstances and as induced by atheroscleratic lesions, are displayed in a more direct way, which may facilitate the diagnosis of these lesions. 

SUMMARY

Atherosclerotic lesions of the carotid arteriles may give rise to cerebrovascular disorders, either by hamodynamic impaiment of cerebral flow due to significant diameter reductions in the absence of adequate collateral circulation, or emboli originating from irregular (ulcerative) vessel walls. Therefore, in patients, suspected of transient ischenic attacks or stroke, the carotid artery circulation is generally evaluated. Non-inwasive diagnosis of cervical carotid artery disease by means of ultrasound Doppler investigations accurately identifies lesions with more than $50 \%$ diameter reduction. The detection of minor stenosis (less than $30 \%$ diameter reduction) and vessel wall irregularities, however, is less reliable.

In in-vitro studies it has been shown that under normal conditions the flow patterns in the carotid artery bifurcation, where early atherosclerotic lesions start to develop, are complicated. Since atherosclerotic lesions at an early stage of the disease are generally diagmosed by detecting the flow disturbances, as induced by these lestions, detailed information about the flow patterns at the carotid artery bifurcation under nomal circumstances might contribute to the accuracy of diagnosing minor lesions. This detailed information can be obtained with multi-gate pulsed Doppler systems. These devices allow the on-line recording of the instantaneous velocities, simultaneously at various sites in the artery, and, hence, the velocity profile, that is the velocity distribution over the cross-sectional area of the vessel, at discrete intervals during the cardiac cycle. Besides, multi-gate pulsed Doppler devices allow the on-line recording of changes in arterial diameter during the cardiac cycle, while the internal artery diameter can be estimated from the width of the velocity profille with these systems. In this way non-invasive assessment of vessel wall properties becomes feasible. The present thesis deals with the applications of a specially designed multi-gate pulsed Doppler system in the evaluation of the carotid artery circulation.

In Chapter II a technical description is giwen of the multi-gate pulsed Doppler device and its features, as used in this thesis, are discussed. Spectral analysis of the Doppler signal, frequently used for diagnosing carotid artery stenosis, is introduced in Chapter III. In Chapter IW the limitations of Doppler spectral broadening in the early detection of carotid artery disease, due to the size of the sample volume, are demonstrated. 
Chapter $V$ deals with the diagnostic accuracy of the multi-gate pulsed Doppler system in detecting moderate carotid stenosis, as compared with biplane arteriography. Based on the favorable results, the multi-gate pulsed Doppler device was employed in an epidemiological study on the prevallence of and the serum HDL/total cholesterol ratio and blood pressure in male volunteers with asymptomatic atherosclerotic lesions of the cervical carotid arteries (Chapter VI).

In Chapter WI the detection of flow disturbances and the assessment of relative arterial diameter changes during the cardiac cycle are discussed, and in Chapter VIII flow velocity patterns in and distensibility of the carotid artery bulb in presumed healthy, male subjects of various ages, as detected with the multi-gate pulsed Doppler system, are presented. Chapter IX deals with non-invasive assessment of age related changes in common caratid artery wall properties in normotensive presumed healthy males.

In Chapter $X$ the results of a pllot-study on the use of disturbances in the flow velocity patterns in and diminished distensibility of the carotid artery bulb in the diagnosis of minor carotid artery stenosis are presented. The vessel wall properties of the common carotid artery in normotensive and borderline hypertensive male subjects of various age, as assessed non-invasively, are described in Chapter XI.

The final conclusions and a discussion on future developments can be found in Chapter XII. 


\section{SAMENVATTING}

De niet-invasieve opsporing van afwijkingen in de a. carotis (halssiagader) is een belangrijk diagnostisch hulpmiddel geworden bij patienten met stoornissen in de hersendoorbloeding. Een vari de meest toegepaste technieken is het meten van de bloedstroomsnelheid met behulp van Doppler ultrageluidstechnieken. Bij deze methodes wordt een bundel ultrasonore trillingen (met een frequentie in de orde van 2-10 $\mathrm{MHz}$ ) door een trillend kristal, diagonal door de bloedwatwand in de bloedstroom, uitgezonden. Het ultrageluid dat wordt teruggekatst door deeltjes in de bloedstroom, voormamelijk de rode bloedcellen, wordt in frequentie verschoven evenredig met de snelheid van de bloedstroom. Deze frequentieverschuiving (het Doppler signaal), die in het hoorbare gebied ligt, wordt bepald door de uitgezonden en terugontvangen signalen met elkaar te vergelijken. Het Doppler signaal bevat niet slechts eén frequentie, maar een band van frequenties, het Doppler spectrum.

In Continuous Wave Doppler (CW) apparaten wordt het ultrageluid continue uitgezonden, waarbij een tweede kristal als ontvanger functioneert. In pulsed Doppler apparaten wordt gewoonlijk én kristal afwisselend als zender en ontvanger gebruikt: het kristal ontwangt het teruggekatste ultrageluid in de pauzes tussen de uitgezonden ultrageluid pulsen. Pulsed Doppler systemen kunnen onderscheiden worden in ëén- en meerkanaals apparaten.

CW Doppler systemen kunnen zeer betrouwbaar vernauwingen in slagaders, die gepaard gaan met een diameterreductie van $50 \%$ of meer, opsporen. Voor geringe ( $<30 \%$ diameterreductie) en matige (30-49\% diameterreductie) vernauwingen is de betrouwbaarheid aanmerkelijk minder.

Geringe vernauwingen in de a. carotis worden gewoonlijk gediagnostiseerd door het opsporen van verstoringen in het stroomgedrag, die ontstaan rond deze vaatwandveranderingen. Deze verstoringen worden in de kliniek in het algemeen opgespoord door de mate van verbreding van het Doppler spectrum, gewoonlijk opgenomen met een apparaat dat een éénkanaals puised Doppler systeem combineert met een 20 echo systeem on de vaatwand af te beelden. Spectrale verbreding treedt echter ook op wanneer in het meetvolume het snelheidsprofiel parabollisch is in plaats van viak, de ultrageluidsbundel niet homogeen van samenstelling is, of indien afbuiging of 
verstrooiting van de bundel optreedt. In pulsed Doppler apparatuur kan er ook nog spectrale verbredüng optreden ten gevolgen van een te klein meetyolume, hetgeen zgn. transit-time effecten kan veroorzaken.

In dit proefschrift worden de beperkingen wan spectrale verbreding van het Doppler sigmaal als diagnostisch hulpmiddel voor het opsporen van geringe carotisafwijkingen met behulp wan pulsed Doppler apparatuur bestudeerd in relatie tot de grootte van het meetvolume. De resultaten van dit onderzoek duiden erop, dat voor opsporing van atherosclerose van de $a$. carotis in een vroeg stadium van de ziekte, kleine meetvolumes en een meting in het centrum van het vat noodzakelijk zijn als men spectraal analyse van het Doppler signaal gebruikt. Zelfs wanneer hieraan voldaan wordt, is het twijfelachtig of dergelijke kleine afwijkingen op deze wijze betrouwbaar op te sporen zijn.

Meer gedetailleerde informatie over het stroomgedrag in normale en afwijkende halsslagaders kan worden verkregen met meerkanals pulsed Doppler systemen. Met een speciaal in Maastricht ontwikkeld meerkanaals pulsed Doppler apparaat is het niet alleem mogelijk gelijktijdig en on-line (zonder vertraging) de snelheidsverdeling langs de ultrageluidsbundel als functie van de tijd, en daarmee het snelheidsprofiel, te registreren, maar ook de relatieve diameterveranderingen van het vat tijdens de hartcyclus kunnen on-line bepaald worden. De gegevens die verkregem worden met meerkanaals pulsed Doppler apparatuur dragen bijj aan een meer betrouwbare opsporing van geringe carotisafwijkingen, vooral omdat met deze systemen ook Doppler spectra kunnen worden apgenomen op iedere plaats in het vat. Het kleine meetvolume van het meerkanals pulsed Doppler apparaat dat gebruikt werd in ons anderzoek, geeft smalbandige spectra in de normale a. carotis, waardoor geringe spectrale verbreding ten gevolge van kleine a. carotisafwijkingen in principe beter kan worden waargenomen.

Door spectraal analyse van het Doppler signaal te combineren met het registreren van stroomverstoringen in de a. carotis, werd een andere aanpak van de diagnostiek van atherosclerose m.b.v. meerkanaals pulsed Doppler systemen ontwikkeld. Met deze aanpak werden bevredigende resultaten voor wat betreft de dignostische betrouwbarheid, sensitiviteit en specificiteit voor vernauwingen van minder dan $50 \%$ diameterreductie gevonden (respectievelijk $84 \%, 83 \%$ en $84 \%$ ), vergeleken met arteriografie van de halsslagaders in twee richtingen. 
Deze aanpak werd daarop gebruikt in een epideniologisch onderzoek. Hierin werd de prevalentie van carotisafwijkingen in een populatie van nomal veronderstelde mannen zonder klachten, wiens naam en adres aselect. uit het bevolkingsregister getrokken waren, onderzocht in relatie tot risicofactoren. De prevalentie van matig tot ernstige asymptomatische carotisafwijkingen (resp. $<50$ en $\geq 50 \%$ diameterreductie) was hoger dan verwacht: $23 \%$ van de onderzochte populatie. De HDL/totaal cholesterol ratio was lager en het voorkomen van hoge bloeddruk frequenter in de groep personen met asymptomat ische carotisafwijkingen, in vergelijk met de nomalen.

Voor het opsporen wan geringe lesies heeft deze aanpak nog zijn beperkingen, vooral wanneer de afwijkingen in de carotisbifurcatie zijn gelocaliseerd, de plats war de a. carotis communis zich splitst in de a. carotis interna en de a. carotis externa. In-vivo en in-vitro studies toonden aan dat op deze plaats onder normale omstandigheden ingewikkelde stroompatronen met wervelingen en terugstroming optreden, voornamelijk in de carotisbulb (het wijdere proximale deel van de a. caratis interna).

In een onderzoek bij 20 vrijwilligers van verschillende leeftijden, die geen aantoonbare carotisafwijkingen hadden, was de bloedstroomsnelheid het hoogst aan de zijde van de flow-divider (stroomverdeler tussen aa. carotides interna en externa), terwijl gebieden met stroomloslating en recirculatie gezien werden aan de zijde tegenover de stroomverdeler. Loslating en recirculatie werden niet continu tijdens de hartcyclus waargenomen, en waren minder uitgesproken en minder frequent bij ouderen. Bij jongeren was de relatieve diametertoename tijdens systole groter in de bulb dan in de a. carotis communis; bij ouderen werd het omgekeerde gevonden. Bovendlen was in deze laatste leeftijdsgroep de distensibiliteit (rekbaarheid) van de carotis significant verminderd in vergelijking met de jongeren. De verminderde stromiloslating en recirculatie bij ouderen zou het gevolg kunnen zijn van de veranderingen in distensibiliteit op de overgang van a. carotis communis naar de carotisbulb. Dat de verminderde distensibiliteit op oudere leeftijd een gevolg is van geringe afwijkingen in de carotisbulb kan niet worden uitgesloten, ondat om ethische redenen geen arteriografie werd vermicht bij deze verondersteld normale, neurologisch asymptomatische vrijwilligers. Bovendien zijn geringe carotisafwijkingen ook miet altijd met arteriografie op te sporen.

De ingewikkelde strompatronen die onder nomale omstandigheden in de 
carotisbulb optreden, geven een verbreding van het Doppler spectrum, welke moellijk te onderscheiden is van verbreding ten gevolge van geringe afwijkingen in de bulb. Als men ook nog de beperkingen wan spectrale verbreding in beschouwing neemt, is het nogal onwarschijnlijk dat de diagmose van geringe afwijkingen met behulp van deze methode betrouwbaar genaakt kan worden.

Naast de gedetallleerde informatie over stroomgedrag in bloedvaten, geven meerkanals pulsed Doppler systemen informatie over vaatwandeigenschappen. Uit de relatieve diametertoename van het bloedvat tijdens systole, en de polsdruk (systole minus diastole bloeddruk) gemeten aan de arm kunnen distensibiliteit en compliantie van slagaders bepaald worden. Gezien de waarschijnlijkheid dat vaatwandeigenschappen met de leeftijd veranderen, werden distensibiliteit en compliantie van de a. carotis communis bestudeerd als functie van de leeftijd bij 80 gezonde proefpersonen, in leeftijd varierend van 20-69 jaar. Zowel distensibiliteit als compliantie namen lineair af met de leeftijd vanaf de derde decade. De afname van de compliantie was minder uitgesproken, waarschijnlijk als een gevolg van de toename in diameter van de a. carotis communis met de leeftijd. Op deze wijze kuninem ouderen toch wolume energie opslaan ondanks een verminderde vaatwandelasticiteit.

In een onderzoek bij 72 proefpersonen van verschillende leeftijd, werd het effect van borderline hypertensie op de vaatwandeigenschappen bestudeerd. Bij borderline hypertensieve personen waren distensibiliteit en compliantie lager dan in nomotensieven van dezelfde leeftijd.

Gebaseerd op onze warnemingen van het stroomgedrag in en de vaatwandelgenschappen van de carotisbulb onder normale omstandigheden en rekening houdend met de veranderingen hierin met het voortschrijden van de leeftijid, werd een nieuwe methode om geringe vaatwandafwijkingen in de carotisbulb op te sporen, opgezet. Een aanzienlijk geringere relatieve diametertoename tijdens systole in de bulb, vergeleken met de a. carotis comunis, en de afwezigheld van recirculatie of het optreden van recirculatie op ongewone plaatsen in de bulb, werden gebruikt als criteria voor de aanwezigheid van geringe afwijkingen in de bulb. Aanvullende informatie over de carotisbifurcatie werd verkregen met een 20 echo systeem. In een pilot-study op 43 halsslagaders waren de diagnostische nauwkeurigheid, sensitiviteit en specificiteit respectievelijk $95.3 \%, 90 \%$ en $90 \%$, vergeleken met arterio- 
grafie in twee richtingen. Wanneer meer ervaring met deze methode is apgedaan, en wooral wanneer het meerkanals pulsed Doppler systeem gecambineerd wordt met een echo systeem met hoog oplossend vermogen, is het diagnostisch potentieel van deze aanpak veelbelovend.

Samenwattend kan gesteld worden dat met een meerkanaals pulsed Doppler systeem geringe, matige en ernstige carotisafwijkingen betrouwbaar opgespoord kunnen worden. Bovendien is het met deze systemen mogelijk op nietinvasieve wijze informatie te krijgen over de vaatwandeigenschappen. De relatief hoge prijs, vergeleken met $C W$ apparatuur, en de vaardigheid die nodig is on tot betrouwbare resultaten te komen, zullen het gebruik van deze systemen waarschijnlijk beperken tot geavanceerde vaatlaboratoria. CW apparaten zijn wel goedkoper, maar onbetrouwbaar in het opsporen van arteriele vaatwandveranderingen, die gepaard gaan met geringe vernauwing van het vat. Met Duplex scanners, minstens even duur als meerkanaals pulsed Doppler systemen, kunnen geringe vaatwandafwijkingen waarschijnlijk niet betrouwbaar gediagnostiseerd worden.

Toekomstige ontwikkelingen kunnen uitgebreidere populatiestudies omvatten, bijvoorbeeld t.a.v. risicofactoren voor carotisafwijkingen, en meer fundamenteel onderzoek naar het ontstaan van atherosclerose in de carotisbifurcatie. Het ontstaan van atherosclerotische veranderingen op plaatsen waar recirculatie gevonden wordt in de normale carotisbulb, en niet op plaatsen met een hoge afschuifspanning is een interessante waarneming die verder onderzoek behoeft.

Recent werden 20 flow-mapping systemen antwikkeld. Deze geavanceerde meerkanaals pulsed Doppler systemen geven de snelheidswerdeling aver het wat in kleur weer in het gelijktijdig verkregen echobeeld van de vaatwanden. Tevens wordt met deze systemen de stroomrichting direct in een kleurcode weergegeven. Dit heeft het voordeel dat stroomverstoringen, zoals. veroorzaakt door geringe afwijkingen, op een meer directe wijze weergegeven worden, hetgeen de diagnostiek van geringe afwijkingen in de carotisbulb kan vereenwouligen. 



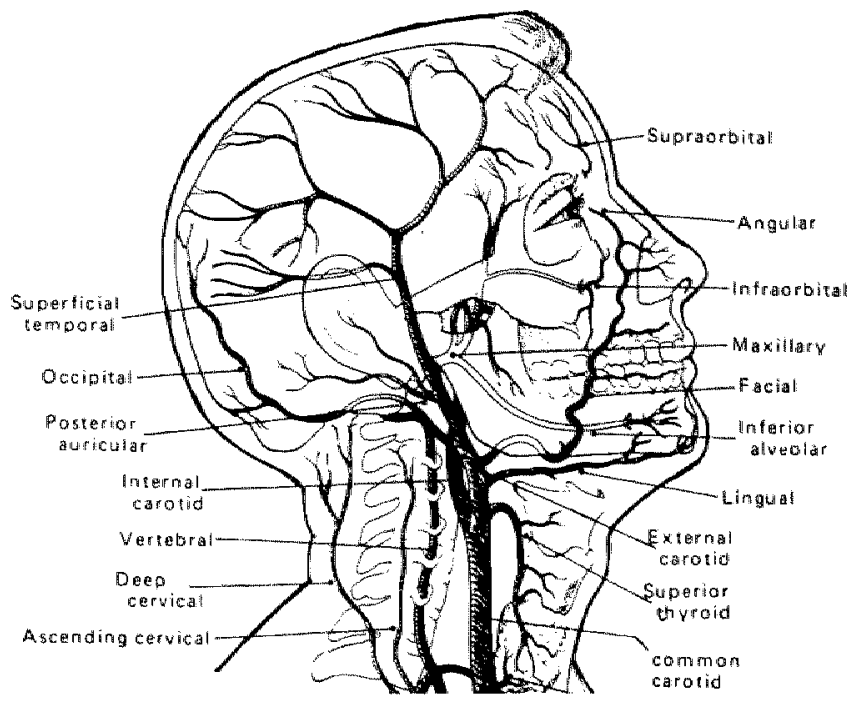

Fig. A.1: Schematic representation of the carotid artery bifurcation with side branches. After Dynamic Anatomy and Physiology. McGraw-Hilz Book Company, New York. 


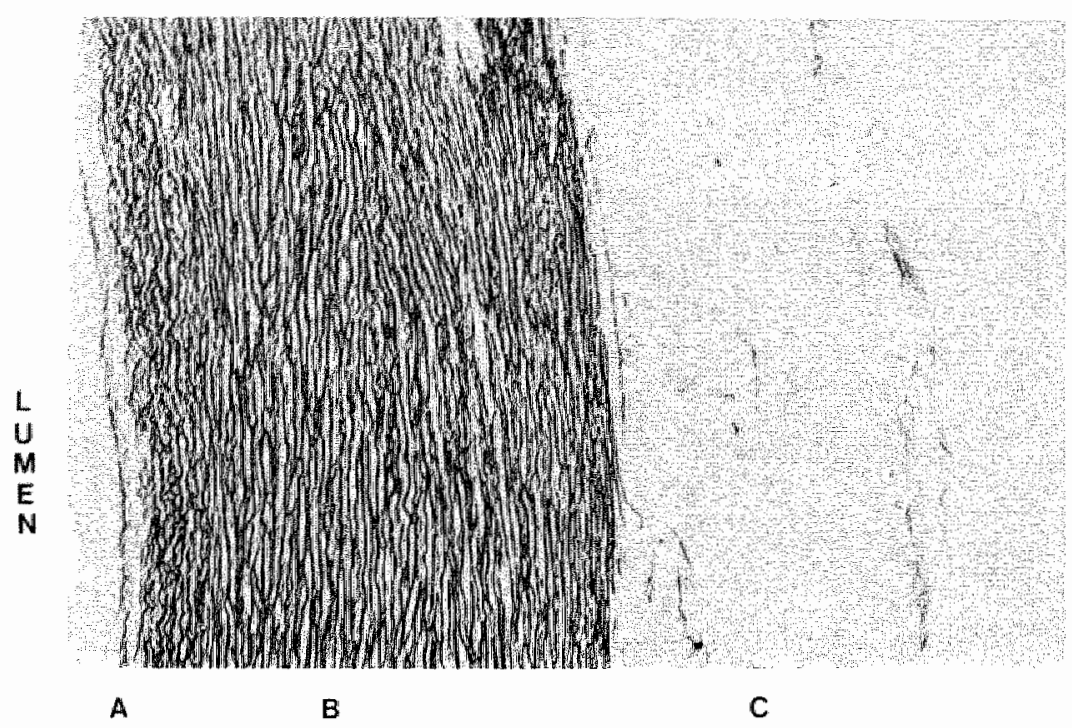

Pig. A.2: Structure of the amtemial wall of the common carotid artery $A=$ tunica intima

$B=$ tunica media

$C=$ tunica adventitia 
APPENDIX II

Protocol practical examination carotid artery with multi-gate pulsed Doppler system

1. place hand-held probe at an angle of about $50^{\circ}$ at skin surface

2. - obtain clear signal from common carotid artery

- feedback by audiosignal and/or symmetry velocity profile

- correction by probe position and/or gain setting

3. - velocity imaging of carotid bifurcation for anatomical orientation

- in the case of unusual or high-pitched signal further examination depending on findings

4. ensure good stability of the hand

5. obtain nearly identical velocity profiles for 10-15 heart beats

6. - watch profile for asymmetry (1ike skewness), local backflow or aliasing

- check influence of pressure of the probe on shape of velocity profille. Avoid skewness due to pressure

7. - freeze Doppler data input memory

8. - transfer data via parallel interface to mini-computer (PDP-11). This provides an off-line hardcopy of both velocity and profthe mode on graphical display/hardcopy unit. Data are stored on floppy disk

9. - switch on vessel wall A-mode

- if necessary adjust gains

- place cursors on echo's thought to be coinciding with vessel wall displacement. 
10. - check proper position cursors by vessel wall displacenent as recorded on oscilloscope. The relative vessel wall movements should be reproducable and equal in amplitude for at least 10 heart beats. The form has to be typical (see Fig. 2.1)

11. vary probe position and cursor position to ensure optimal result

12. freeze Doppler data input memory see nrs. 7,8

13. procedures 1 through 12 are repeated for other recording places along the carotid artery, depending upon the study

Tirne needed: $30 \mathrm{~min} / \mathrm{side}$.

When coupled to B-mode imager the probe of this device is used, and kept at an angle of $60^{\circ}$ with the longitudinal axis of the vessel.

In this case the anatomical information is obtained directly from the B-mode image. 


\section{CURRICULUM VITAE Tiny van Merode}

10 julf 1955: geboren te Leeuwarden

1967-1972 : Rijks-HBS-b te Leeuwarden

1972-1979 : studie Geneeskunde aan R.U. Groningen

5 ju1i 1979 : artsdiploma

1979-1980 : arts-assistent Chirurgie en Verloskunde, Hengelo-0

1980-1984 : verbonden aan capaciteitsgroep Fysiologie van de R.U. Limburg in het kader van het project: "Vroege detectie van atherosclerotische vaatwandafwijkingen"

1984-1985 : beroepsopleiding tot huisarts, R.U. Limburg

1985-1986 : researchmedewerker vaatlaboratorium Algemene heelkunde, Eindhoven

1985-heden : verbonden als arts aan het Consultatiebureau voor Alcohol en Drugs, Maastricht

1986-heden : tijdelijk medewerker capaciteitsgroep Fysiologie, R.U. Limburg 

NAWOORD

Het schrijven van een proefschrift wordt vaak gezien als het sluitstuk van gericht onderzoek. Meestal is het gelukkig geen afronding alleen, maar ook vertrekpunt voor verdere studje.

Bij veelomvattende onderwerpen als meerkanaals pulsed Doppler systemen en vernauwingen van de a. carotis $k a n$ dit natuurlijk niet het werk van één onderzoeker zijn. Het wetenschappelijk onderzoek, waarop dit proefschrift gebaseerd is, kwam tot stand door de samenwerking van een heel team van mensen. Daar is de promovendus maar eentje van.

In de eerste plaats wil ik mijn promotor, Prof.Dr. R.S. Reneman bedanken. Beste Rob, zonder jou was onderzoek noch proefschrift van de grond gekomen. Dat je ondanks je drukke bestaan, altijd aandacht en tijd voor me had heb ik zeer gewaardeerd. Vele bekertjes thee ging je onvermoeibaar bij de besprekingen voor me halen.

Ook mijn co-promotor Dr. A.P.G. Hoeks wil ik bedanken voor zijn aandeel in het geheel, niet in het minst natuurlijk voor het ontwikkelen van het multi-gate pulsed Doppler apparaat zoals dat gebruikt werd in de studies.

Paul Hick wil ik bedanken voar al die jaren samenwerking en $z$ ' $n$ steun en kalmte onder alle onstandigheden. Daarnaast was hij de onmisbare aanvullende factor, waardoor veel waardevolle gegevens tijdig en hervindbaar opgeslagen werden. Als een apparaat plotseling uitviel, sleutelde je het binnen de kortste keren weer voor elkaar. Bovendien sprak jij als eerste de nodige (mini) computertaal.

Dok Kees Ruissen en Frans Smeets wii ik voor hun hulp en samenwerking bedanken. Kees ontwierp bovendien de voorplaat van dit proefschrift. Arno Muytjens heeft bijzonder veel bijgedragen aan de statistische verwerking van de data. Harry Peeters bedank ik voor zijn hulp bij het opzetten van het databestand.

Bij de samenwerking met de kliniek wil ik vooral Jan Lodder en Prof.Dr. K.H. Rahn danken voor hun hulp bij het verzamelen van de patientengegevens.

Bij het bloedonderzoek verrichtte Astrid Dingjan nauwgezet het medischanalytisch voorwerk, waarna de vakgroep Humane Voeding, in het bijzonder $Z$. Kruyswijk en $\mathrm{Dr}$. C.E. West, van de Landbouwhogeschool Wageningen de cholesterolbepalingen voor zijn rekening nam. 
Het grootste deel van het manuscript is op vakkundige wijze op de tekstverwerker gezet door Lucienne de Boer. Oak Mariet de Groot, Yvonne Houten, Jos Heenskerk en Karin wan Brussel hebben een bijdrage aan het type-werk geleverd. Rosy Hanssen verzorgde op haar gebruikelijke accurate wijze de verdere lay-out. De paranimfen Paul Hick en Annie Klink wierpen tenslotte een laatste kritische blik.

Last, maar zeker niet least wil ik alle proefpersonen die aan de Dopplemetingen hebben meegewerkt hartelijk bedanken. Zij kwamen uit alle windstreken en namen soms kennis of buurman mee. Zonder hen was dit proefschrift al helemal nooit geschreven. 